\title{
Current methodologies and approaches for the formation of core-sheath polymer fibers for biomedical applications ${ }^{\circ}$
}

Cite as: Appl. Phys. Rev. 7, 041302 (2020); https://doi.org/10.1063/5.0008310

Submitted: 20 March 2020 . Accepted: 14 September 2020 . Published Online: 14 October 2020

(D) S. Mahalingam, (D) R. Matharu, (D) S. Homer-Vanniasinkam, and (D) M. Edirisinghe

COLLECTIONS

F This paper was selected as Featured
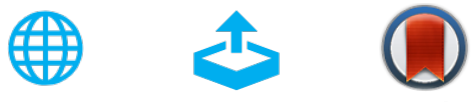

\section{ARTICLES YOU MAY BE INTERESTED IN}

Robust non-Pt noble metal-based nanomaterials for electrocatalytic hydrogen generation Applied Physics Reviews 7, 041304 (2020); https://doi.org/10.1063/5.0021578

Hydrogen embrittlement in ferritic steels

Applied Physics Reviews 7, 041301 (2020); https://doi.org/10.1063/5.0012851

Application of ion beam technology in (photo)electrocatalytic materials for renewable energy Applied Physics Reviews 7, 041303 (2020); https://doi.org/10.1063/5.0021322

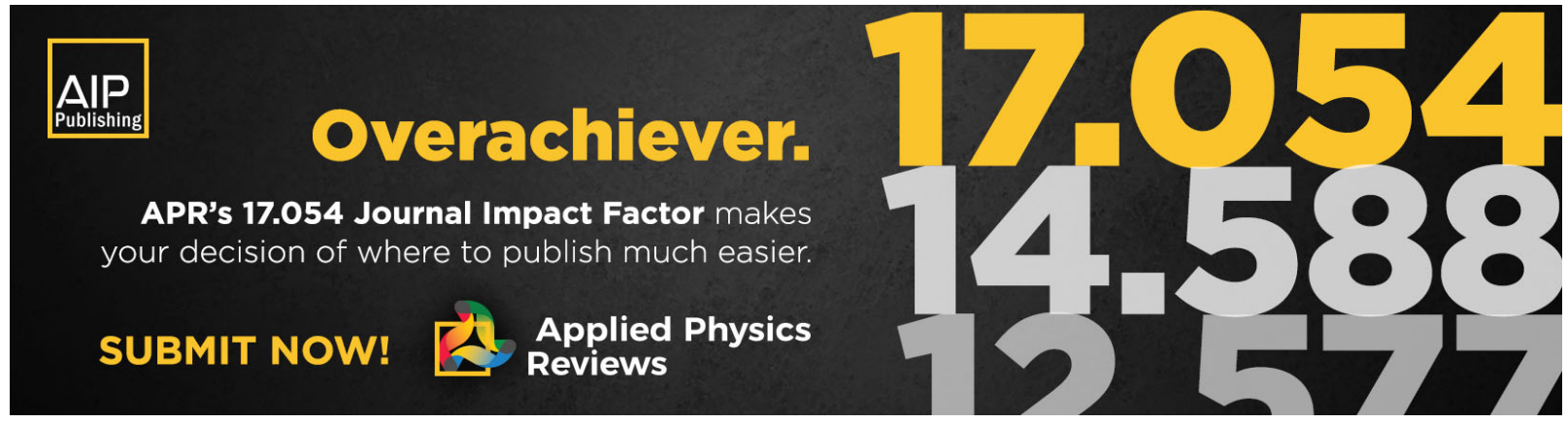




\title{
Current methodologies and approaches for the formation of core-sheath polymer fibers for biomedical applications
}

Cite as: Appl. Phys. Rev. 7, 041302 (2020); doi: 10.1063/5.0008310

Submitted: 20 March 2020 - Accepted: 14 September 2020 •

Published Online: 14 October 2020

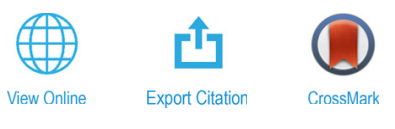

S. Mahalingam, ${ }^{\text {a) }}$ (D) R. Matharu, (D) S. Homer-Vanniasinkam, (D) and M. Edirisinghe (D)

\author{
AFFILIATIONS \\ Department of Mechanical Engineering, University College London, London WC1E 7JE, United Kingdom \\ a) Author to whom correspondence should be addressed: suntharavathanan.mahalingam@ucl.ac.uk
}

\begin{abstract}
The application of polymer fibers has rocketed to unimaginable heights in recent years and occupies every corner of our day-to-day life, from knitted protective textile clothes to buzzing smartphone electronics. Polymer fibers could be obtained from natural and synthetic polymers at a length scale from the nanometer to micrometer range. These fibers could be formed into different configurations such as single, core-sheath, hollow, blended, or composite according to human needs. Of these several conformations of fibers, core-sheath polymer fibers are an interesting class of materials, which shows superior physical, chemical, and biological properties. In core-sheath fiber structures, one of the components called a core is fully surrounded by the second component known as a sheath. In this format, different polymers can be applied as a sheath over a solid core of another polymer, thus resulting in a variety of modified properties while maintaining the major fiber property. After a brief introduction to core-sheath fibers, this review paper focuses on the development of the electrospinning process to manufacture core-sheath fibers followed by illustrating the current methodology and approaches to form them on a larger scale, suitable for industrial manufacturing and exploitation. Finally, the paper reviews the applications of the core-sheath fibers, in particular, recent studies of core-sheath polymer fibers in tissue engineering (nerve, vascular grafts, cardiomyocytes, bone, tendons, sutures, and wound healing), growth factors and other bioactive component release, and drug delivery. Therefore, core-sheath structures are a revolutionary development in the field of science and technology, becoming a backbone to many emerging technologies and novel opportunities.
\end{abstract}

(C) 2020 Author(s). All article content, except where otherwise noted, is licensed under a Creative Commons Attribution (CC BY) license (http:// creativecommons.org/licenses/by/4.0/). https://doi.org/10.1063/5.0008310

\section{TABLE OF CONTENTS}

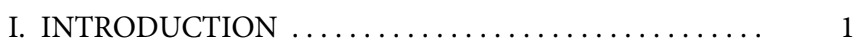

II. CORE-SHEATH FIBERS . . . . . . . . . . . . . . 2

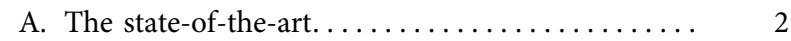

III. ELECTROSPINNING AND THE EVOLVEMENT OF CORE-SHEATH FIBERS. ................

IV. CURRENT METHODOLOGIES FOR THE FORMATION OF CORE-SHEATH FIBERS ........

V. CORE-SHEATH FIBERS IN BIOMEDICAL APPLICATIONS .

A. Tissue engineering $\ldots \ldots \ldots \ldots \ldots \ldots \ldots \ldots \ldots \ldots \ldots$

1. Vascular grafts $\ldots \ldots \ldots \ldots \ldots \ldots \ldots \ldots \ldots$

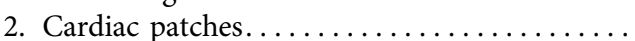

3. Nerve tissue engineering $\ldots \ldots \ldots \ldots \ldots \ldots$

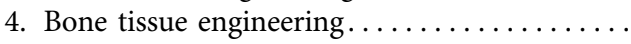

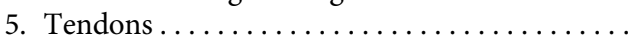

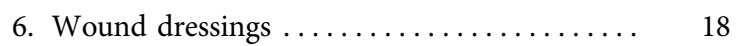

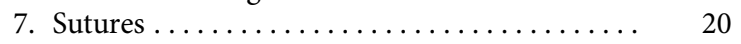

8. Encapsulation of nanoparticles, drugs, and bioactive molecules................... 20

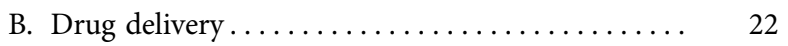

1. Biphasic drug delivery ................. 25

2. Stimuli-responsive drug release $\ldots \ldots \ldots \ldots . \ldots 26$

3. Dual drug release ................. 27

VI. CONCLUDING REMARKS ................ 28

\section{INTRODUCTION}

Core-sheath fibers inherited roots in the polymer fiber family in the field of polymer science and engineering over the last two decades. They are made with different polymers that could be extruded from the same spinneret but separated by a fine plane. The polymers are chosen to make the core-sheath structure differ in chemical nature or 
physical properties, such as molecular weight, ultimately benefitting from the properties of dissimilar polymers. The multicomponent core-sheath fibers could be produced from either thermoplastic or thermoset polymers, aqueous or non-aqueous soluble polymers, or natural or synthetic polymers. ${ }^{1}$ These polymers are selected based on final applications and processing methodology to make core-sheath fibers with different cross-sectional geometries. Generally, in a core-sheath configuration, a core provides the desired physical characteristics, whereas the sheath polymer gives a specific functionality to the filament. In addition to the main polymers adapted to produce these structures, there is also a possibility to add filler materials such as nanoparticles, cells, drugs, proteins, and peptides during the manufacturing process to impart further specific functionalities to core-sheath fibers. ${ }^{2}$

Forming core-sheath fibers with two or more dissimilar polymers has numerous advantages and uses than their single component counterparts. They are (i) immobilizing the sheath part by surrounding the core in a highly reactive and volatile environment, thus isolating the unstable component and minimizing the chances of decomposition, (ii) a time-dependent release of a substance (e.g., drug molecules) to a particular receptor, (iii) backbone to tissue engineering and tissue regeneration where biocompatible and biodegradable polymers mimic the natural extracellular matrix (ECM), and (iv) reinforcing a material to improve and/or impart new properties (e.g., mechanical).

There are compelling pieces of evidence that core-sheath fibers and core-sheath fiber-based architectures (e.g., scaffolds) made significant breakthrough and progress over the years in the field of biomedical and tissue engineering. ${ }^{3-9}$ They served as a precious gemstone (Kohinoor diamond) in regenerative medicine with the goal of repairing and reconstructing diseased and defective tissues. Primarily, the form and nature of culture scaffolds are important in controlling cell behavior and constructing tissues from individual cells. These scaffolds have to be a "hotel" for cells to stay and facilitate tissue regeneration. They must act as an underlying architecture to cell adhesion, proliferation, penetration, and differentiation. The enhanced functions of all these are achieved in three-dimensional micro-environment and fibrillar ECMs. In clinical settings, the ideal scaffolds not only provide a suitable cellular environment but are also readily available, maybe as an "off-the-shelf" product, reproducible and with minimum and/or nil side effects. Moreover, the surface of the scaffolds is critical to determine their interaction with cells over short and long-term performances. In addition, these scaffolds have been utilized to securely deliver therapeutic ingredients like signaling molecules and stem cells. Typically, the therapeutic molecules and cells can be secured and partitioned within the layered core-sheath structure and can be delivered to target defects. Furthermore, the capacity to load the molecules and cells safely and securely, tunability of the compositions of the materials, and flexibility in designing various shapes and sizes are beneficial facets of core-sheath structures. Consequently, core-sheath architectures are considered to have a multi-facet nature, providing and delivering on-demand biomaterial platforms for drug delivery and tissue engineering.

Therefore, the overall motivation of this review paper is to discuss the current methodologies and approaches undertaken to create the core-sheath fibers and their application in the biomedical field. This review paper is divided into four main sections, first a general introduction to core-sheath fibers and then the electrospinning process followed by current methodologies to form the core-sheath fibers. Thereafter, it focuses on the application of core-sheath fibers in tissue engineering including vascular grafts, cardiomyocytes, nerve, bone, tendons, sutures, and wound healing. It also discusses the recent studies on growth factor release, nanoparticle release for antimicrobial activity, and release of other bioactive components. Finally, it presents the use of core-sheath fibers in drug delivery.

\section{CORE-SHEATH FIBERS}

\section{A. The state-of-the-art}

In core-sheath fibers, two or more different components are distributed over the entire length of the fibers. The classification of coresheath fibers is done according to the distribution of each component within the cross-sectional area (Fig. 1). ${ }^{10}$ Typical cross section configurations include side-by-side, where two dissimilar materials are attached next to each other [Fig. 1(a)]. It could be visualized as attaching two coconut shells with different surface morphologies. Generally, the core-sheath fibers take a form where the core is encapsulated with the sheath component. For example, in power cables, the copper wire (core) is surrounded by a polymer material (sheath). Depending on the location of the core, it could be categorized as concentric coresheath fibers and eccentric core-sheath fibers [Figs. 1(b) and 1(c)]. When the core is at the center of the axis, it will be referred to as concentric and if it is off the center, then it is called as eccentric. Another variety of core-sheath fibers is the island on sea structure. Here, there are several core components embedded in a single sheath material [Fig. 1(d)]. It is comparable to asymmetric digital signal lines (ADSL) coming from the street box and connected to several households. Alternating segments of core-sheath fibers consist of alternating layers of core and sheath material one after another [Fig. 1(e)]. Figure 1(f) shows the pie configuration of the core-sheath fibers, where alternating segments are arranged in a radial direction. It could be visualized as a pizza having different toppings in each segment (core and sheath). The citrus configuration core-sheath fibers are similar to pie configuration core-sheath fibers, but the only difference is that they have a core wheel at the center. It could be imagined as a jackpot spinning wheel containing different segments [Fig. 1(g)]. The tipped trilobal configuration contains the sheath component at the tip of the core component arranged in a Y-shaped catapult [Fig. 1(h)].

\section{ELECTROSPINNING AND THE EVOLVEMENT OF CORE-SHEATH FIBERS}

The fundamentals of electrospinning could be dated back to the 18th century when Rayleigh discovered the deformation of thin liquid jets under the influence of an electric field. ${ }^{11}$ Later in the early 19th century, Cooley ${ }^{12}$ and Morton ${ }^{13}$ systematically produced patents about electrohydrodynamic atomization where liquids could be electrically dispersed. Although the term electrospraying or electrospinning is not mentioned in their work or in Rayleigh's research, the fundamental underlying principle is the same as that of electrospraying or electrospinning which are common terminologies in the present day scientific literature. Formhals ${ }^{14}$ is the first person to coin the term electrospinning and presented a methodical approach for the production of fibers using an electric field. The main difference between electrospraying and electrospinning is that the former uses a less viscous and low molecular weight solution to produce liquid droplets and the latter 


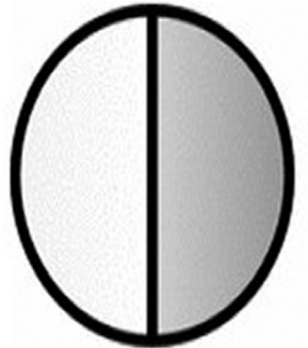

(a)

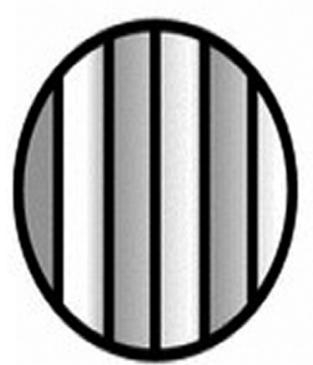

(e)

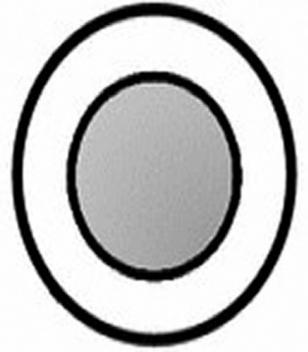

(b)

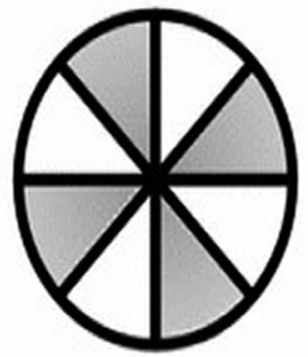

(f)

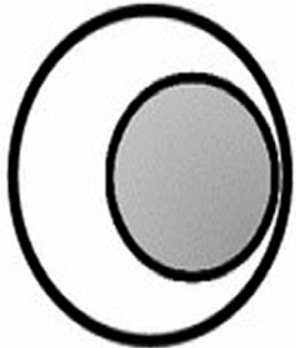

(c)

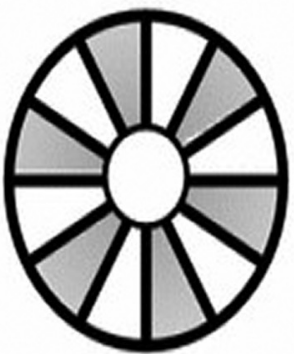

(g)

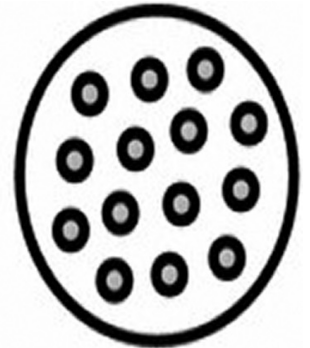

(d)

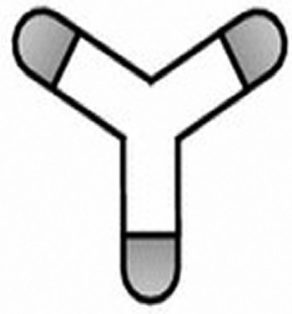

(h)

FIG. 1. Type of core-sheath fibers: (a) side-by-side, (b) concentric, (c) eccentric, (d) island in the sea, (e) alternating segments with stripes, (f) alternating segments in pie, (g) citrus, and (h) tipped trilobal. Reproduced with permission from Dasdemir et al., J. Mater. Sci. 47, 5955 (2012). Copyright 2012 Springer.

uses a viscous polymer solution subjected to the electric field to generate fibers. Thereafter, many dedicated their lives researching the phenomena of electrospraying and electrospinning, but it came to limelight and household mantras (research-wise) in the mid-1990s and in millennium years. It was a hot topic in both academic and industrial communities and has spawned out a huge amount of publications and patents.

Even though there are many methods for fabricating fibers such as wet spinning, ${ }^{15-21}$ which could be categorized as dry-jet wet spinning $^{22-24}$ and shear wet spinning, ${ }^{25}$ solution blow spinning, ${ }^{26}$ emulsion spinning, ${ }^{27}$ melt spinning, ${ }^{28,29}$ melt blowing, ${ }^{30-32}$ and rotary jet spinning, ${ }^{33,34}$ electrospinning is perhaps the simplest, most straightforward, and cheapest method to manufacture polymer fibers by forcing a polymer solution or polymer melt through a spinneret in an electric field. ${ }^{35-41}$ It is the most decorated fiber spinning technology on this planet so far!

A typical electrospinning setup essentially consists of a nozzle attached to a syringe tube containing a polymer solution, syringe pump, high voltage power supply, ground electrode, and collector, as shown in Fig. 2. In this process, when a viscoelastic liquid, generally a polymer solution, is pumped through the nozzle, ${ }^{42,43}$ it tends to form a spherical droplet at the end of the nozzle due to the withholding surface tension force. A high voltage is applied to the nozzle and the ground electrode generates positive charges within the polymer solution and the negative charges in the ground electrode result in a large electrostatic force between the electrodes. This electrostatic force now interacts with the polymer droplet at the end of the nozzle and overcomes the surface tension of the solution and destabilizes the spherical droplet. ${ }^{44}$ Figure $3(\mathrm{a})$ shows the time-dependent deformation of a droplet due to its interaction with the electric field. ${ }^{45}$ When the repulsion is strong enough, the droplet will be deformed into a conical shape and a fine jet of a solution will emanate from the apex of a cone [Fig. 3(b)]. ${ }^{45}$ The diameter of the fluid jet continues to shrink as a result of synergistic effects of the electric field and the same surface charge repulsion, until it starts to bend. Due to this, the jet after its straight path undergoes "bending instability" and a "whipping motion." 46 Figure 3(c) shows a typical whipping regime in the

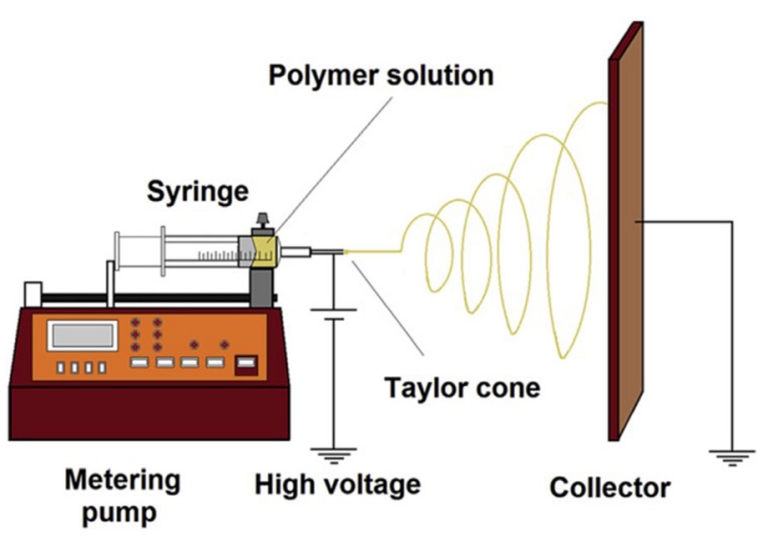

FIG. 2. Typical electrospinning setup to generate polymer fibers. Reproduced with permission from Riazi et al., Polymer 104, 240 (2016). Copyright 2016 Elsevier. 


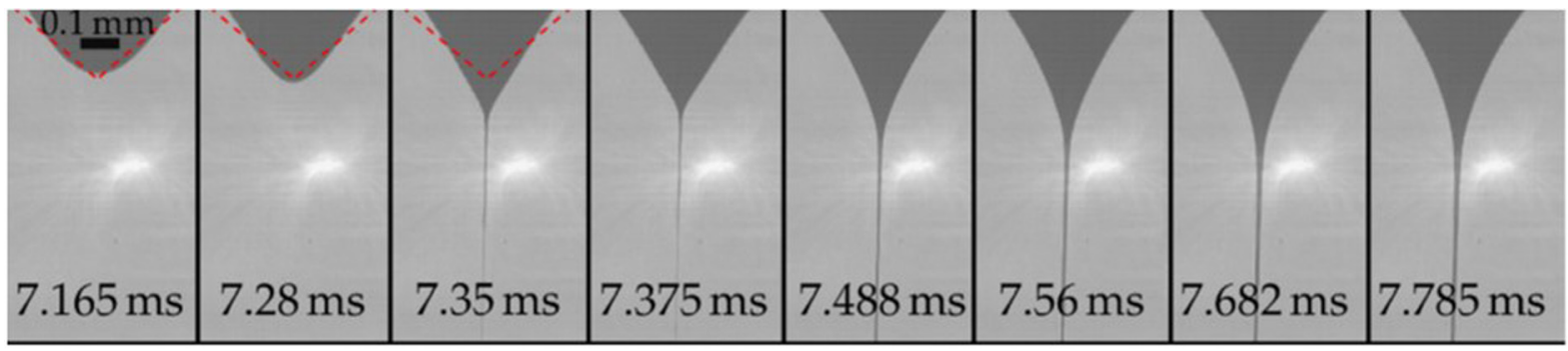

(a)

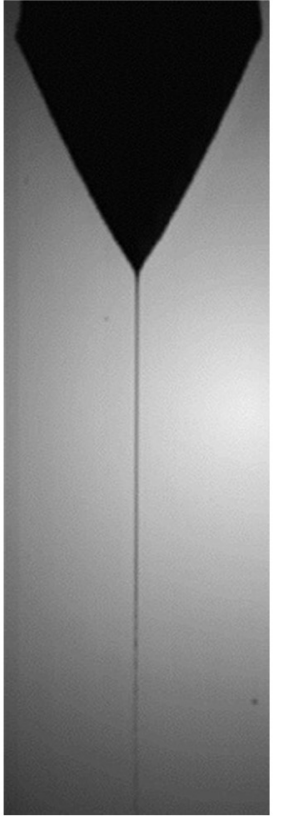

(b)

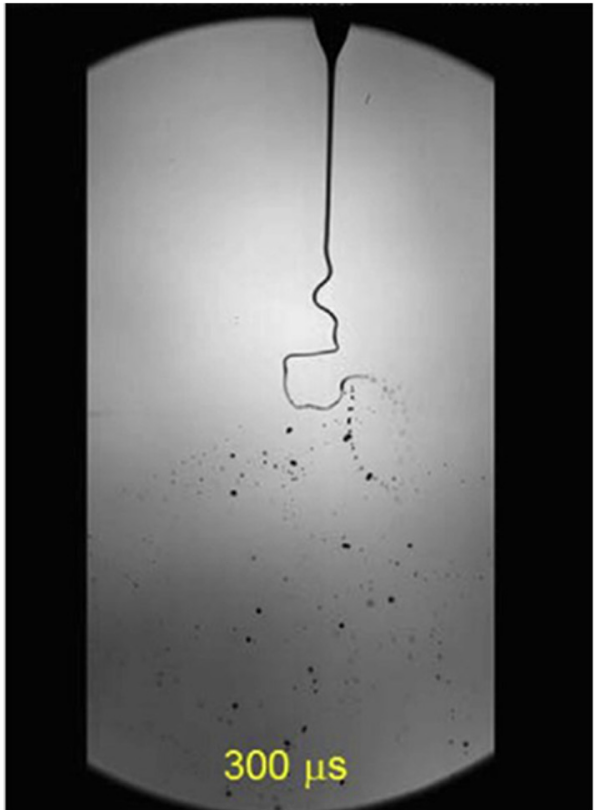

(c)

FIG. 3. (a) Time-dependent deformation of a droplet due to electric field interaction. The meniscus is transformed into a Taylor cone emitting liquid jet over a short time. (b) A typical uniform electrified jet emerges from an apex of the cone. Reproduced with permission from Verdoold et al., J. Aerosol Sci. 67, 87 (2014). Copyright 2014 Elsevier. (c) Whipping regime in the electrospinning process. Reproduced with permission from Kim et al., J. Aerosol Sci. 42, 249 (2011). Copyright 2011 Elsevier.

electrospinning process. ${ }^{47}$ In the final stage of the process, the solvent evaporates and the solid dry fibers are deposited on the collector. Typical polymer nanofibers formed using an electrospinning technology are shown in Fig. 4.

There are many parameters that govern an electrospinning process. These could be categorized into (i) solution parameters, (ii) process parameters, and (iii) ambient parameters. It is very important to understand how these parameters affect the fiber formation and their morphologies. It is vital to get the optimal conditions to form fibers with high quality and better performance. The characteristics of the polymer fibers are shown to depend on the polymer solution's chemical and physical properties such as electrical conductivity, surface tension, density, solvent volatility, and the dielectric constant. ${ }^{43,48-59}$ The processing parameters, applied voltage, fluid flow rate, and nozzlecollector distance, have been shown to have a direct influence on the fiber size, fiber size distribution, fiber length, and the morphology of the fibers. Different types of fiber morphologies such as aligned, random, beaded fibers, bead-free fibers, and bead-on string fibers could be obtained by a systematic adjustment of the processing parameters. ${ }^{60-70}$ The beaded fiber morphology is commonly associated with the axisymmetric instability which originates in the straight jet path during the whipping process to generate nonuniform and non-smooth fibers. ${ }^{71}$ The ambient parameters such as temperature, relative humidity, and vapor pressure of the solvents have been shown to affect fiber morphology, pore formation on the surface, and the interior of the fibers.

There are predictive quantitative mathematical models derived by researchers to determine the diameter of electrospun fibers. Generally, in electrospinning, fiber thinning occurs in the whipping regime of the process. Yarin et al. ${ }^{46}$ calculated the bending force acting in the electrified liquid jet by considering the mutual Coulomb interactions. They used this force to analyze the electrically driven bending 

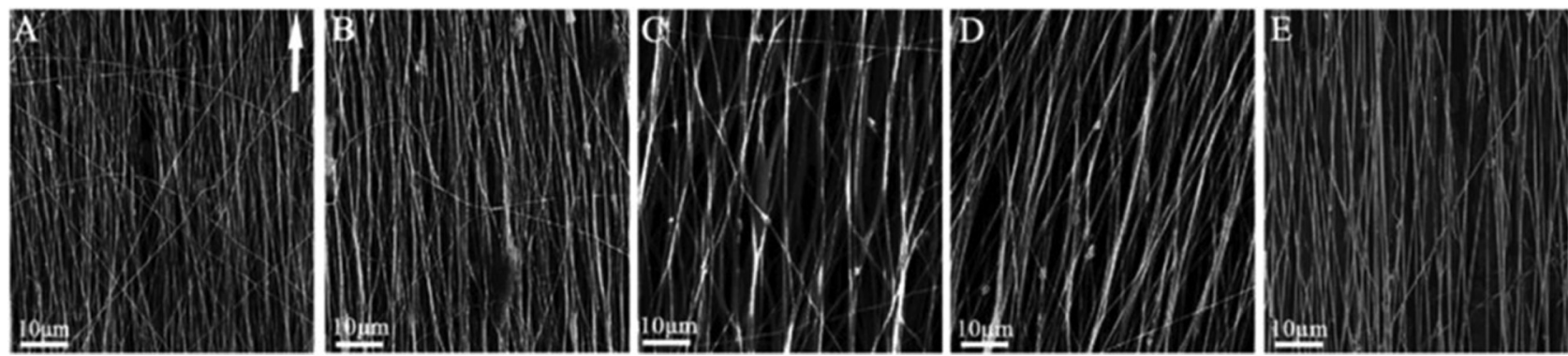

FIG. 4. Typical polymer nanofibers obtained from the electrospinning setup. Uniform and well-aligned nanofibers were obtained by using the rotating drum collector. The average fiber diameter increased by changing the concentration of polyethylene oxide [(a)-(e)]. Reproduced with permission from Lu et al., Polymer 115, 52 (2017). Copyright 2017 Elsevier.

instability and the aerodynamically driven instability. Discretized forms of quasi one dimensional and partial differential equations have been used to calculate the jet paths during nonlinear bending instability, leading to the formation of larger loops and resulting in nanofibers. ${ }^{46}$ Fridrikh et al..$^{77}$ presented a simple analytical model to determine the fluid jet diameter as a function of surface tension, flow rate, and the electric current in the jet. ${ }^{77}$ They treated the whipping jet as a viscous slender object, assumed that the fluid is Newtonian, and neglected the elastic effects of the drying jet. The authors essentially assume that the final jet diameter is determined by an equilibrium between the Coulombic repulsions between the charges of the jet and the surface tension force. ${ }^{77}$ The final jet diameter $d_{f}$ is presented by them as

$$
d_{f}=\gamma^{\frac{1}{3}}\left(\frac{Q}{I}\right)^{\frac{2}{3}}\left(w_{p 0}\right)^{1 / 2},
$$

where $\gamma$ is the surface tension, $\mathrm{Q}$ is the flow rate of the polymer solution, $\mathrm{I}$ is the electric current in the jet, and $\mathrm{w}_{\mathrm{p} 0}$ is the initial polymer volume fraction in the spinning solution. Stepanyan et al. ${ }^{78}$ predicted the final jet diameter by considering the competing effect of elongation under the influence of the electric repulsion between the charges on the surface of the fibers and the viscoelastic forces growing as a function of time due to evaporation and stopping the fiber elongation and thinning. ${ }^{78}$ They performed scaling and numerical analysis to calculate the final fiber diameter $\left(d_{f}\right)$ as a function of viscosity, specific charge, and evaporation rate, resulting in

$$
d_{f}=\left(k \rho_{s} \eta_{0}\right)^{\frac{1}{3}}\left(\frac{Q}{I}\right)^{2 / 3},
$$

where $\rho_{s}$ is the solvent density, $\eta_{0}$ is the polymer solution viscosity before evaporation, $\mathrm{Q}$ is the flow rate of the polymer solution, I is the electric current in the jet, and $\mathrm{k}$ is a constant.

Recently, Lei et al. ${ }^{79}$ developed a model to predict the final jet radius with correlation to the stable jet length, the aspect ratio of the jet, and the dielectric constant of the polymer solution. The final jet radius $r_{f}$ is given by

$$
r_{f}=C^{1 / 2}\left[\gamma \bar{\varepsilon} \frac{Q^{2}}{I^{2}} \frac{2}{\pi(2 \ln \chi-3)}\right]^{1 / 3},
$$

where $\mathrm{C}$ is the concentration of the solution, $\gamma$ is the surface tension, $\bar{\varepsilon}$ is the dielectric constant, Q is the flow rate of the polymer solution, I is the electric current in the jet, and $\chi$ is the aspect ratio of the jet.
Schubert ${ }^{80}$ analyzed electrospinning in three stages, the first is a pure flow stage where the fiber is stretched to a certain extent reaching equilibrium and then undergoes potential jet splitting followed by a drying stage, where the final jet diameter (d) is determined by the concentration of the polymer solution. He mentioned that the concentration of the polymer solution and the viscosity of the solution strongly influence the final diameter of the jet. According to his analysis, the final jet diameter after stage one scales to

$$
d \sim c^{1 / 2} \eta^{1 / 3} p_{v} U^{-2 / 3},
$$

where $\mathrm{c}$ is the concentration of the polymer solution, $\eta$ is the viscosity, $p_{v}$ is the vapor pressure, and $U$ is the applied voltage.

He further states that the diameter of the split jets and its dried form could be related to the following scaling law: ${ }^{80}$

$$
d \sim c^{1 / 2} \cdot \eta^{4 / 9} \cdot p_{v}{ }^{2 / 9} \cdot U^{-14 / 9} .
$$

The co-axial electrospinning concept was conceived in the earlier millennium years due to the popularity of electrospinning of nanofibers. It has brought a novel idea to the arena combining two dissimilar materials in the form of fibers. Because of the simple and straightforward characteristics of this process, it is possible to develop new forms of complicated fibers with defined microstructures, novel morphologies, and new functions for a wide variety of applications. The general setup used to generate fibers are very much similar to the single needle (nozzle) electrospinning process but with a modification in the spinneret. A typical co-axial electrospinning process is shown in Fig. 5. In this configuration, the spinneret is made of a smaller inner capillary that fits concentrically inside the larger outer capillary. ${ }^{81}$ The outer nozzle is attached to a syringe holding the sheath polymer solution and the inner nozzle is connected to a syringe containing the core polymer solution. A careful selection of flow rates of polymer solutions by the syringe pumps and applied voltage by a high voltage power supply will generate co-axial polymer fibers, commonly known as coresheath polymer fibers. ${ }^{82}$ Typical core-sheath polymer fibers fabricated using this process are shown in Fig. 6.

The process of coaxial electrospinning is conceptually not dissimilar to the virgin electrospinning process. It makes use of the electric force acting on polymer solutions in the electric field, resulting in stretching of liquid jets due to direct pulling and growth of electrically driven bending perturbations. ${ }^{83}$ When a high voltage is applied to polymer solutions, the charge accumulation occurs predominately in 


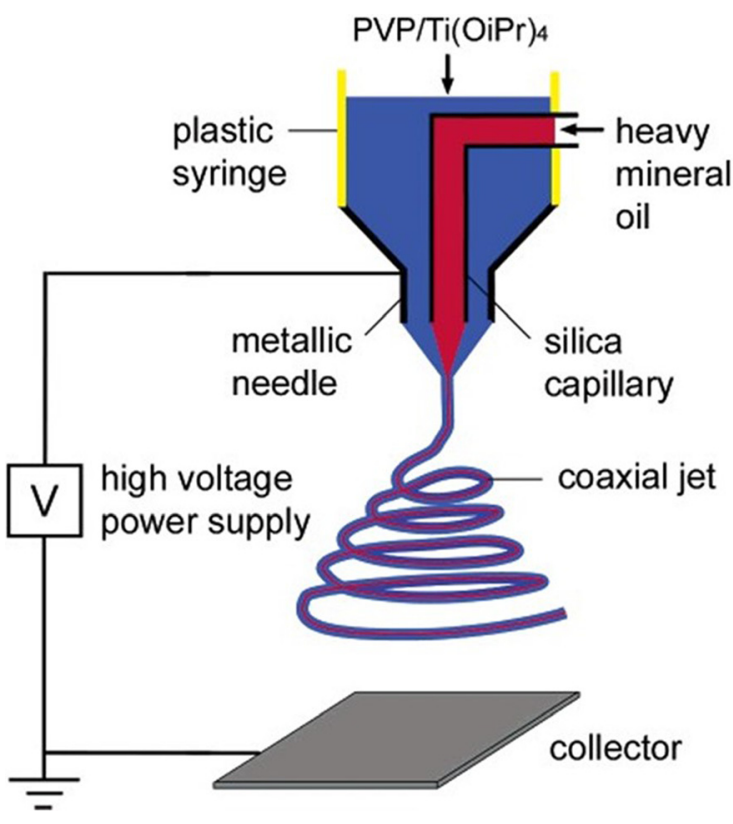

FIG. 5. Co-axial electrospinning setup to generate core-sheath polymer fibers. Reproduced with permission from Li and Xia, Nano Lett. 4, 933 (2004). Copyright 2004 American Chemical Society.

the sheath polymer solution flowing from the outer needle (Fig. 7). ${ }^{84}$ The outer liquid shields the inner liquid from the electric field and the whole two phases become nearly equipotential. Due to charge-charge repulsion, the pendant droplet of the sheath solution elongates and stretches to form a cone shape and once the charge accumulation reaches a threshold value to an increased applied voltage, a fine jet emanates from the tip of the cone. ${ }^{85}$ The primary forces that generate the stress in the sheath solution are viscous dragging and contact friction. ${ }^{81}$ Thus, the core polymer solution deforms into a conical shape and forms a compound co-axial jet. Then, the solvent will evaporate and the compound jet will solidify, resulting in compound core-sheath fibers. The stability of the compound co-axial jets will be affected when the flow rate of the inner core solution is comparable to or larger than the flow rate of the outer nozzle. ${ }^{86}$ Otherwise, equilibrium is achieved in co-axial electrospinning. There are situations when the core liquid flow dominates in electrified compound jets. In this case, the inner polymer solution injects the charges to outer polymer solutions, maintaining the stability of the compound jets. ${ }^{87}$ In addition, when the viscosity of the outer fluid is not large or small relative to the inner fluid, the diameter of the compound electrified jets is similar to the single-phase liquid jet. ${ }^{86}$

The term "co-axial" bequeathed its root from co-axial electrospraying or co-axial electrohydrodynamic atomization. The novel spinneret consisting of two concentrical capillaries originally reported by Loscertales et al. ${ }^{88}$ was to electrospray two immiscible liquids to generate nanoparticles. ${ }^{88}$ The idea to produce co-axial electrified jets based on analogies between flow focused (mechanical) and electrical cone jets had a great impact in manufacturing polymer fibers and these remarkable achievements have been attained along this line of thought since then. Larsen et al. ${ }^{89}$ are the first to report the formation of hybrid fibers consisting of organic and inorganic constituents in a diameter range from submicrometer to micrometer by combining sol-gel chemistry and electrically forced liquid jets. ${ }^{89}$ Sun et al. ${ }^{90}$ prepared core-sheath polymer nanofibers using two polymer solutions with the aid of co-axial electrospinning. ${ }^{90}$ The hollow fibers are considered as a special type of core-sheath fibers, where the core is made from a cavity and the sheath is made of a solid. In this regard, Loscertales et al. ${ }^{91}$ demonstrated that hollow nanofibers could be formed in one-setup, utilizing the electrified coaxial liquid nanojets made of a shell forming liquid on the outside and an inert immiscible liquid on the inside. Thereafter, $\mathrm{Li}$ and $\mathrm{Xia}^{81}$ generated ceramic hollow fibers using two capillary spinnerets, followed by selective removal of the core. ${ }^{81}$ Recently, the coaxial needle setup was used to form hollow biohybrid microfibers after dissolving the core polymer (Ranjan et al. .) ${ }^{92}$ Hollow fibers were also prepared using a single needle electrospinning process using a blended solution and post-treatment process. ${ }^{93}$ Moreover, Suzuki et al. ${ }^{94}$ prepared $\mathrm{SnO}_{2}$ hollow fibers using template-free electrospinning by precisely controlled heat treatment. ${ }^{94}$ Multi-layered or multicomponent fibers made from more than two needles generated a considerable amount of interest among the researchers. Ahmad et al. ${ }^{95}$ and Labbaf et al. ${ }^{96}$ have shown that multilayered core-sheath polymer fibers could be manufactured using three and four needle configurations, respectively. Very recently, multilayered structures were prepared to control the delivery of drugs for treating brain tumors. ${ }^{97}$

Coaxial electrospinning depends on the same parameters as those in the single electrospinning process. However, different phases introduce an interface interaction (miscibility and stress due to the viscosity) and the individual physical behavior of different phases (solidification and conductivity) complicates coaxial electrospinning. ${ }^{98}$ During spinning, the sheath layer acts as a barrier to retard the evaporation of materials inside and ensures smooth mass transfer. ${ }^{99}$ A welldefined core-sheath structure is obtained by choosing two immiscible liquids. ${ }^{100}$ Lowering the interfacial surface tension by selecting the same solvents could promote a well-defined core-sheath microstructure. ${ }^{101}$ On the other hand, the selection of two miscible fluids will lower the interfacial surface tension. ${ }^{100}$ A careful selection of solvents and the polymer solution reduces the interfacial surface tension and complications in the coaxial electrospinning process such as varicose breakup. ${ }^{102}$ In addition, the diffusion rates of the inner and outer polymer solutions and thermodynamic and kinetic factors also influence the quality of the processed core-sheath fibers. ${ }^{103}$ Therefore, the coaxial electrospinning process depends on many parameters in addition to primary parameters that govern conventional electrospinning.

\section{CURRENT METHODOLOGIES FOR THE FORMATION OF CORE-SHEATH FIBERS}

Although electrospinning has been seen a very successful fiber spinning technology, it suffers from drawbacks such as the usage of high voltage, need for specialized equipment, and electrically conductive targets. In addition, the physical properties of the spinning solutions (e.g., electrical conductivity) are absent in many biological solutions/suspensions. Consequently, there are several novel strategies and new directions emerging in the market for fiber making on a large scale and a higher manufacturing throughput. One of these new developments is pressurized gyration. Pressurized gyration was invented by Mahalingam and Edirisinghe in 2013; it involves rotating a perforated 

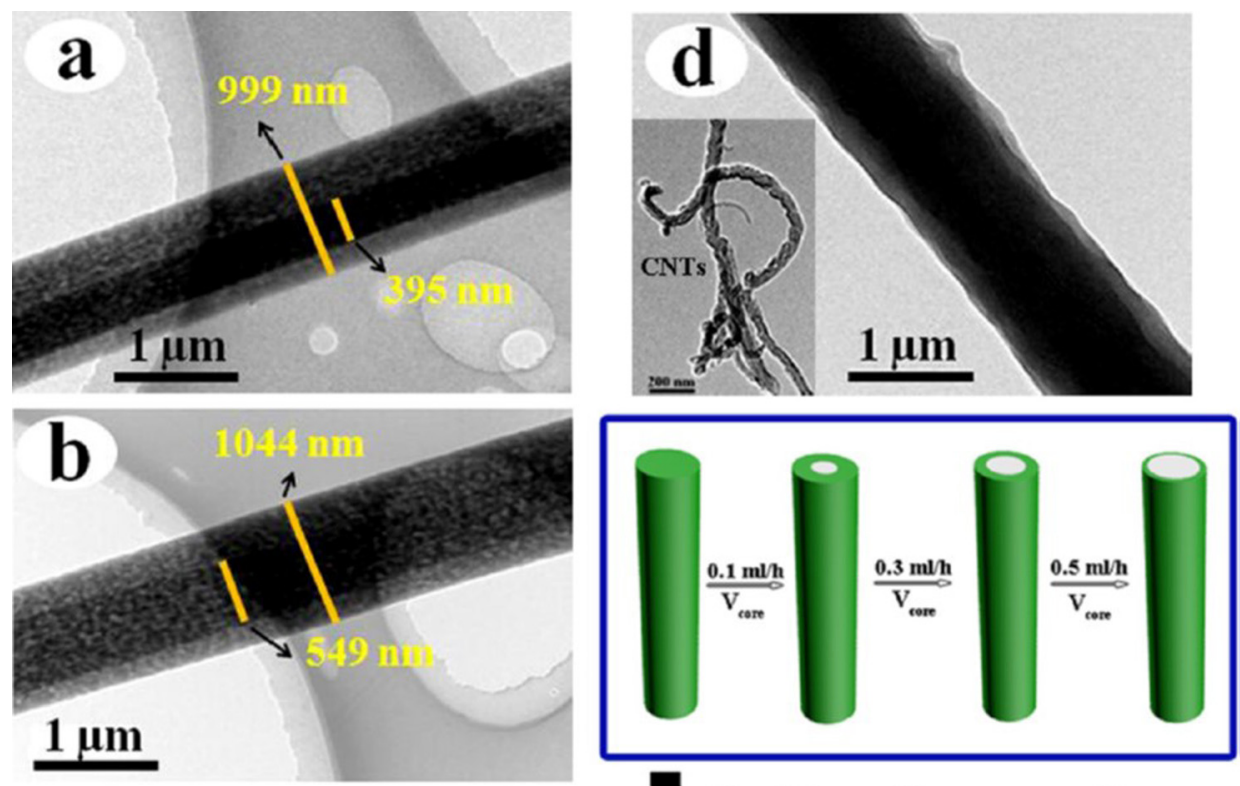

FIG. 6. Typical core-sheath polymer fibers obtained from the coaxial electrospinning setup. The average core diameter increased with the flow rate of the polymer solution. Reproduced with permission from Lu et al., ACS Appl. Mater. Interfaces 10, 12759 (2018). Copyright 2018 American Chemical Society.

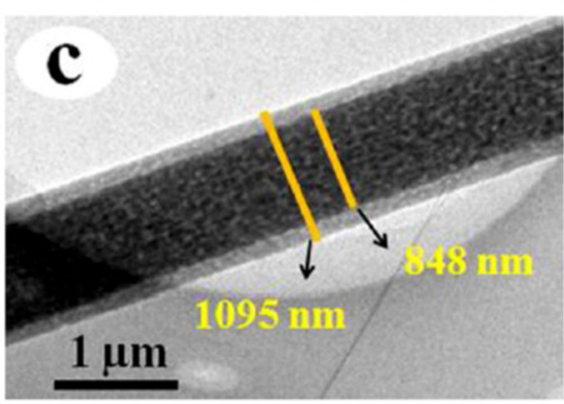

Coaxial nanofiber cross section

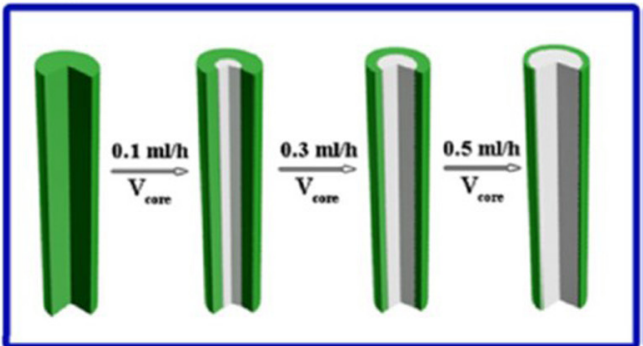

pot containing a polymer solution at high speed and has become a promising alternative method of spinning nanofibers and nanofibrous structures. ${ }^{104,105}$ This technique has attracted wide interest in the research community because it overcomes the limitations of other spinning methodologies and it has already been exploited to generate fibers, microbubbles, and capsules using polymer and protein solutions. ${ }^{106-114}$ A high production rate, ease of production, and highly controlled fiber morphology are salient features of this technique. ${ }^{104}$ The current pressurized gyration equipment consists of an aluminum cylindrical vessel with about 20 roundshaped orifices typically with a dimension $\sim 0.5 \mathrm{~mm}$ on its face (Fig. 8). One end of the device is connected to a DC motor and the other end is coupled to pressurized gas. The rotating speed of the vessel is controlled by a bi-directional regulator. The rotating speed can reach up to $\sim 40000 \mathrm{rpm}$ and the gas pressure can go up to three times the atmospheric pressure, with possibilities of increasing these values by $\sim 2 \times$. Depending on the processing conditions, various fibrous architectures could be manufactured in a single step on a large scale. The process and the typical products obtained by this method are shown in Fig. 9. The process combines centrifugal spinning and solution blowing by the simultaneous application of centrifugal and dynamic fluid flow forces which act against the surface tension force to generate fibers. The process control parameters such as rotating speed, working pressure, and the

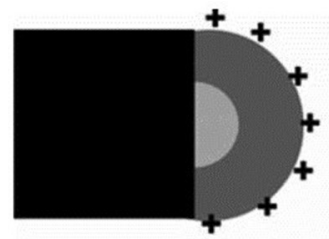

A

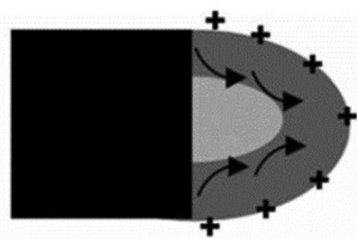

B

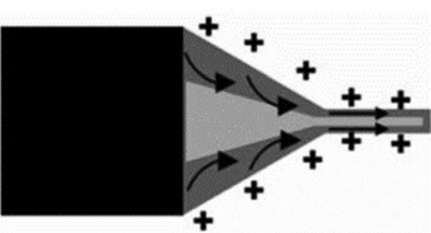

C
FIG. 7. Schematic illustration of compound co-axial jets and charge accumulation on the sheath polymer solution. Reproduced with permission from Moghe and Gupta, Polym. Rev. 48, 353 (2008). Copyright 2008 Taylor and Francis. 


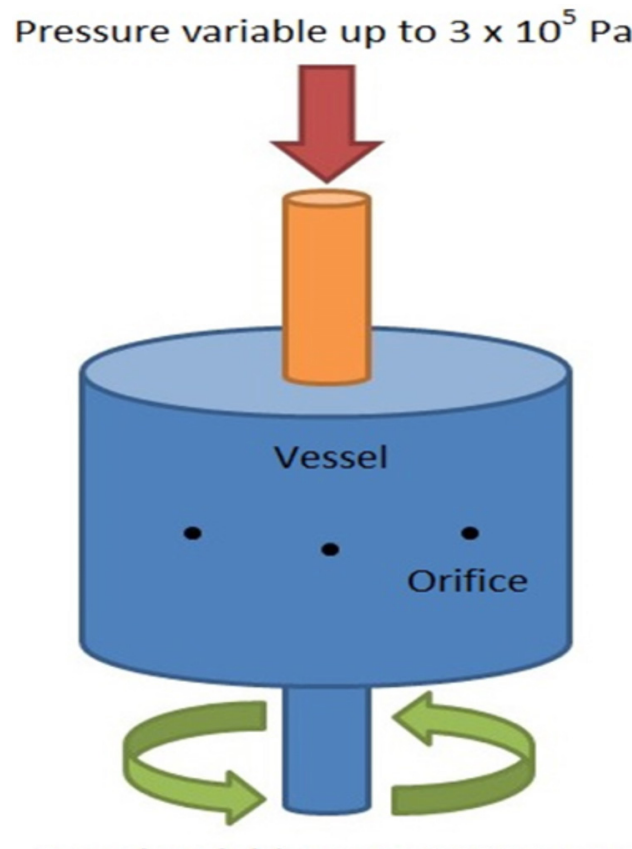

\section{Speed variable up to $36000 \mathrm{rpm}$}

FIG. 8. Schematic illustration of the pressurized gyration process. Reproduced with permission from Mahalingam et al., Langmuir 31, 659 (2015). Copyright 2015 American Chemical Society.

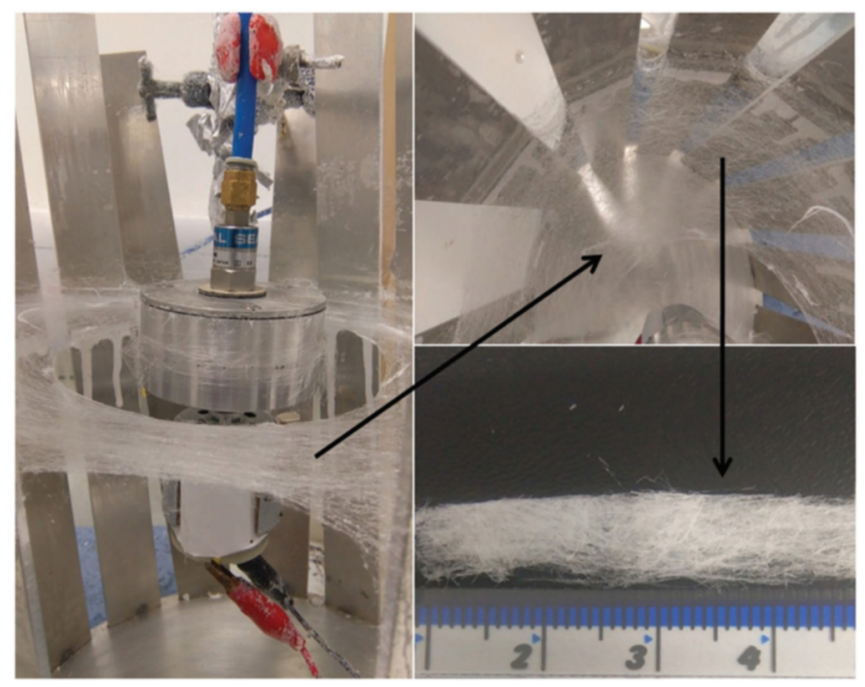

FIG. 9. Typical pressurized gyration process setup to generate polymer fiber constructs and typical products obtained. Reproduced with permission from $\mathrm{X}$. W. Wu, S. Mahalingam, S. K. VanOosten, C. Wisdom, C. Tamerler, and M. Edirisinghe, "New generation of tunable bioactive shape memory mats integrated with genetically engineered proteins," Macromol. Biosci. 17, 1600270 (2017). Copyright 2017 licensed under a Creative Commons Attribution (CC BY) license. concentration of polymer influence the fiber size, fiber size distribution, and the morphology.

The yield and the quality of the fibers are primarily influenced by polymer concentration and the evaporation rate of the solvent. A mathematical model relating the fiber size and the flow properties such as surface tension and viscosity and processing parameters (rotating speed and working pressure) has been published. ${ }^{115}$ In addition, the influence of the evaporation rate of solvents on the fiber diameter is mathematically proven. ${ }^{107}$ Silver nanoparticle embedded nylon nanofibers generated using this technique have shown excellent antibacterial resistance to gram-negative microorganisms. ${ }^{116}$ Moreover, this method has been shown to generate amorphous solid dispersions of poorly water-soluble drugs with enhanced dissolution performance. ${ }^{117}$ Genetically modified bioactive peptide incorporated blend fibers and mats have been reported to show shape memory properties. ${ }^{113}$ Furthermore, pressurized gyration is used to process graphene nanoplatelet incorporated fibers, graphene, and carbon fibers. ${ }^{111,112}$ The mechanical and electrical properties of carbon fibers are tuned with the concentration of graphene content in the fibers. ${ }^{112}$ Besides, this method has been shown to mass-produce ceramic fibers using preceramic polymers. $^{118}$

Over the years, since 2013, pressurized gyration encountered various modifications and new developments to generate novel functional materials and structures. The flow of polymer solution to the gyration vessel could be controlled and regulated by an infusion syringe pump. Thus, infusion gyration offers a simple and effective way of making nanoassemblies with diverse functionalities. ${ }^{119}$ Figure 10 shows the infusion gyration process and engineered protein embedded nanofibers prepared using this process. Infusion pressure gyration is another development of this exciting processing technique, where the flow, pressure, and rotation could be controlled to form nanofibers. ${ }^{120-122}$ A typical infusion pressure gyration process is shown in Fig. 11. Furthermore, the advancement of this technology resulted in pressurized melt gyration (PMG), which does not require solvents as it forms a polymer melt in a gyrating pot containing orifices on its surface. ${ }^{123}$ The pot temperature can be controlled in micrometer size fibers, the surface roughness could be tailored, and the fibers can be used to architecture tissue engineering bio-constructs and antimicrobial mats. The pressurized melt gyration is illustrated in Fig. 12. Very recently, we have used a transparent pot to experimentally observe the pressurized gyration process and compare it with centrifugal spinning. ${ }^{124}$ The process was also modeled in this work and theoretical and experimental findings were compared as well. $^{124}$

Core-sheath pressurized gyration was invented by Mahalingam et al. in 2019. It was developed intending to generate core-sheath polymer fibers with two or more different phases in a single electric-free step. ${ }^{125}$ Figure 13 shows the design of the co-axial pressurized gyration device. It contains two aluminum cylindrical reservoirs in the same vessel co-axially placed and hence is sometimes referred to as co-axial pressurized gyration. The diameter of the outer vessel is typically $100 \mathrm{~mm}$ and the inner vessel is approximately $80 \mathrm{~mm}$ in diameter. In the middle of their alignment, there is an opening for the pressurized gas connection. The opening has dimensions of $15 \mathrm{~mm}$ outer diameter and $6 \mathrm{~mm}$ inner diameter. The thickness of the outer reservoir is $20 \mathrm{~mm}$ and the inner reservoir is $10 \mathrm{~mm} .{ }^{125}$ In addition, there are two 


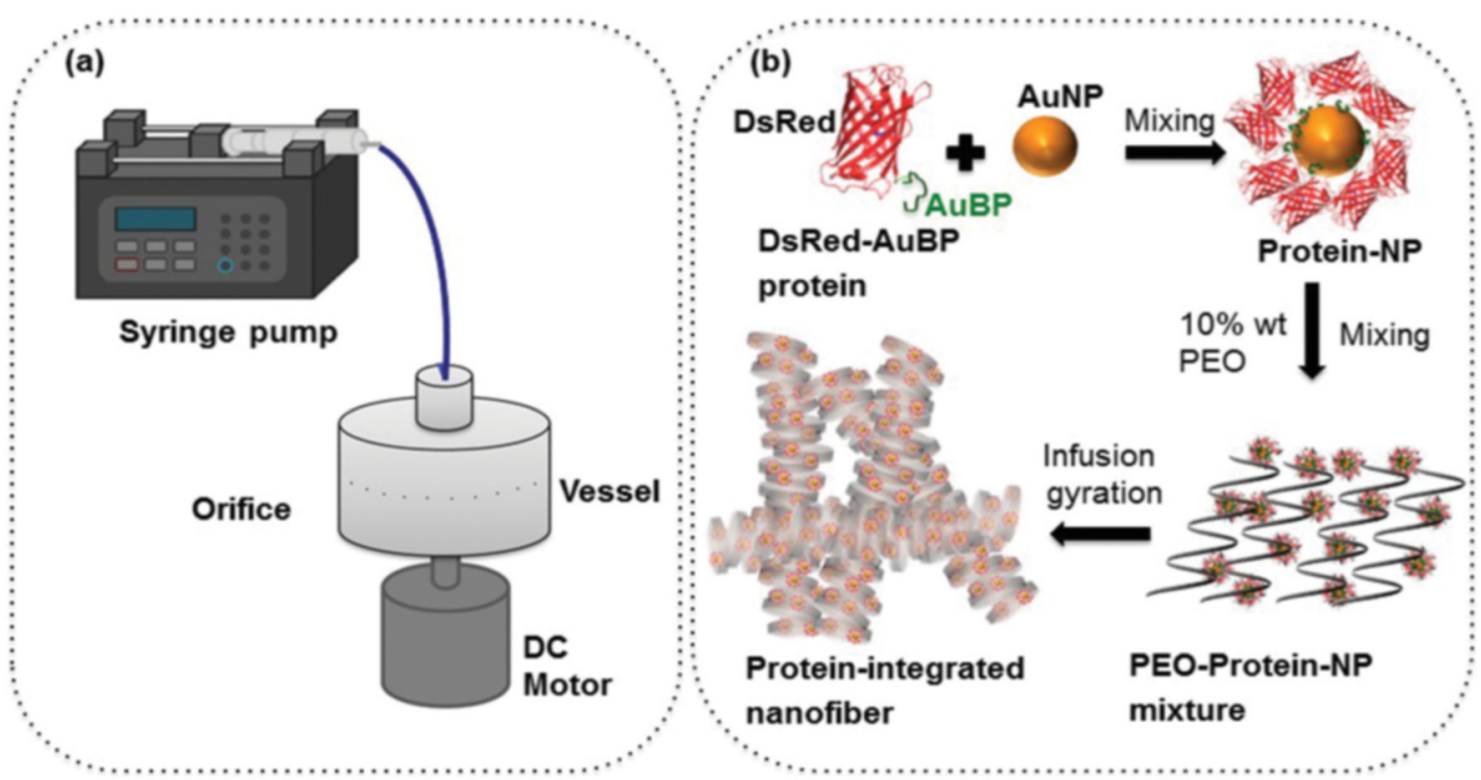

FIG. 10. (a) Infusion gyration process setup to generate polymer fibers. (b) Engineered protein embedded nanofibers obtained from infusion gyration process. Reproduced with permission from S. Q. Zhang, B. T. Karaca, S. K. VanOosten, E. Yuca, S. Mahalingam, M. Edirisinghe, and C. Tamerler, "Coupling infusion and gyration for the nanoscale assembly of functional polymer nanofibers integrated with genetically engineered proteins," Macromol. Rapid Commun. 36, 1322 (2015). Copyright 2015 licensed under a Creative Commons Attribution (CC BY) license.

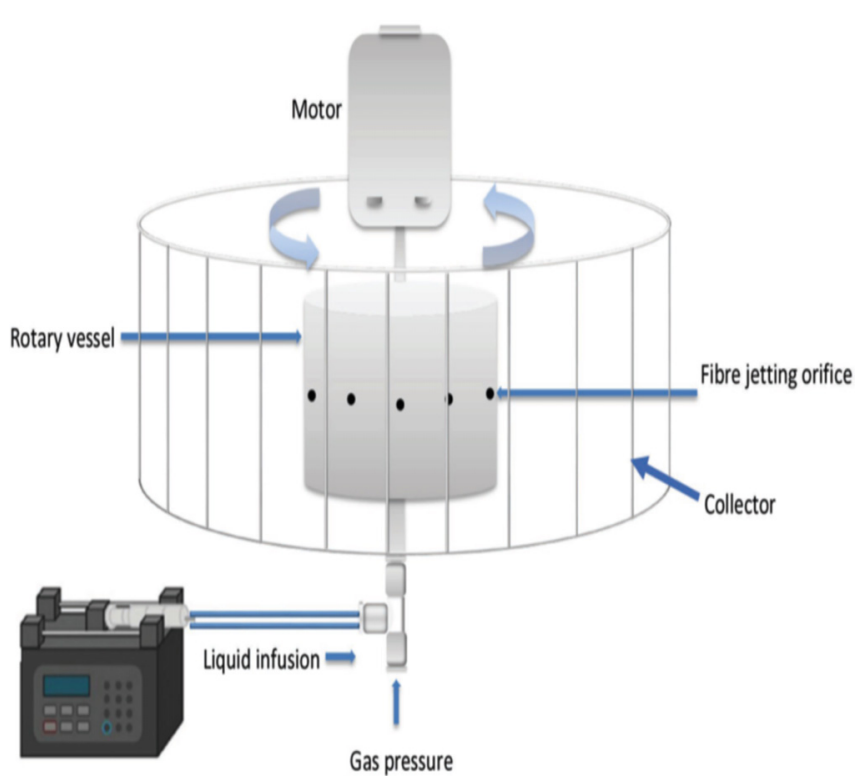

FIG. 11. Infusion pressure gyration process setup to generate polymer fibers. Reproduced with permission from X. Z. Hong, S. Mahalingam, and M. Edirisinghe, "Simultaneous application of pressure-infusion-gyration to generate polymeric nanofibers," Macromol. Mater. Eng. 302, 1600564 (2017). Copyright 2017 licensed under a Creative Commons Attribution (CC BY) license.

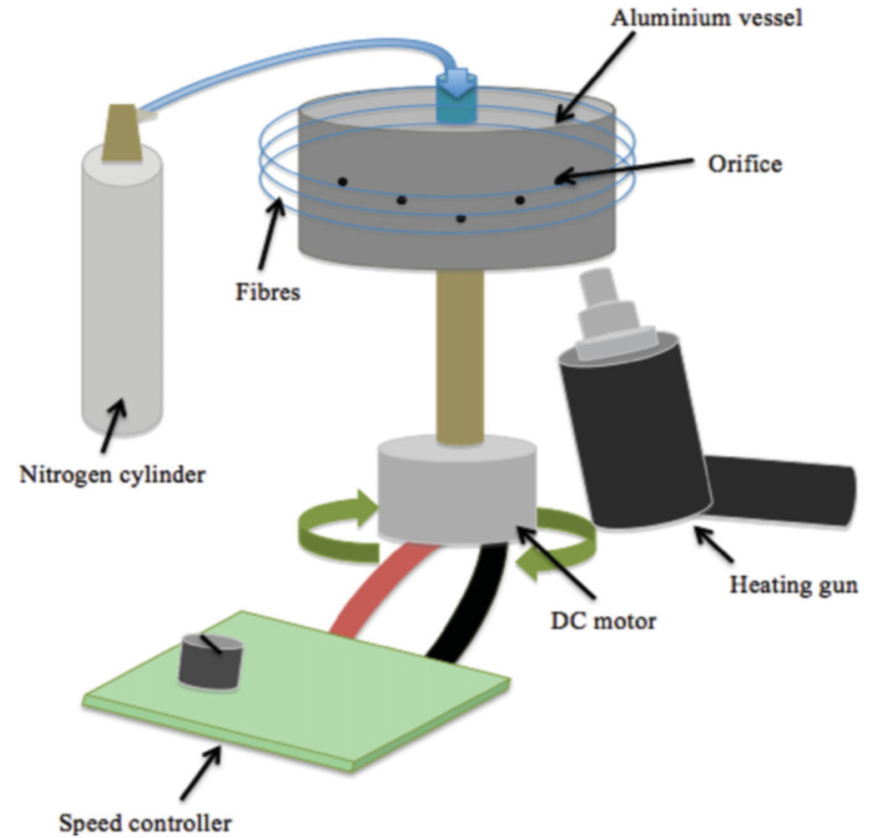

FIG. 12. Schematic illustration of the pressurized melt gyration process to form polymer fibers. Reproduced with permission from Z. W. Xu, S. Mahalingam, P. Basnett, B. Raimi-Abraham, I. Roy, D. Craig, and M. Edirisinghe, "Making nonwoven fibrous poly(epsilon-caprolactone) constructs for antimicrobial and tissue engineering applications by pressurized melt gyration," Macromol. Mater. Eng. 301, 922 (2016). Copyright 2016 licensed under a Creative Commons Attribution (CC BY) license. 


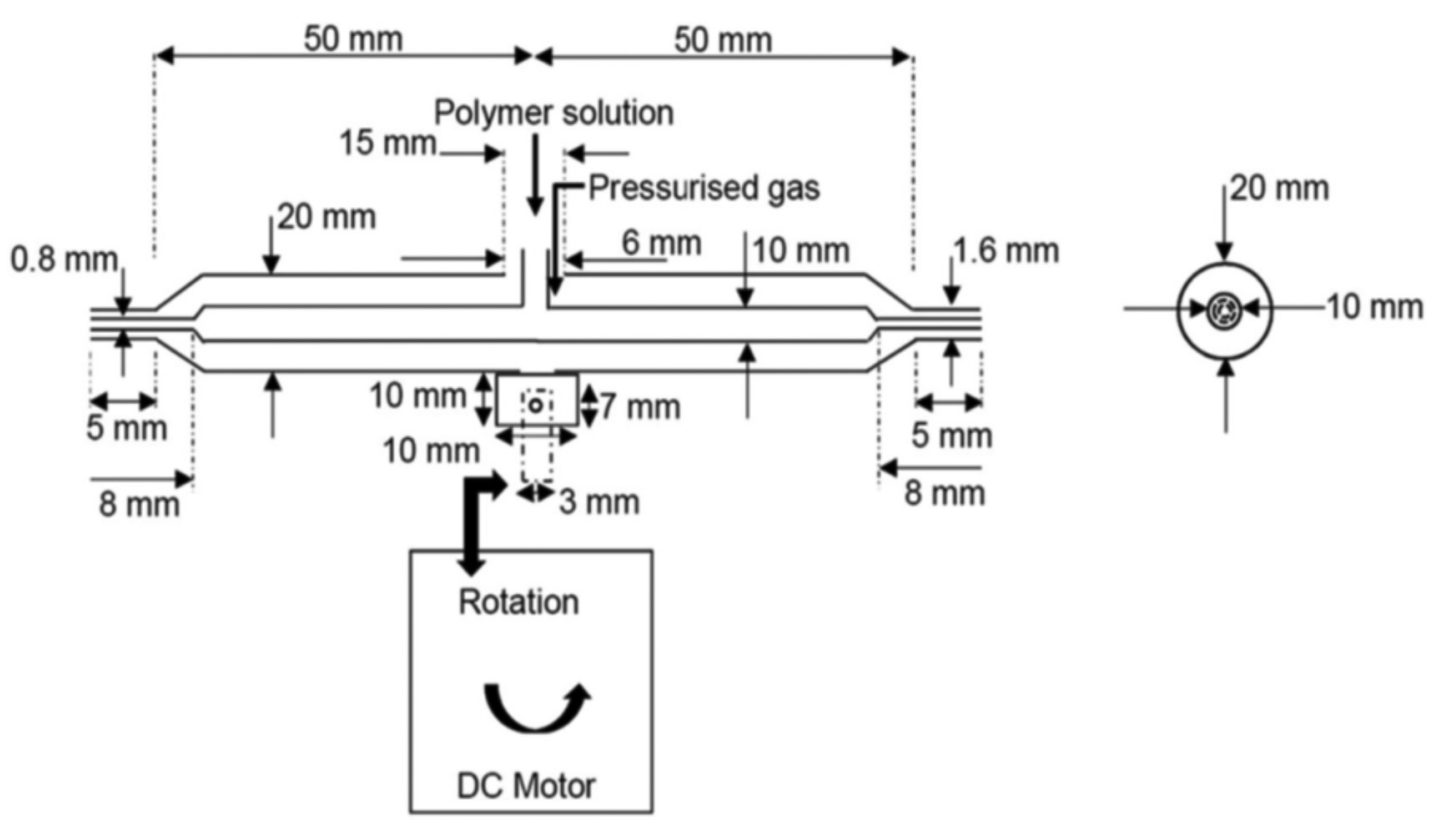

FIG. 13. Design of the co-axial pressurized gyration device which enabled the formation of core-sheath polymer fibers. Reproduced with permission from S. Mahalingam, S. Homer-Vanniasinkam, and M. Edirisinghe, "Novel pressurized gyration device for making core-sheath polymer fibers," Mater. Des. 178, 107846 (2019). Copyright 2019 licensed under a Creative Commons Attribution (CC BY) license.

protruding capillaries connected to the reservoirs. The dimensions of these capillaries are typically $1.6 \mathrm{~mm}$ in outer diameter and $0.8 \mathrm{~mm}$ in inner diameter. The device was designed in such a way that upper and lower die halves could be assembled using bolts. The two halves of the device are shown in Fig. 14. The materials used to process (e.g., polymer solutions) are placed in the lower half of the device in appropriate quantities. The vessel is connected to a DC motor at the bottom through a screw-joint. ${ }^{125}$ Typical co-axial pressurized gyration or

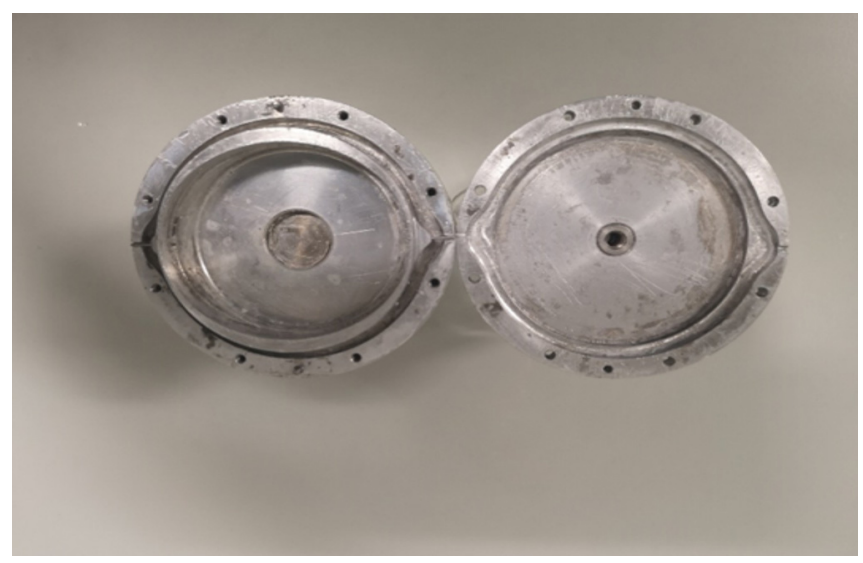

FIG. 14. Two halves of the novel setup making the co-axial pressurized gyration device. Reproduced with permission from S. Mahalingam, S. Homer-Vanniasinkam, and M. Edirisinghe, "Novel pressurized gyration device for making core-sheath polymer fibers," Mater. Des. 178, 107846 (2019). Copyright 2019 licensed under a Creative Commons Attribution (CC BY) license. twinned reservoir pressurized gyration process is illustrated in Fig. 15(a). The schematic illustration of the process is shown in Fig. 15(b). In this setup, one end of the vessel is connected to a motor which can generate apparent speeds up to $6000 \mathrm{rpm}$, while the other end is connected to a nitrogen gas stream, the pressure of which can be varied up to $3 \times 10^{5} \mathrm{~Pa}$. The magnitude of these values can be further increased, and this is the aim of present work. The collection of fibers is carried out by a stationary collector made of aluminum foil placed around the spinning vessel. ${ }^{125}$ Different combinations of polymer systems have been used to generate core-sheath polymer fibers using co-axial pressurized gyration. Table I shows the polymer systems, spinning time, and the volume of polymer solutions used to prepare the core-sheath fibers. The polymer fiber diameter can be tailored by adjusting the processing conditions. The core diameter in the range of $5-10 \mu \mathrm{m}$ and the sheath diameter in the range of $20-30 \mu \mathrm{m}$ could be obtained using this process, but this has been further improved to the nanoscale very recently (see below). ${ }^{125}$ Typical core-sheath fibers and the diameters of core and sheath formed in this process is shown in Fig. 16. Figure 17 shows the scanning electron micrograph of the core-sheath fibers obtained from different combinations of the polymer system. In all cases, the surface of the fibers appears as smooth and continuous. To show the flexibility of this method, nanoparticlecontaining polymethylmethacrylate (PMMA) fibers have also been produced and incorporation of the nanoparticles in the sheath of the fibers has been verified by electron microscopy x-ray analysis. ${ }^{125}$ The verification of core-sheath fibers is done using focused ion beam milling and imaging and the results are summarized in Fig. 18. However, it should be noted that very recently core-sheath nanofibers were generated by the combination of two water-soluble polymers, polyvinyl alcohol (PVA) and polyethylene oxide (PEO), using twin vessel pressurized gyration. ${ }^{126}$ 

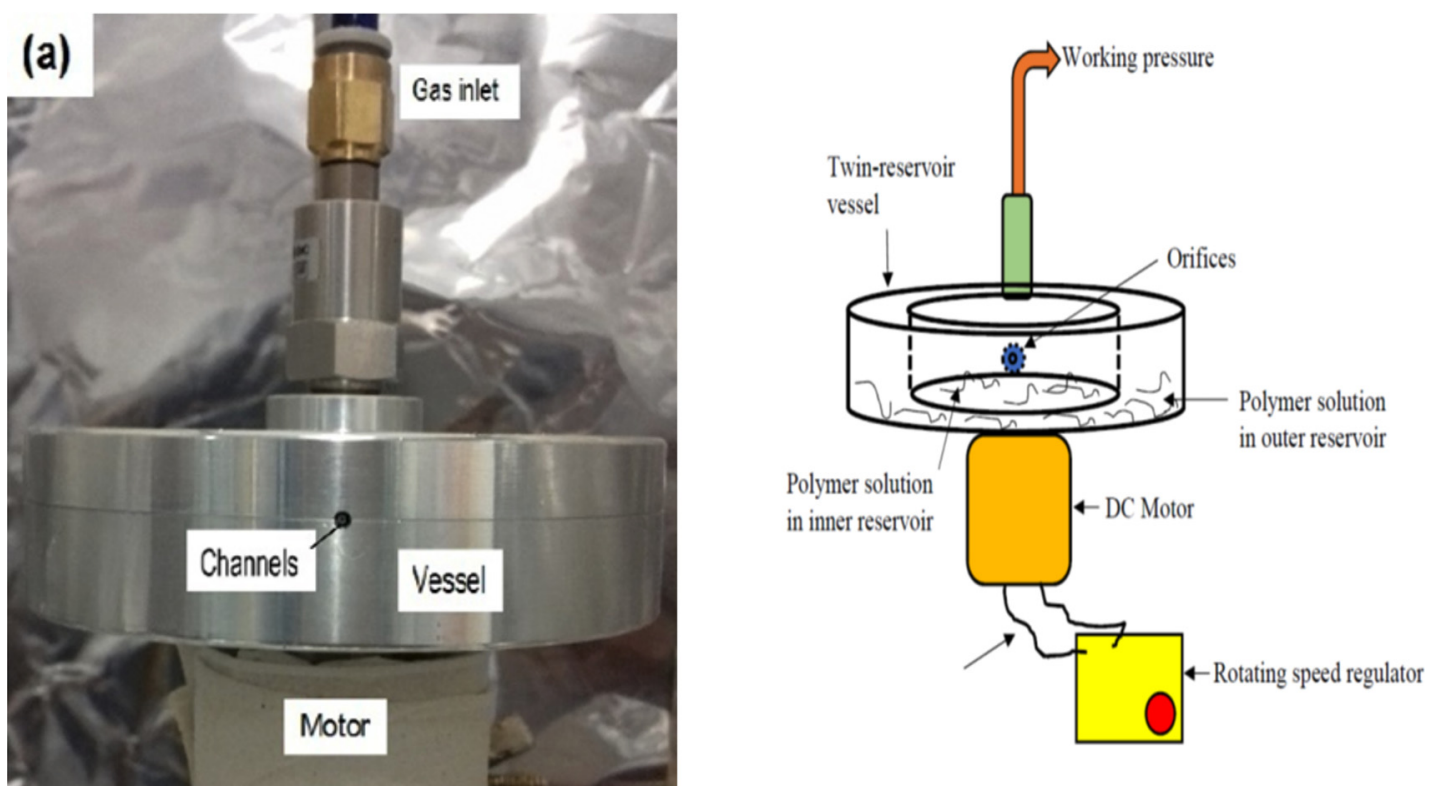

FIG. 15. (a) Typical pressurized gyration experimental setup used to generate core-sheath fibers at ambient temperature. (b) Schematic illustration of the process. Reproduced with permission from S. Mahalingam, S. Homer-Vanniasinkam, and M. Edirisinghe, "Novel pressurized gyration device for making core-sheath polymer fibers," Mater. Des. 178, 107846 (2019). Copyright 2019 licensed under a Creative Commons Attribution (CC BY) license.

Wet spinning technique is another methodology utilized to generate core-sheath fibers. In a typical wet spinning setup, the spinning solutions are injected into a coaxial spinneret and drawn out using pneumatic or piston-driven actuators and then dried to form fibers. ${ }^{127-129}$ In coaxial centrifugal spinning, the polymer solutions are rotated and extruded at a rapid rate to form core-sheath and hollow fibers. ${ }^{130}$ Coaxial solution blowing is another promising approach to produce core-sheath fibers in scalable quantities. In this approach, two polymer solutions are pumped into two nozzles within the outer air nozzle, which induces changes to the chemical environment to extrude polymer core-sheath fibers. ${ }^{131}$

\section{CORE-SHEATH FIBERS IN BIOMEDICAL \\ APPLICATIONS}

\section{A. Tissue engineering \\ 1. Vascular grafts}

Human health has been plagued with vascular diseases, such as coronary artery disease mainly caused by arteriosclerosis and peripheral vascular disease, which requires vascular graft surgery for more than a million patients every year. ${ }^{132}$ Arteriosclerosis is associated with a heart disease, where thickening of the arterial wall and subsequent decrease in arterial lumen results in decrease or loss of circulation distal to the disease site. Peripheral vascular disease related to the buildup of fatty deposits in blood vessels outside the heart causes pain in the body and muscles, alleviated by restoring the blood flow to tissue distal to restrictions or blockage. Due to this, the demand for bioengineered arteries and blood vessels increases continuously over the years. Vascular grafts have to not only possess sufficient mechanical properties but also should recapitulate biological functions. Core-sheath fibers and fibrous structures could be used as scaffolds in vascular graft tissue engineering. Here, the function of a scaffold is to act as a cell growth template and provide mechanical support. The selected fibrous scaffolds should show biocompatibility and biodegradability. Generally, a high rate of platelet adhesion and limited biocompatibility was regarded as the chief weaknesses of vascular tissue engineering scaffolds. To overcome this issue, vascular grafts were

TABLE I. Different combinations of core-sheath fibers prepared, spinning time, and volume used in the process. Reproduced with permission from Mahalingam et al., Mater. Des. 178, 107846 (2019). Copyright 2019 Elsevier.

\begin{tabular}{|c|c|c|c|c|c|}
\hline \multicolumn{4}{|l|}{ Core } & \multicolumn{2}{|c|}{ Sheath } \\
\hline Polymer (wt. \%) & Spinning time (s) & Dye (wt. \%) & Volume (ml) & Polymer (wt. \%) & Volume (ml) \\
\hline PEO (15) & 60 & Food (0.5) & $1-5$ & PMMA (15) & $1-4$ \\
\hline PMMA (15) & 30 & Sudan IV (0.5) & $1-5$ & PEO (15) & $1-4$ \\
\hline PMMA (15) & 30 & Sudan IV (0.5) & $1-5$ & PMMA (15) & $1-4$ \\
\hline PEO (15) & 60 & Food (0.5) & $1-5$ & PEO (15) & $1-4$ \\
\hline
\end{tabular}




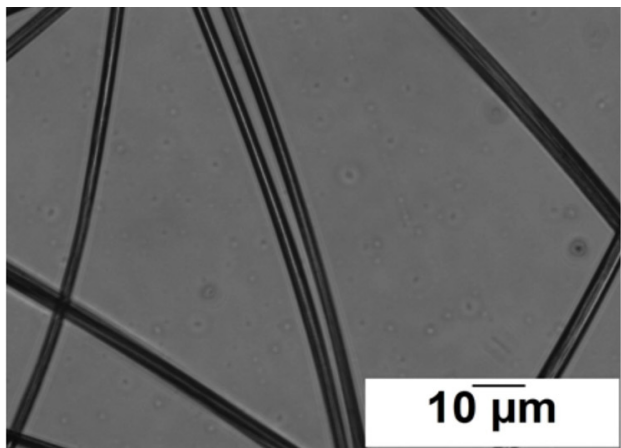

(a)

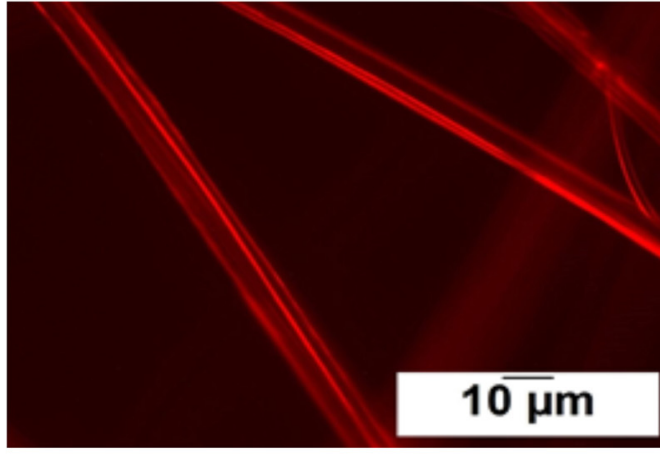

(b)

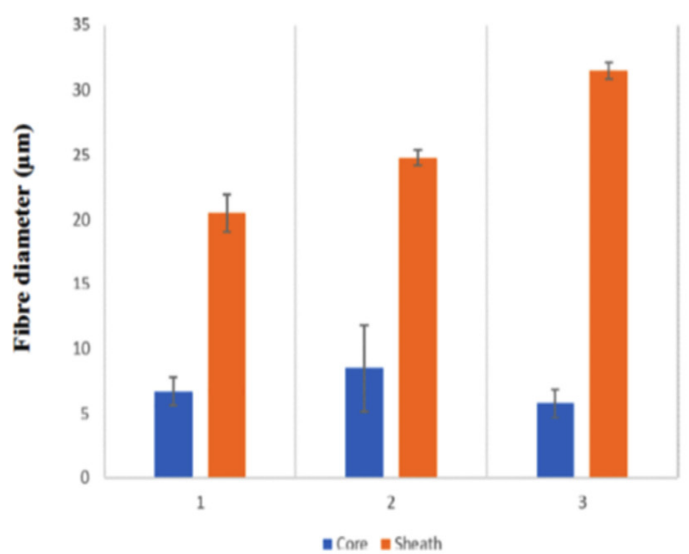

(c)

FIG. 16. Typical core-sheath fibers generated by twin reservoir pressurized gyration. (a) Optical microscopy. (b) Use of fluorescence microscopy to illustrate core-sheath structures. (c) Diameter analysis of core-sheath fibers. Reproduced with permission from S. Mahalingam, S. Homer-Vanniasinkam, and M. Edirisinghe, "Novel pressurized gyration device for making core-sheath polymer fibers," Mater. Des. 178, 107846 (2019), Copyright 2019 licensed under a Creative Commons Attribution (CC BY) license.

made with cistanche polysaccharide (CDPS) and PLA core-sheath fibers, where they have exhibited similar mechanical properties such as tensile strength, elongation to break, and compressive strength to the natural blood vessels. ${ }^{133}$ The counting of thrombocytes with a platelet counter suggested a lower rate of platelet adhesion occuring in these fibers and could pave the way to eliminate crude artificial blood vessels. In addition, hemolysis and cytotoxicity evaluation implied a lower hemolysis ratio and nontoxic behavior. The in vivo study of CDPS-PLA scaffolds on mice showed good cellular affinity and histocompatibility. ${ }^{133}$

Nagiah et al. ${ }^{134}$ developed three different vascular grafts with three different hydrophobic core polymers and a gelatin sheath layer. Of these grafts, the PCL-gelatin combination revelated higher suture retention, while the PU-gelatin exhibited higher modulus and tensile strength. Figure 19 shows the representative stress-strain curves, complex modulus-strain curves, and strain sweep results of three coresheath vascular graft scaffolds. The burst pressure study showed that the pressure values are inversely proportional to the thickness of the sheath gelatin layer. Figure 20 demonstrates the representative curves showing the percentage of change in graft diameter with respect to increasing pressure. In this regard, PU-gelation fibers displayed higher burst pressures. However, all three vascular grafts possessed adequate strength, $\sim 3-5$ times the physiological pressure, for implantation. ${ }^{134}$ Higher compliance values were observed for PCL-gelatin and PU-gelatin vascular grafts compared to PLA-gelatin grafts and suggested superior compliance values compared to the native saphenous vein and umbilical vein and similar to the elastic artery. The in vitro cell assessment carried out with human pulmonary artery endothelial cells (hECs) and human pulmonary artery smooth muscle cells (hSMCs) indicated that cell growth is the highest in PCL-gelatin and reached confluency after 6 days. ${ }^{134}$ This result is presented in Fig. 21. In general, porous structures favor cell infiltration, whereas it could easily dilate or rupture when bearing the arterial pressure; contrarily, a dense structure provides stable resistance but limited cell infiltration and tissue regeneration. This could be solved by creating bilayered vascular grafts, combining the porous and the dense structures that could be ideal for clinical settings, and avoiding any catastrophe after implantation. The rational design of PCL sheath nanofiber around PGS core grafts showed that enhanced mechanical properties could initiate high-quality muscular remodeling and contribute to adequate 

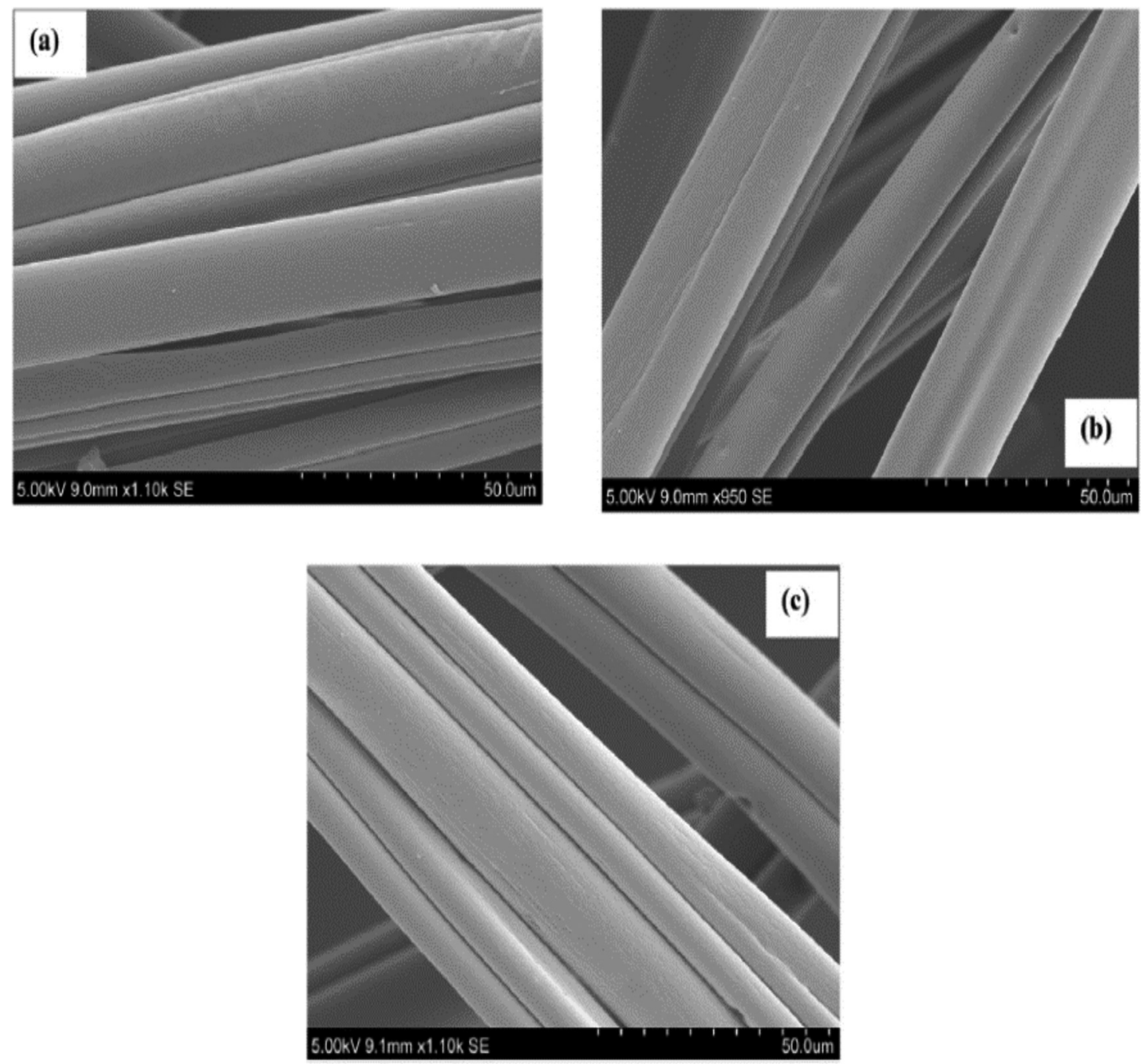

FIG. 17. Scanning electron micrographs showing the surfaces of the core-sheath fibers. Reproduced with permission from S. Mahalingam, S. Homer-Vanniasinkam, and M. Edirisinghe, "Novel pressurized gyration device for making core-sheath polymer fibers," Mater. Des. 178, 107846 (2019), Copyright 2019 licensed under a Creative Commons Attribution (CC BY) license.

pressure resistance, ideal surgical handling, and long term success in arterial circulation. ${ }^{135}$ The vascular grafts made with coaxial fibers with a PVA core and a gelatin sheath promoted human umbilical vein endothelial cell (HUVEC) and rat smooth muscle cell (rSMC) growth and migration. ${ }^{136}$ Development and fabrication of these grafts are relevant for the clinical application that can modulate thrombosis and subsequent restenosis. Figure 22 shows the results of cell migration in a cylindrical assay performed with HUVEC or rSMC cells. Continued outward cell migration was observed for both cell lines in PVA-gelatin core-sheath fibers. Interestingly, the increase in cell migration in these scaffolds was increased with the stiffness of the scaffolds. ${ }^{136}$ Recently, vascular grafts constructed with core-sheath PCL-gelatin nanofibers showed superior graft performance, biomechanical properties, and blood compatibility. ${ }^{137}$ The average burst pressure of the grafts was increased with core-to-sheath ratio; the swell ratio (indication that the grafts were hydrogel in nature) was decreased with core-to-sheath ratio and exhibited no water leakage at optimal flow pressure. In addition, the introduction of a thin PCL "cap" layer outside the PCL-gelatin coaxial layer possessed good suturability and anti-kinking capability, resembling the biomechanics of native artery.

\section{Cardiac patches}

Myocardial infarction (MI) causes cardiac wall thinning as a result of the loss of functional myocardium, increased left ventricular (LV) sphericity, and dilated heart with decreased pumping efficiency. Tissue engineering solutions with the combination of gene therapy have been pursued to treat the damaged and at-high risk cardiac tissues. Adeno-associated virus (AAV), known for its persistent transgene expression and low pathogenicity, was incorporated into 

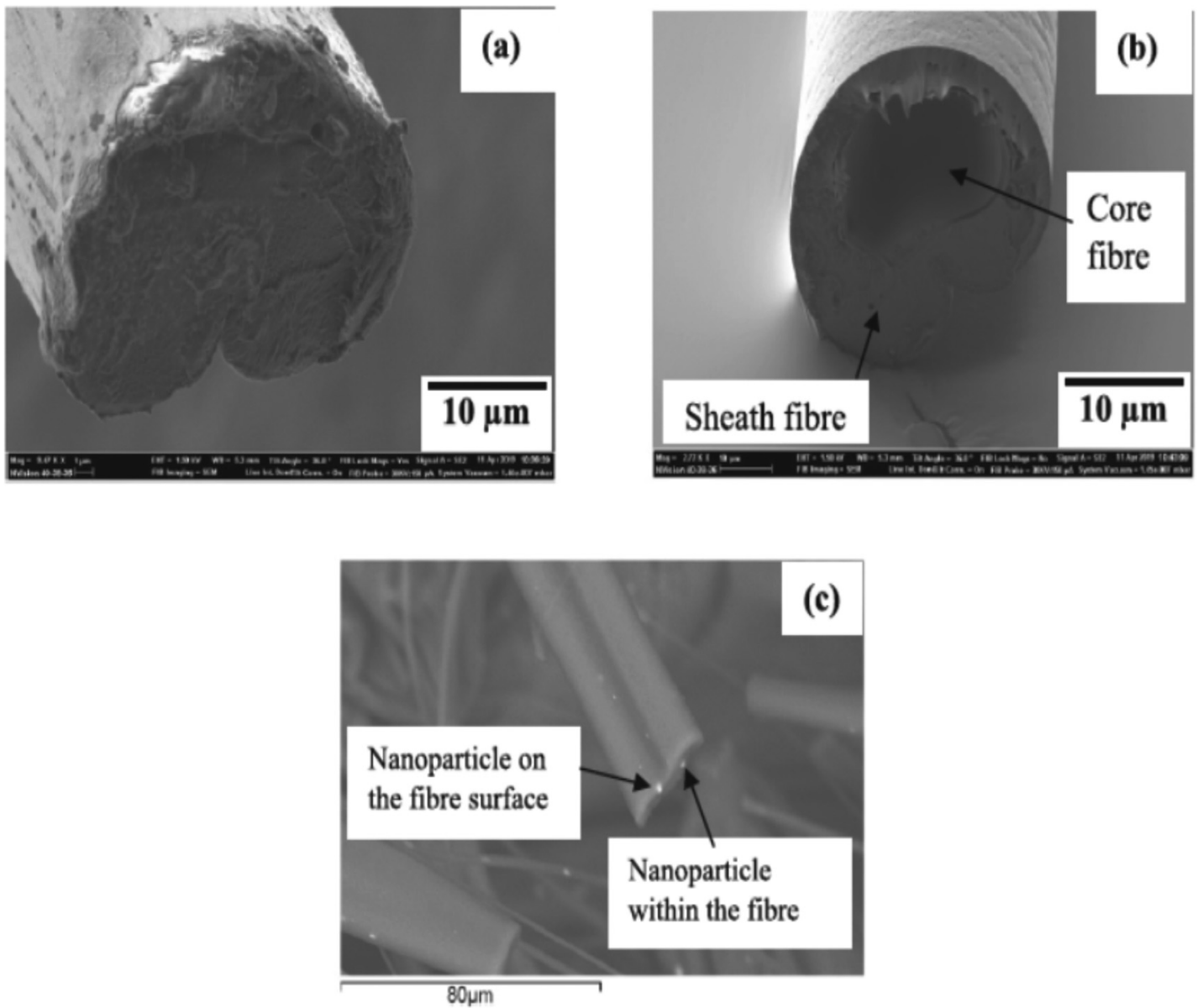

FIG. 18. Scanning electron micrographs of core-sheath fibers (a) before ion milling, (b) after ion milling, and (c) the backscattered image showing the nanoparticles within the fiber and nanoparticles on the surface. Reproduced with permission from S. Mahalingam, S. Homer-Vanniasinkam, and M. Edirisinghe, "Novel pressurized gyration device for making core-sheath polymer fibers," Mater. Des. 178, 107846 (2019). Copyright 2019 licensed under a Creative Commons Attribution (CC BY) license.

polyurethane (PU) and polyethylene glycol (PEG) core-sheath fibers and sustained viral particle delivery was achieved over 2 months in vitro. The in vivo implantation of biodegradable core-sheath cardiac patches over rat left ventricular lesions showed that prolonged transgene expression and elastomeric mechanical properties make them an attractive option for cardiac tissue engineering (Fig. 23). ${ }^{6}$ In another study, carbon nanotubes (CNTs) loaded core-sheath fibrous scaffolds were used to tune the electrical conductivity and inner structure of cardiomyocytes. These scaffolds were shown to increase the conductivity, maintain cell viability, induce cell elongation, and enhance the production of sarcomeric $\alpha$-actinin and troponin I to promote the synchronous beating of cardiomyocytes (Fig. 24). ${ }^{5}$ Figure 25 demonstrates the different beating rates of cardiomyocytes achieved in blended and core-sheath fibers with varying amounts of CNTs. Although the conductivity of blended fibers is slightly higher than that of coaxial fibers with the same CNT loadings, the lower exposures to CNTs resulted in higher cell viability, elongation, extracellular matrix secretion, and beating rates for cardiomyocytes on core-sheath fibers. ${ }^{5}$
Three dimensional (3D) structures have also been developed and produced to mimic the cardiomyocytes and cardiovascular tissues. Cell-laden structures with tunable 3D microenvironments have been made with gelatin methacryloyl (GelMA)-alginate core-sheath microfibers; these were shown to contain very good perfusion and diffusion properties, thus useful to generate vascularized tissues due to the ability of nutrients, oxygen, and waste to exchange through the porous walls of microfibers. A wide variety of cells such as MCF7, NIH/3T3, HUVEC, and MDA-MB-231 seeded on the constructs displayed a varying degree of cell spreading and proliferation. ${ }^{138}$ Nagata et al. ${ }^{139}$ developed 3D fibrous scaffolds consisting of a PMMA core layer and a thin sheath layer of photoresponsive polymer spiropyran (SP). Their study showed that surface chemical properties of the core-sheath fibers changed during exposure to UV light, without affecting the surface morphology. The UV-stimulated chemical change regulated the cell attachment, thus controlling the cell behavior on 3D fibrous scaffolds by photostimulation. ${ }^{139}$ Cell metabolism and cell cultivation are different in $2 \mathrm{D}$ and $3 \mathrm{D}$ culture environments. In a $2 \mathrm{D}$ environment, surface-only cultivation is possible with limited cell migration; 

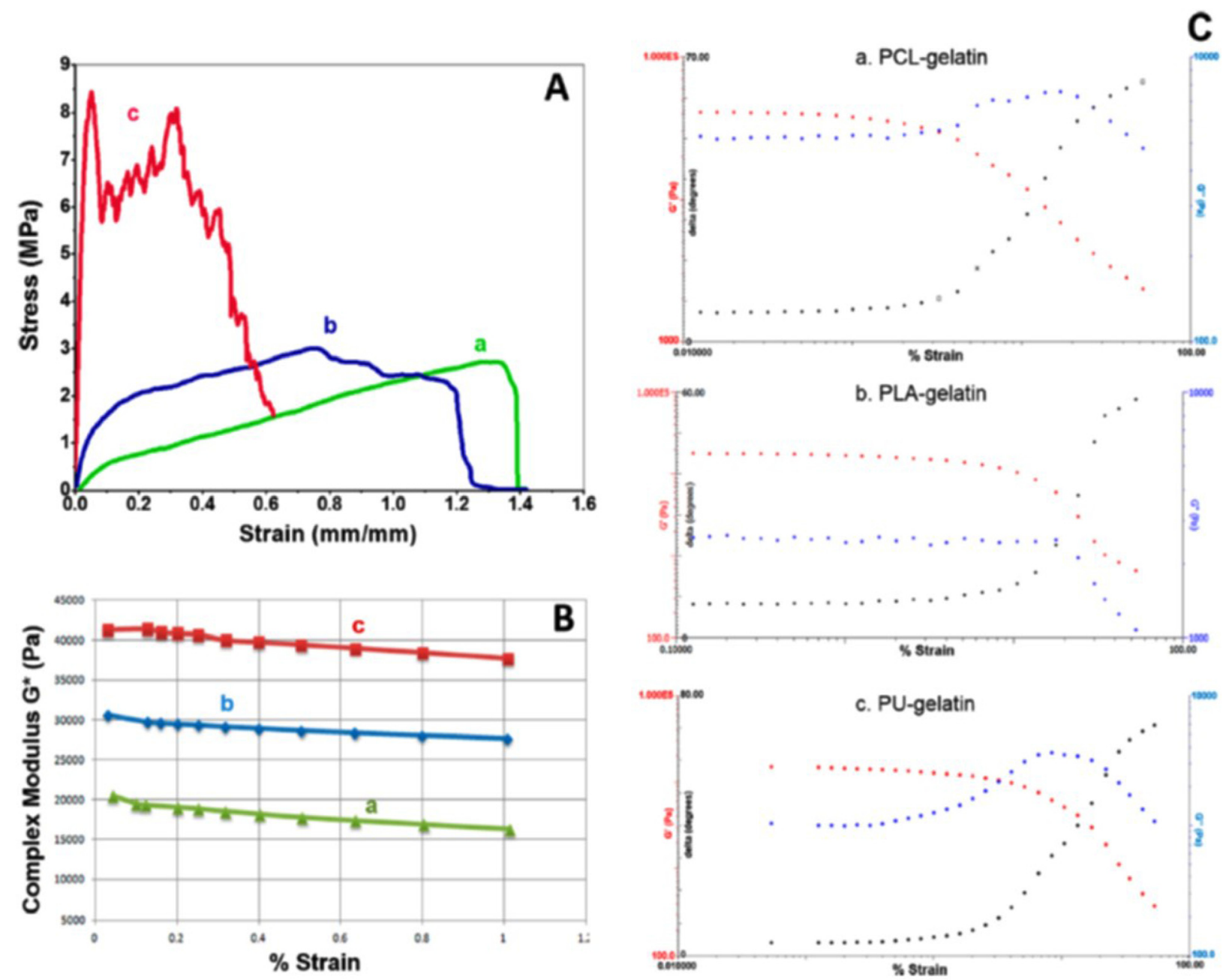

FIG. 19. Mechanical properties of scaffolds made with core-sheath fibers. (a) PCL-gelatin, (b) PLA-gelatin, and (c) PU-gelatin. (A) Representative results from uniaxial tensile tests. (B) Results of complex modulus as a function of strain. (C) Representative strain sweep results showing viscoelastic properties of scaffolds. Reproduced with permission from Nagiah et al., Langmuir 31, 12993 (2015). Copyright 2015 American Chemical Society.

conversely, in a 3D microenvironment, the cells intermix with porous fibrous structures and they enable cells to migrate horizontally on the scaffolds and interfere with the 3D stretching of the cytoskeleton. In this regard, alginate hydro nanofibers, obtained by mimicking the alginate-PCL core-sheath fibers by cross-linking and organic-phase washing (peeling) showing deep infiltration of the cells from the top to bottom, could be an alternative for soft tissue engineering. ${ }^{140}$ In another study, core-sheath fibers prepared with cellulose acetate (CA) and PCL displayed higher cell attachment and spreading with no toxicity to human umbilical vein endothelial cells. ${ }^{141}$ Liu et al. ${ }^{3}$ reported that silk fibroin (SF) and poly(lactide-co- $\varepsilon$-caprolactone) core-sheath fibers improved the mechanical strength and elongation than pure SF. The culturing of EA.hy926 cells on the core-sheath structures permitted cellular adhesion, proliferation, and spread like that of pure SF. ${ }^{3}$ The use of SF is hampered by toxicity issues in the processing of silk, but the recent work by Heseltine et al. ${ }^{142}$ will attempt to couple waterbased routes and pressurized gyration to improve this.

\section{Nerve tissue engineering}

Neural tissue engineering involves a combination of cell, scaffold, and bio/chemical/physical cues to treat injuries such as damage to the sensory and motor neural pathway. The rate of regeneration of damaged tissue is very important in these cases, and currently, patients treated for peripheral nerve repair have a lengthy denervation period with a distant target and the regeneration rate approaches $1 \mathrm{~mm}$ day $^{-1}$ in humans. The outcome of this can emaciate denervated tissues by the time regenerative axons arrive at the tissue. In this respect, electrical simulation-based tissue engineering approaches are quite appealing in neural tissue growth. Borah et al. ${ }^{143}$ reported that a better electrical conductivity could be achieved with poly[2-methoxy-5-(2-ethyl-hexyl-oxy)-1,4phenylene vinylene] (MEH-PPV) and PCL core-sheath nanofibers and electrical stimulation can play a crucial role in activating neurons and promoting the speed and accuracy of motor and 

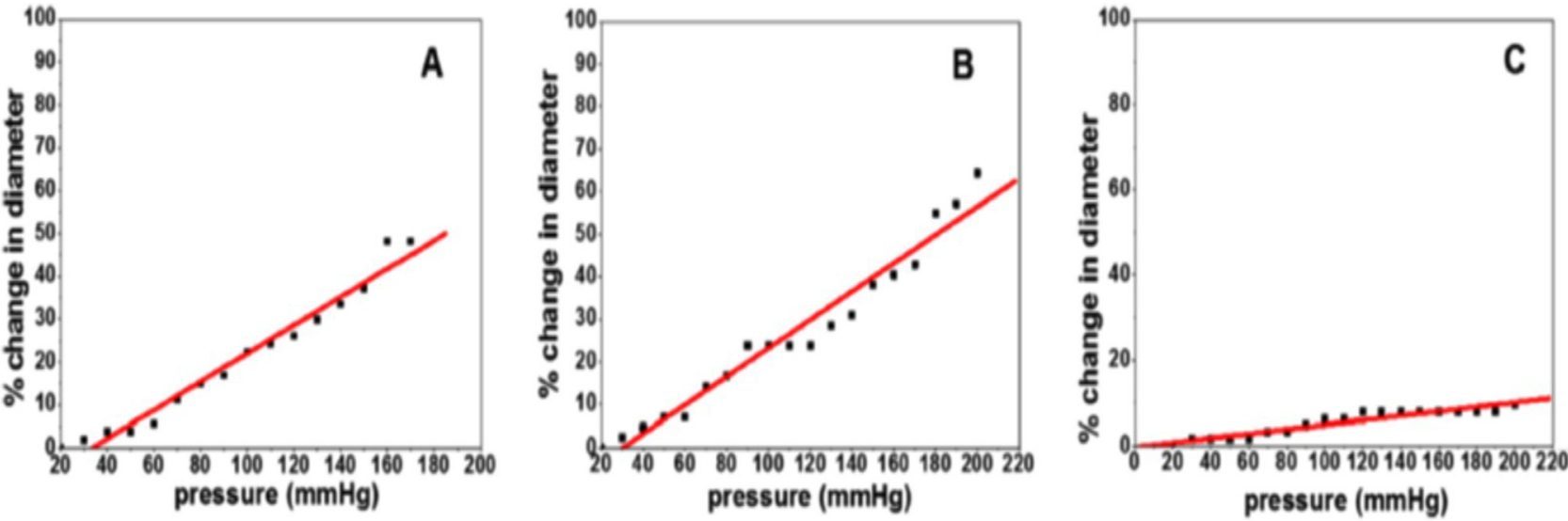

FIG. 20. Compliance of scaffolds made with three different polymer systems: (a) PCL-gelatin, (b) PLA-gelatin, and (c) PU-gelatin. Reproduced with permission from Nagiah et al., Langmuir 31, 12993 (2015). Copyright 2015 American Chemical Society.

sensory axon regeneration. ${ }^{143}$ In another study, core-sheath fibrous yarns made with electrically conducting polymers and their derivatives could be stimulated by electrical signals during tissue regeneration and were shown to develop nerve guidance conduits
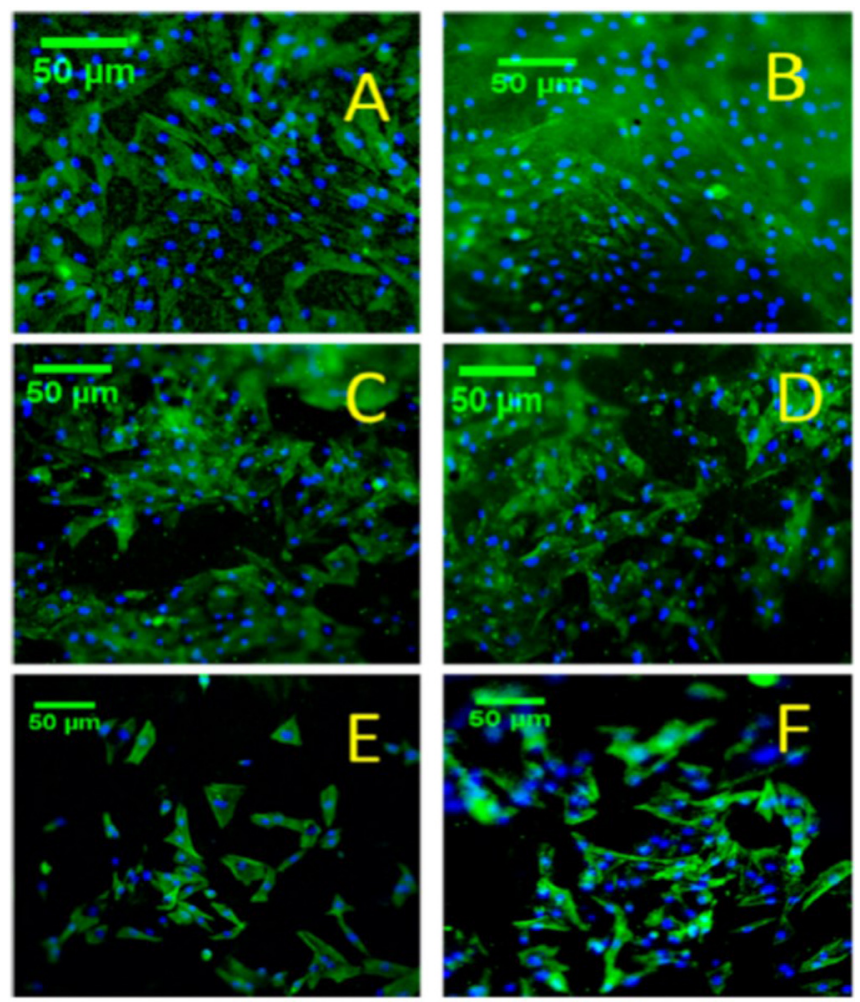

FIG. 21. Fluorescence microscopy images showing F-actin and DAPI stains in hECs [(a), (c), and (e)] or hSMCs [(b), (d), and (f)] cocultured on core-sheath fibrous scaffolds composed of PCL-gelatin [(a) and (d)], PLA-gelatin [(c) and (d)], or PU-gelatin $[(\mathrm{e})$ and $(\mathrm{f})]$. Reproduced with permission from Nagiah et al., Langmuir 31, 12993 (2015). Copyright 2015 American Chemical Society. for nerve repair. ${ }^{144}$ The surface functionalization of electrically conductive PCL core and MEH-PPV sheath nanofibers enhances the cell-biomaterial interaction, and the electric field stimulated cell culture showed a remarkable improvement in the neurite formation and growth in neural tissue engineering. ${ }^{145}$ Figure 26 shows 3 T3 cell interaction with materials, attachment, and spreading after 3 days of culture. Figure 27 demonstrates the immunolabeling of beta (III) tubulin in differentiated PC12 cells with DAPI-stained nuclei after a 7 day culture on surface functionalized PCL-MEH-PPV core-sheath fibers. Characteristic neurite formation was observed in these pictures with long neurites with or without branches of varying complexity, round somas of variable size, and many growth cones. The spinal cord tissue regeneration after spinal cord injury (SCI) is a part of nerve tissue engineering but more complicated than the other nerve systems, since SCI is a primary nerve system. Zamani et al. ${ }^{146}$ have studied PLGA based core-sheath 3D scaffolds to promote the spinal code axon regeneration using in vitro and in vivo biological tests. The nerve cells A-172 derived from the human brain showed enhanced attachment and proliferation in the scaffolds. Histology analysis showed successful implantation of scaffolds on injured mice and the implant was found to integrate into the injured spinal cord and formed a rostrocaudal bridge across the lesion site. In addition, the grafts proved effective stimulation effects for recovery and limb movement. ${ }^{146}$ Table II provides an overview of the polymer systems (core and sheath) used and their applications.

\section{Bone tissue engineering}

The osteochondral interface is the structurally connected area between a hyaline cartilage layer and the underlying bone plate, which is crucial in maintaining the cartilage integration. The repair of cartilage defects is generally pursued by integrative osteochondral repair methodology, where the biomimicking of scaffolds is achieved by effectively mimicking the extracellular matrix of the natural cartilage and subchondral bone. To prove this point, Zhang et al. ${ }^{147}$ developed biomimetic osteochondral scaffolds consisting of an oriented cartilage layer, a compact layer, and a 3D 


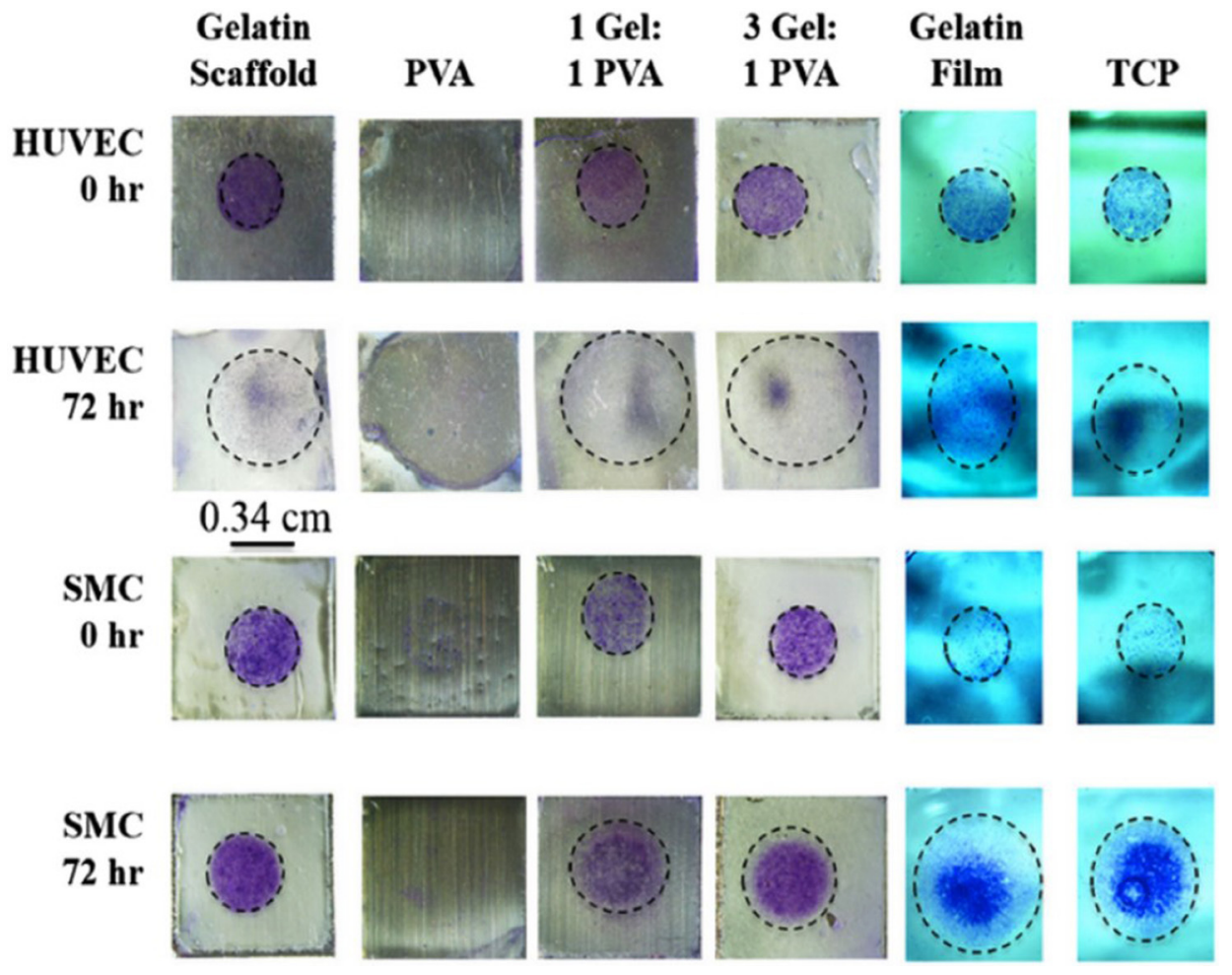

FIG. 22. Human umbilical vein endothelial cell (HUVEC) and smooth muscle cell (SMC) migration in gelatin scaffolds, PVA scaffolds, 1 Gelatin:1 PVA coaxial scaffolds, 3 Gelatin:1 PVA scaffolds, gelatin films, and tissue culture polystyrene (TCP) well after $72 \mathrm{~h}$. The 1:1 and 3:1 indicate the material flow rates of gelatin and PVA solutions used to produce the core-sheath fibers. The dotted lines demarcate the leading cell edge, indicating the area occupied by cells. Reproduced with permission from Merkle et al., Acta Biomater. 27, 77 (2015). Copyright 2015 Elsevier. printed core-sheath structured bone layer. The oriented cartilage layer was fabricated with cartilage-chitosan materials, whereas the core-sheath structured bone layer was fabricated with poly(L-lactide-co-glycolide)/ $\beta$-tricalcium phosphate-collagen materials. The in vitro bone mesenchymal stem cells (BMSCs) cultured on the scaffolds showed uniform distribution of cells and proliferation into cartilage and bone layers after 7 days. Additionally, cell clusters on the surface were observed and cells have grown into the pores of the cartilage layer and BMSCs spread into the bone layer over time. The implantation of BMSC-scaffold constructs into a goat articular defect model showed no sign of redness, suppuration or infection as well as no obvious inflammation, disability, and claudication in the goats, with most recovering 5 days after the implantation (Fig. 28). ${ }^{14}$

Total joint replacement (TJR) is a surgical procedure which involves removal and replacement of an arthritic or a damaged joint with a prosthetic, which can function as a normal healthier joint. The failure of TJR occurs most commonly in ageing of the population due to aseptic loosening $(\mathrm{AL})$, which requires repeated surgery. This can be attributed to dysfunctional osseointegration and implant infection and has paced an even greater demand on drug-loaded core-sheath nanofiber scaffolds to promote rapid osseointegration and prevent microbial colonization. Doxycycline (Doxy) and dexamethasone (Dex) incorporated PCL/PVA/HA/Type I collagen composite coresheath nanofibers are shown to have enhanced osseointegration. The generated scaffolds displayed burst and extended release of drugs and inhibited the MRSA colonization. ${ }^{148}$ In another study, the same authors described doxycycline loaded core-sheath nanofibers which enhanced the osseointegration in titanium implants and prevented $S$. aureus infection. ${ }^{149}$ On the other hand, in vitro bone tissue engineering showed that osteogenic differentiation of BMSCs on PLGA/ $\beta$-TCP-Type I collagen core-sheath fibers was significantly greater $(\mathrm{P}<0.05)$ than control groups. ${ }^{150}$ Gelatin-PCL/HA core-sheath nanofibers and gellan-HA hydrogel hybrid biomimetic scaffolds are suitable to create a bone-like microenvironment. The coiled core-sheath nanofibers mimic the osteon and have been tested with osteosarcoma fibroblast cells to indicate the possibility of bone tissue regeneration. ${ }^{151}$ The composite fibers of a cellulose acetate (CA) core and a silk fibroin (SF)/polyethylene oxide (PEO) loaded with nanohydroxyapatite (n-HA)/bone morphogenetic protein 2 (BMP-2) sheath are used to fabricate bone tissue engineering scaffolds made up with micro/submicrometer-scale features. The prepared scaffolds displayed good biocompatibility and increased mechanical properties compared to single component SF. The scaffolds exhibited rapid release of BMP-2 for the initial (few) days and a controlled sustained release thereafter for three weeks. The fabricated scaffolds also showed the profound effect of attachment, proliferation, and osteogenic differentiation of bone marrow mesenchymal stem cells (BMSCs) in vitro, compared to scaffolds without HA and BSM-2. ${ }^{152}$ Figure 29 demonstrates the effects of osteogenic differentiation and alkaline phosphate activity on different types of scaffolds measured at 7 days. Figure 30 displays the histological examination results where the new bones were formed in the defects of all the experiments. It also shows that new bone formation was much higher in core-sheath fibers than in the single fibers. 
(a)
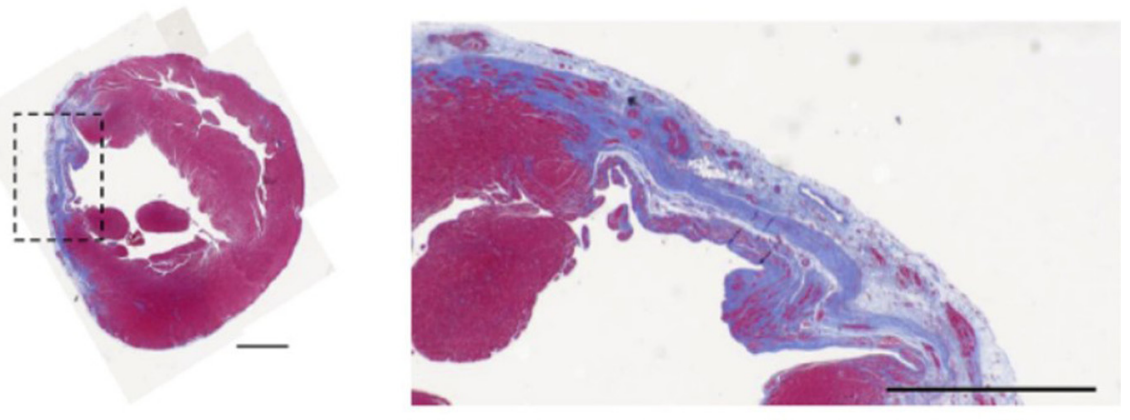

(b)
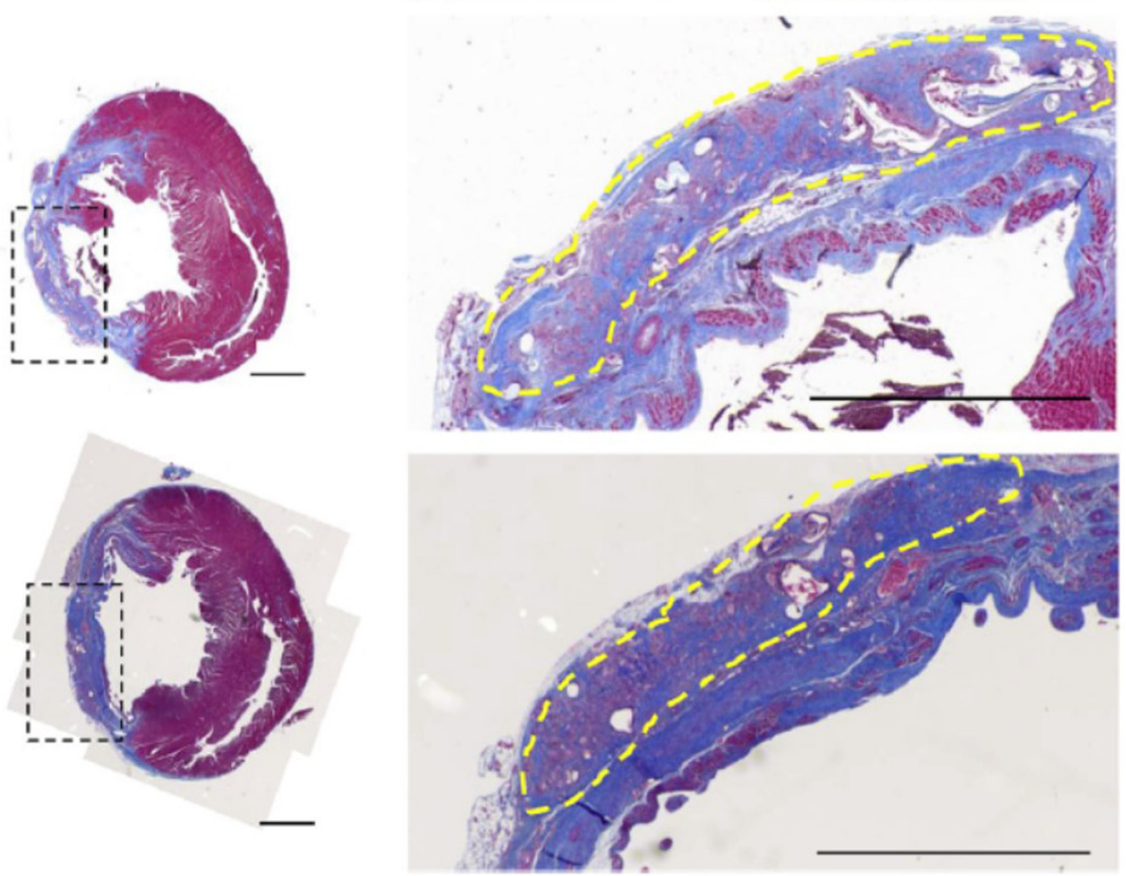

FIG. 23. Representative composite views of cross sections of infarcted rat hearts harvested at 12 weeks and sustained by Masson's trichrome for (a) direct injection of AAVcmv-GFP, (b) implantation of PEEUU fibrous scaffolds, and (c) implantation of PEEUU fibrous scaffolds containing AAV-cmv-GFP. The black dashed boxes indicate a higher magnification and are shown in the right panels. The yellow dashed lines trace the implanted material areas. Scale bars: $2 \mathrm{~mm}$. Reproduced with permission from Gu et al., Biomaterials 133, 132 (2017). Copyright 2017 Elsevier.

\section{Tendons}

Tendons are a vital part of the musculoskeletal system and consist of highly specialized fibrous tissues to transfer force between the muscle and bone. Tendon injuries may include rupture, laceration, degeneration, or inflammation, very common in sports and workplaces. The treatment for tendon injuries requires surgical invention and requires a longer time to heal through fibrous scar formation. Asymmetric chitosan scaffolds containing a dense membrane layer and a loose sponge layer displayed a higher level of tenogenic specific gene expression and protein production and could be a feasible approach for tendon repair and regeneration of injured tendons. ${ }^{153} \mathrm{Ag}$ NP embedded PEG/PCL shell and hyaluronic acid (HA)/ibuprofen in the core fibrous membranes have been shown to impart multifunctionalities like lubrication, prevention of fibroblast attachment, anti-infection, and anti-inflammation. ${ }^{154}$

\section{Wound dressings}

The tissue engineering of human skin would allow clinical treatment of wounds, burns, and nonhealing ulcers more rapidly. The created tissue-engineered scaffold is not only a biodegradable template that reproduces the natural skin microenvironment, but also holds a barrier function of the epidermal component and the mechanical stability and elasticity of the dermal component. ${ }^{155}$ Hyaluronan is a natural polymer and a major component of ECM distributed in the body composed of repeating disaccharide of (1-3)- and (1-4)-linked $\beta$-Dglucuronic acid and $\mathrm{N}$-acetyl- $\beta$-D-glucosamine monomers generally used in cosmetic and plastic surgery. ${ }^{156}$ On the other hand, exogenous growth factors, such as an epidermal growth factor (EGF) stimulating keratinocyte proliferation and migration, may induce faster reepithelization and mitigate the risk of infection. ${ }^{157}$ In addition, cell mitosis and chemotaxis are accelerated in the presence of an EGF. ${ }^{158}$ 
a
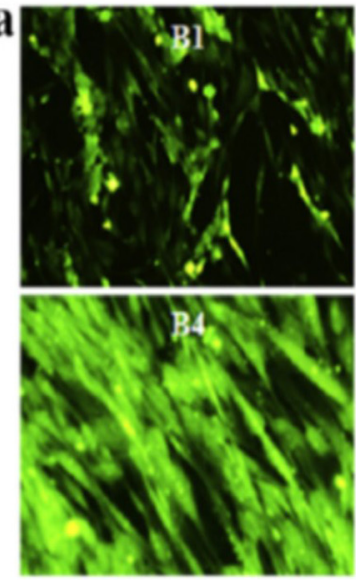

b
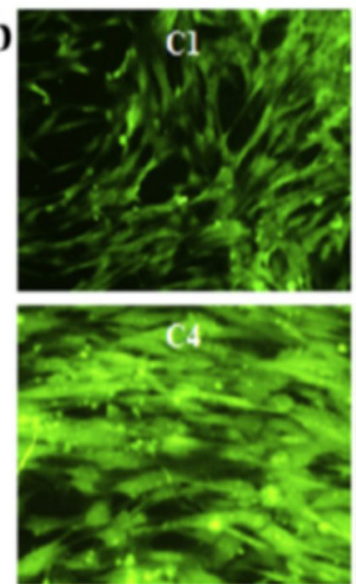
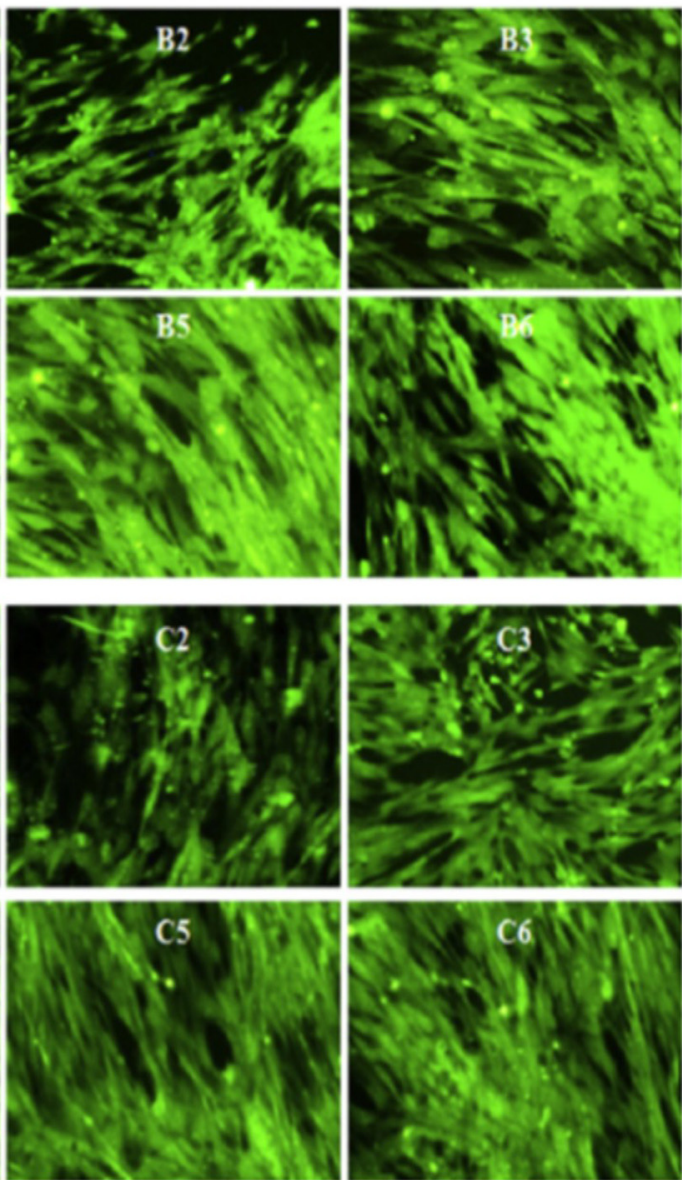
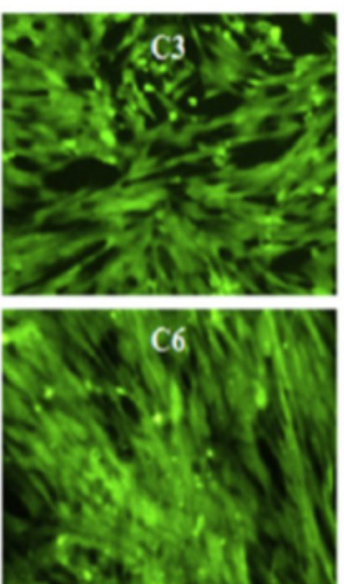
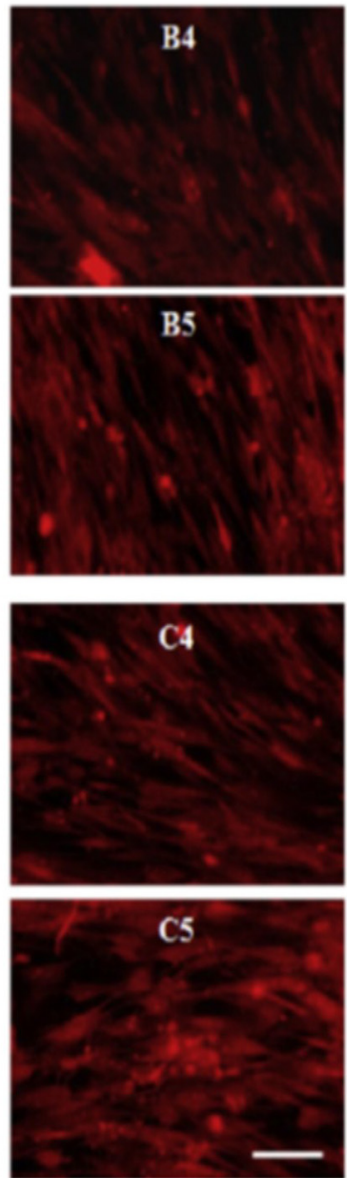

FIG. 24. Typical immunofluorescent staining images of $\alpha$-actinin (green) and troponin 1 (red) synthesized by cardiomyocytes after incubation for 10 days on (a) blend and (b) coaxial fibrous mats containing different amounts of CNTs. The bar represents $100 \mu \mathrm{m}$. Reproduced with permission from Liu et al., Mater. Sci. Eng., C 69 , 865 (2016). Copyright 2016 Elsevier.

Great care should be taken when handling the human EGF in clinical medicine and it must be delivered in a sustained and localized fashion to be effective, due to its short life and rapid dilution in the microenvironment. A study conducted by Wang et al. ${ }^{159}$ indicated that the EGF contained in PCL-HA core-sheath nanofibers could deliver a burst release in the first four days, followed by a sustained release over the last 25 days. The cell proliferation and infiltration study of FEK4 human primary fibroblast cells and HaCaT human epidermal cells on the core-sheath scaffold assessed with MTS assay showed no increase in cells in the first four days, but on the fifth day a significant increase in cells occurred. The FEK4 dermis cells showed remarkable cell migration and infiltration, and the cells were penetrated at a depth of $\sim 40 \mu \mathrm{m}$ from the surface. The in vivo test of wound healing performed on the dorsum of rats caused a faster wound healing rate in PCL/HA/EGF grafts after surgery. There was no excessive inflammation or necrosis after one week of surgery. The wounds were closed after two weeks and a complete would healing process had been achieved after four weeks, since the scaffolds were grafted. The regenerated skin appeared smooth with a thick epidermal layer; the thickest epidermis and skin appendages could be seen in the PCL/HA/EGF scaffold implantation.

Diabetic ulcer wounds have been cured using polyplexes of basic fibroblast growth factor-encoding plasmid (pbFGF) with poly(ethylene imine) (PEI) incorporated into PEG fibers. The in vivo healing processes revealed a gradual pbFGF release with a significantly larger recovery rate with improved vascularization, complete re-epithelization, and formation of skin appendages. ${ }^{160}$ In another report, Yang et al. ${ }^{161}$ showed that pDNA polyplexes could be encapsulated in core-sheath fibers and the release profiles of pDNA polyplexes, cytotoxicity, and transfection efficiencies could be manipulated by the inclusion of PEI and PEG. ${ }^{161}$ Dimethyloxalylglycine (DMOG) loaded core-sheath fibers are competitive inhibitors of prolyl hydroxylases (PHDs), can stabilize HIF- $1 \alpha$, and prevent delayed healing of diabetic chronic wounds. ${ }^{162}$ Hybrid nanofibrous scaffolds containing the epidermal growth factor (EGF) showed a sustained release of protein and exhibited excellent blood clotting and platelet adhesion in comparison to commercial wound dressings. An MTT assay indicated 

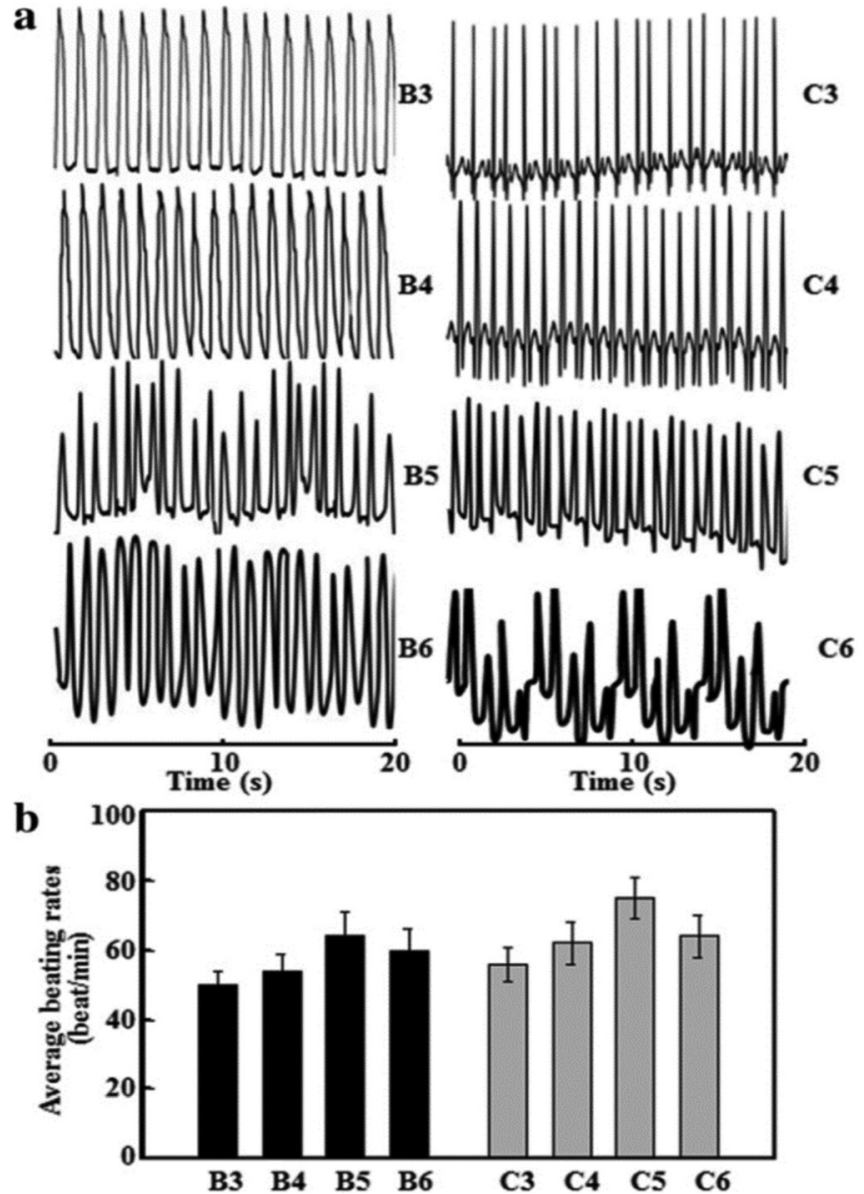

FIG. 25. (a) Beating signals and (b) beating rates of cardiomyocytes after incubation for 10 days on blend and coaxial fibers containing different amounts of CNTs. Reproduced with permission from Liu et al., Mater. Sci. Eng., C 69, 865 (2016). Copyright 2016 Elsevier.

increased cell proliferation and cell infiltration with human fibroblast, exhibited higher gene expression of collagen type I and III, and could be an alternative for skin tissue engineering. ${ }^{163}$ The core-sheath yarns made of a PCL sheath and PGA multi-strand filaments as a core are another promising tissue engineering scaffolds in wound healing, exhibiting better differentiation, and proliferation with BALB/3T3 cells. ${ }^{164}$ Many antimicrobial nanocomposites and new materials like graphene are making fibrous wound healing patches more effective and them combined with core-sheath technology can really enhance wound healing capabilities. ${ }^{165,166}$

\section{Sutures}

A suture is a medical device used to close wounds or hold body tissues after surgery until self-healing occurs to provide mechanical support during a healing process. A very good suture must have certain qualifications and/or functions to restore strength to the injured sites and overcome any infections after the operation. To solve this problem, drugs and growth factors have been incorporated in core- sheath fibrous yarns to enhance mechanical strength and prevent microbial inhibition. Gu et al. ${ }^{8}$ concluded that summarized TGF- $\beta 1$ loaded PLGA based micro-nano fiber core-sheath fibers imparted superior tensile strength and elongation without any fluctuation before breakage, compared to single polymer fibrous yarns. In addition, an in vitro release of TGF- $\beta 1$ from PLGA core-sheath yarns in phosphate buffer saline (PBS) at $37^{\circ} \mathrm{C}$, calculated based on the calibration curve of TGF- $\beta 1$, revealed a burst release within $24 \mathrm{~h}$ followed by gradual elution of the growth factor. Moreover, the excellent growth of HUVEC cells on TGF- $\beta 1$ loaded fibers was observed. ${ }^{8}$ Vasculogenesis and angiogenesis were promoted in vascular endothelial growth factor (VEGF) encapsulated regenerated silk fibroin (RSF) and bladder acellular matrix graft (BAMG) composite scaffolds. The controlled release of VEGF lasted more than 16 days. An in vitro assay indicated that VEGF loaded scaffolds induced the attachment and proliferation of porcine iliac endothelial cells (PIECs) compared with those without VEGF. In addition, VEGF remained bioactive for 7 days and composite scaffolds showed greater tensile properties and suture retention than the bare RSF scaffolds. ${ }^{4}$ Drug loaded sutures are widely used to deliver anesthetic, analgesic, anti-inflammatory, or antibiotic drugs at wound sites and offer a direct and efficient route for drug delivery. Aceclofenac and insulin loaded PLGA sheath and PLA core fibrous yarn sutures exhibited a higher loading capacity of $15 \%$ and $4 \%$ and release lasted for 10 and 7 days, respectively. In addition, the sutures which were yarns consisting of aceclofenac demonstrated reduced epidermal hyperplasia and cellularity in skin inflammation while the insulin-eluting sutures showed enhanced cell migration in wound healing assay. ${ }^{16}$

\section{Encapsulation of nanoparticles, drugs, and bioactive molecules}

Core-sheath structures can carry bioactive signals such as growth factors, genes, DNA, and other frail biomolecules (proteins and peptides) to stimulate cell proliferation in a sustained manner. Nanoparticles and drugs containing core-sheath architectures are shown to inhibit microorganisms after surgery and accelerate the healing process. Controlled drug release of hydrophilic antibiotic tetracycline hydrochloride (TCH) was achieved in core-sheath fibers made of TCH/alginate/soy protein isolate (core) and PCL (sheath). A burst release of TCH in phosphate buffer saline (PBS) was obtained $(\sim 49 \%)$ after $6 \mathrm{~h}$, followed by a sustained release $(\sim 80 \%)$ of the total loaded drug after 2 weeks. The composite fibers also exhibited antibacterial properties against the microorganisms Staphylococcus aureus and Escherichia coli. An indirect cytotoxicity test using human dermal fibroblast confirmed the nontoxicity of core-sheath fibers and $100 \%$ cell viability. ${ }^{168} \mathrm{ZnO}$ nanoparticles containing polymethylmethacrylate (PMMA) sheath and PVP core nanofibers inhibited the growth of gram-positive bacteria Bacillus subtilis (B. subtilis). ${ }^{169}$ Kemp et al. ${ }^{170}$ observed excellent antimicrobial activity against a gram-positive Staphylococcus aureus and a gram-negative Pseudomonas aeruginosa in poly[styrene-co-N-N ${ }^{\prime}$, $\mathrm{N}^{\prime}$-dimethyl-3-aminopropyl)maleimide] sheath and nylon six core nanofibers. ${ }^{170} \mathrm{Li}$ et al. ${ }^{9}$ have reported that a high bioadhesive membranes formed with core-sheath polymer nanofibers could facilitate physical isolation and pharmaceutical treatment of peritoneal adhesion, which is a complex fibrosis and inflammatory 


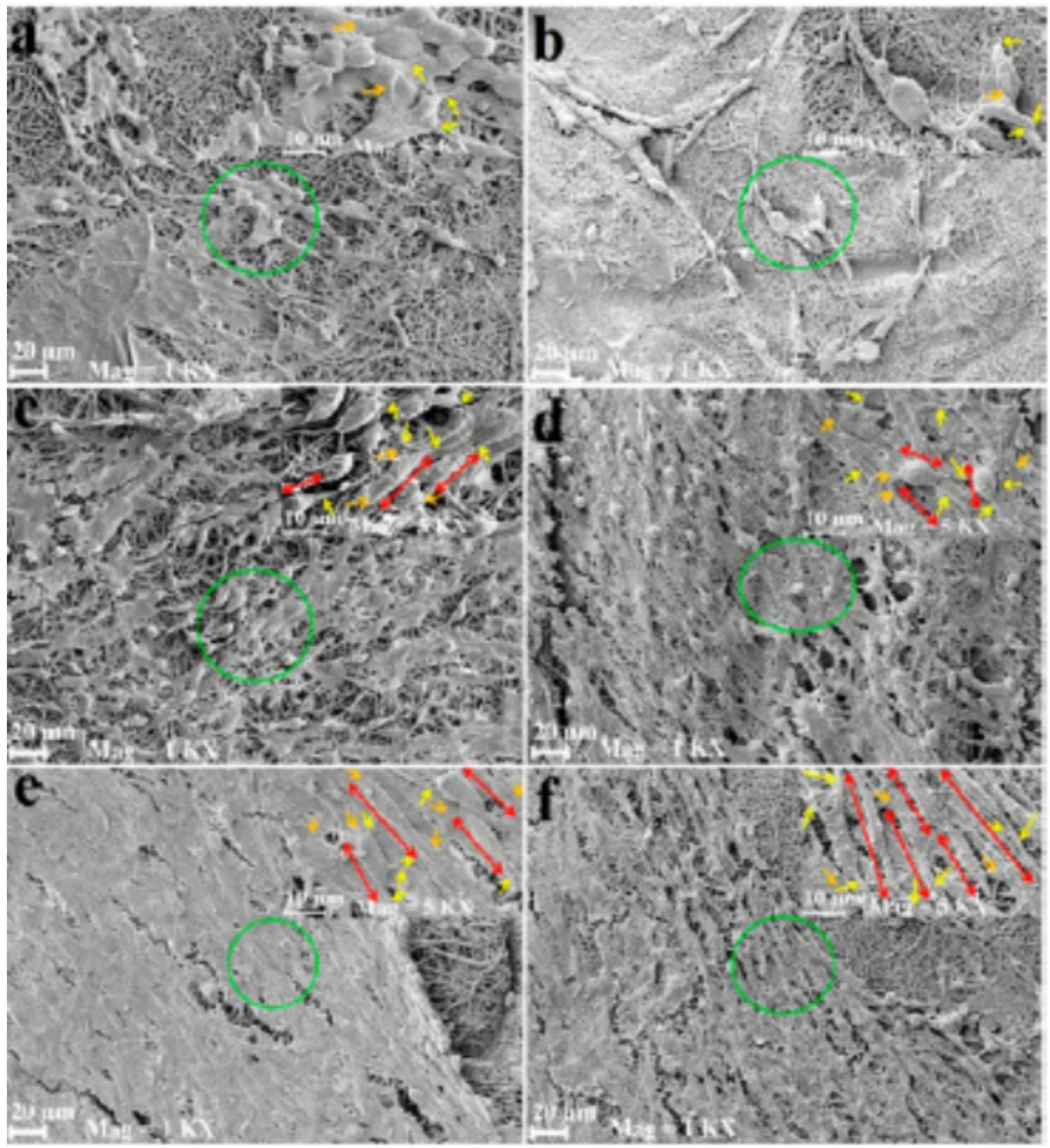

FIG. 26. Scanning electron micrographs of 3T3 fibroblasts after 3 days of culture on various types of core-sheath fibers. (a) and (b) PCL-MEP-PPV core-sheath fibers prepared by electrospinning with two different flow rates; (c) and (d) APTES functionalized PCL-MEP-PPV coresheath fibers; and (e) and (f) 1,6-hexanediamine functionalized PCL-MEP-PPV core-sheath fibers. The red, yellow, and green arrows indicate the direction of cell alignment and filopodia- and lamellipodialike extensions. Reproduced with permission from Borah et al., ACS Biomater. Sci. Eng. 4, 3327 (2018). Copyright 2018 American Chemical Society.

process. 10-hydroxycamptothecin (10-HCPT) and diclofenac sodium (DS) loaded core-sheath fibrous membranes displayed continuous drug release for several days, prevented fibrosis formation, and inhibited inflammatory response. ${ }^{9}$ The core-sheath composite scaffolds comprised isothiocyanate-dextran (FITCdextran) poly(lactic-co-glycolic acid) (PLGA) and type I collagen/ PLGA, and demonstrated a sustained release of encapsulated FITC-dextran for 7 weeks. The prepared scaffolds showed excellent osteoblastic activity with the MC3T3-E1 cell line and cytocompatibility. These results demonstrate that these scaffolds could support early stages of osteoblast behavior as well as immediate and later stages. ${ }^{171}$ Tissue engineering scaffolds made with PCL-SF core- sheath composite nanofibers exhibited excellent biodegradability, surface properties, outstanding mechanical strength, and controlled drug release. The fabricated scaffolds showed improved cell adhesion and proliferation in association with human skin primary fibroblast cells (FEK4). The release profile of FITC drugs showed an initial burst release of $\sim 26 \%$ in core-sheath nanofibers compared to $\sim 37 \%$ in pure PCL nanofibers. The release profile was continuous thereafter, showing $\sim 62 \%$ for core-sheath structures for $80 \mathrm{~h}$ and $\sim 49 \%$ for single fibers lasting $10 \mathrm{~h}^{17}$

Functionalization of nanofibrous scaffolds with active biomolecules is one of the many strategies adopted in tissue engineering to manipulate and regulate the fate of stem cells within the hierarchical structure within which cells can attach, spread, differentiate, and proliferate. Chen et al. ${ }^{173}$ functionalized co-spun poly(L-lactide)-polyethylene glycol) $-\mathrm{NH}_{2}$ and poly(L-lactide) nanofibers with fluorescein isothiocyanate- and rhodamine-labeled bovine serum albumin by activation of amino and carboxyl reactive groups on the surface of nanofibers. In addition, the controlled release of a model drug TCH loaded in the core of the nanofibers was observed. These nanofibers retained their antimicrobial capacity even after their surface functionalization and this indicates that the multi-functional nanofibers could be developed into wound dressings or peritoneal membranes or used in more complicated tissue systems, where multiple growth factors and anti-infection precautions are critical for successful implantation and tissue regeneration. ${ }^{173}$ Proteins also have been 

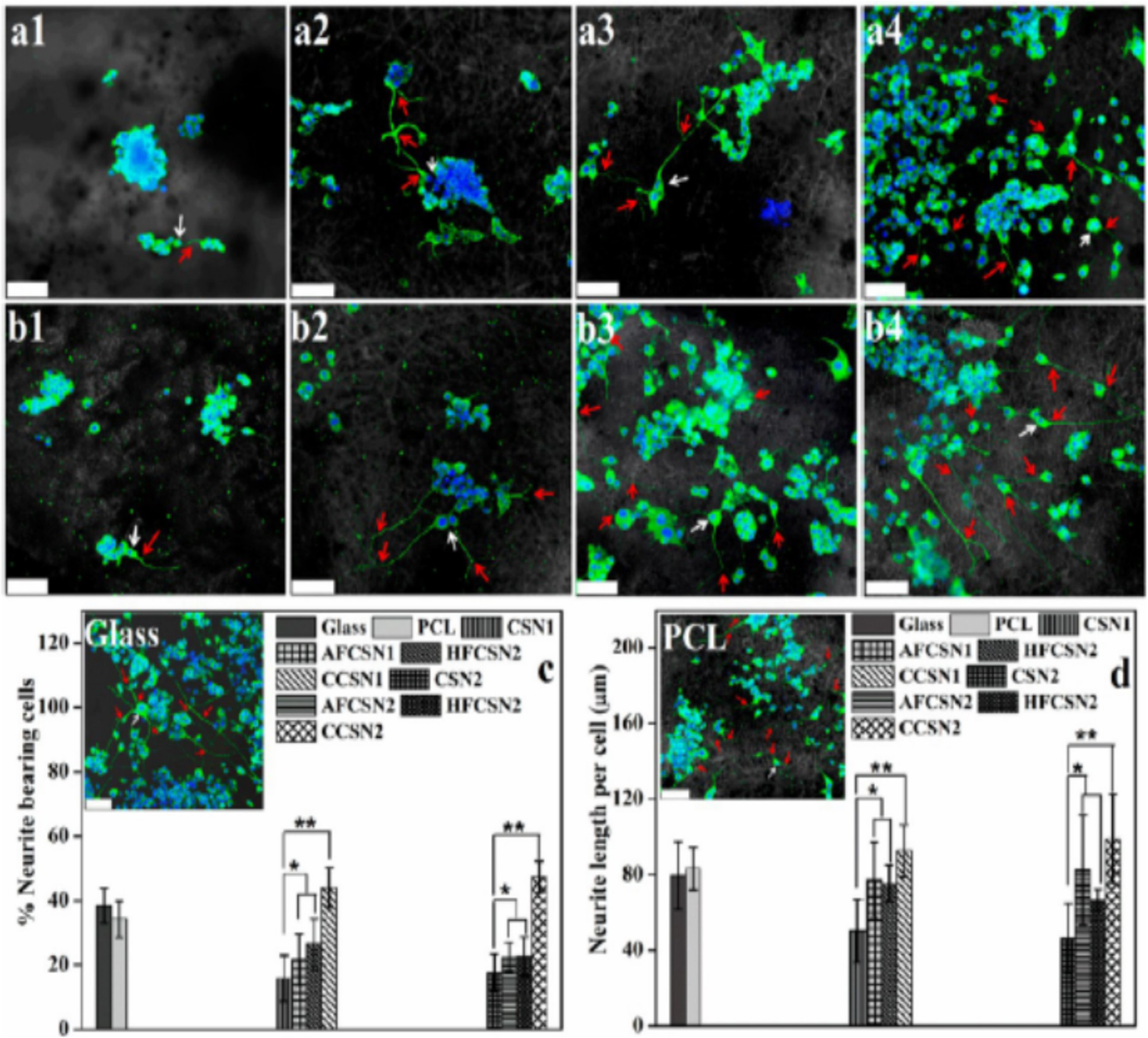

Glass $\square$ PCL IIIIIIII|CSNI

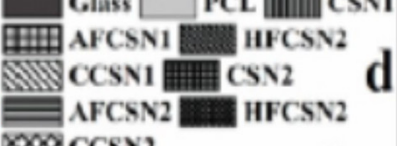

$808 \mathrm{CCSN}_{2}$
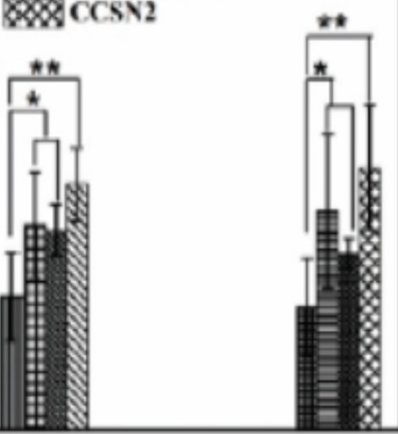

FIG. 27. Immunolabeling of beta (III) tubulin in differentiated PC12 cells with DAPI-stained nuclei after 7 days of culture. (a1) and (b1) Core-sheath fibers prepared with two different flow rates, (a2) and (b2) APTES functionalized core-sheath fibers, (a3) and (b3) 1,6-hexanediamine functionalized core-sheath fibers, and (a4) and (b4) collagencoated core-sheath fibers. The white arrows show neuronal cell bodies with at least one neurite formed. The red arrows represent neurons with long branched neurites and/or growth cones. (c) Percentage of neurite-bearing cells. (d) Neurite length per cell on different fibrous meshes along with collagen-coated glass presented with mean \pm SD. Reproduced with permission from Borah et al., ACS Biomater. Sci. Eng. 4, 3327 (2018). Copyright 2018 American Chemical Society.

encapsulated in core-sheath nanofibers and their release studies have been assessed. Zhang et al. ${ }^{174}$ fabricated fluorescein isothiocyanate-conjugated BSA containing PEG/PCL nanofibers and showed that two different characteristic release profiles could be attained. The first stage involved the faster release of protein before inflexion and the second stage contains a constant linear release. ${ }^{174}$ The combination of synthetic and natural polymers in core-sheath fibers and scaffolds is a very attractive alternative in tissue engineering. The attributes of individual polymer components such as durability, mechanical strength, degradability, and cell adhesion could be attained in a combined core-sheath structure. In this respect, the PU core and PCL/gelatin sheath encouraged and promoted cell migration and proliferation in the interior of the scaffolds with minimal fibrous capsule formation. ${ }^{175}$

\section{B. Drug delivery}

Material selection and design is a core feature of drug delivery applications, provided that the selected biomaterial should enhance the functionality and performance. The performance of a delivery 
TABLE II. Overview of polymer systems used in making core-sheath fibers and their applications.

\begin{tabular}{|c|c|c|c|c|}
\hline Polymer system & Core & Sheath & Application & Reference \\
\hline $\begin{array}{l}\text { Cistanche polysaccharide } \\
\text { (CDPS)-polylactic acid (PLA) }\end{array}$ & CDPS & PLA & Vascular grafts & 133 \\
\hline $\begin{array}{l}\text { Polyurethane (PU)-gelatin, polycapro- } \\
\text { lactone (PCL)-gelatin, and } \\
\text { PLA-gelatin }\end{array}$ & PU, PCL, and PLA & Gelatin & Vascular grafts & 134 \\
\hline Poly (glycerol sebacate) (PGS)-PCL & PGS & PCL & Vascular grafts & 135 \\
\hline Polyvinyl alcohol (PVA)-gelatin & PVA & Gelatin & Vascular grafts & 136 \\
\hline PCL-gelatin & PCL & Gelatin & Vascular grafts & 137 \\
\hline PU-polyethylene oxide (PEO) & PEO & $\mathrm{PU}$ & $\begin{array}{l}\text { Cardiac tissue } \\
\text { engineering }\end{array}$ & 6 \\
\hline $\begin{array}{l}\text { Poly(ethylene glycol) polylactide } \\
\text { (PELA) copolymers - carbon nano- } \\
\text { tubes (CNTs)-PELA }\end{array}$ & PELA/CNTs & PELA & $\begin{array}{l}\text { Cardiovascular tissue } \\
\text { engineering }\end{array}$ & 5 \\
\hline $\begin{array}{l}\text { Gelatin methacryloyl } \\
\text { (GelMA)-alginate }\end{array}$ & GelMA & Alginate & $\begin{array}{l}\text { Cardiovascular tissue } \\
\text { engineering }\end{array}$ & 138 \\
\hline $\begin{array}{l}\text { Polymethylmethacrylate } \\
\text { (PMMA)-spiropyran methacrylate } \\
\text { (SPMA) }\end{array}$ & PMMA & SPMA & $\begin{array}{l}\text { Cardiovascular tissue } \\
\text { engineering }\end{array}$ & 139 \\
\hline Alginate-PCL & Alginate & PCL & $\begin{array}{c}\text { Cardiovascular tissue } \\
\text { engineering }\end{array}$ & 140 \\
\hline Cellulose acetate (CA)-PCL & PCL & CA & $\begin{array}{c}\text { Cardiovascular tissue } \\
\text { engineering }\end{array}$ & 141 \\
\hline $\begin{array}{l}\text { Silk fibroin (SF)-poly(lactic-co- } \\
\varepsilon \text {-caprolactone) (PLCL) }\end{array}$ & PLCL & SF & $\begin{array}{c}\text { Cardiovascular tissue } \\
\text { engineering }\end{array}$ & 3 \\
\hline $\begin{array}{l}\text { PCL-poly[2-methoxy-5-(2-ethyl- } \\
\text { hexyl-oxy)-1,4-phenylene vinylene } \\
\text { (MEH-PPV) }\end{array}$ & PCL & MEH-PPV & $\begin{array}{l}\text { Nerve tissue } \\
\text { engineering }\end{array}$ & 143 and 145 \\
\hline PCL-polypyrrole (PPy) & PCL & PPy & $\begin{array}{l}\text { Nerve tissue } \\
\text { engineering }\end{array}$ & 144 \\
\hline $\begin{array}{l}\text { Poly(lactic-co-glycolic acid) } \\
\text { (PLGA)-PLGA }\end{array}$ & PLGA & PLGA & $\begin{array}{l}\text { Nerve tissue } \\
\text { engineering }\end{array}$ & 146 \\
\hline $\begin{array}{l}\text { PLGA/tetra calcium phosphate } \\
\text { (TCP)-collagen }\end{array}$ & PLGA/TCP & Collagen & Bone tissue engineering & 147 \\
\hline $\begin{array}{l}\text { PCL/collagen-PVA/hydroxy apatite } \\
\text { (HA) }\end{array}$ & PCL/collagen & PVA/HA & Bone tissue engineering & 148 and 149 \\
\hline PLGA/ $\beta$-TCP-collagen & $\mathrm{PLGA} / \beta-\mathrm{TCP}$ & Collagen & Bone tissue engineering & 150 \\
\hline PCL-gelatin/HA & PCL & Gelatin/HA & Bone tissue engineering & 151 \\
\hline $\mathrm{CA}-\mathrm{SF} / \mathrm{PEO}$ & CA & SF/PEO & Bone tissue engineering & 152 \\
\hline Chitosan-chitosan & Chitosan & Chitosan & $\begin{array}{c}\text { Tendon tissue } \\
\text { engineering }\end{array}$ & 153 \\
\hline $\begin{array}{l}\text { Poly(ethylene glycol) (PEG)/ } \\
\text { PCL-hyaluronic acid (HA) }\end{array}$ & PEG/PCL & $\mathrm{HA}$ & $\begin{array}{l}\text { Tendon tissue } \\
\text { engineering }\end{array}$ & 154 \\
\hline PCL-HA & PCL & HA & Wound healing & 159 \\
\hline Poly(ethylene imine) (PEI)-PEG & PEI & PEG & Wound healing & 160 \\
\hline $\begin{array}{l}\text { PELA-bFGF growth factor/ } \\
\text { cyclodextrin }\end{array}$ & bFGF/cyclodextrin & PELA & Wound healing & 161 \\
\hline $\begin{array}{l}\text { Dimethyloxalylglycine (DMOG)/PCL/ } \\
\text { collagen-PCL/collagen }\end{array}$ & DMOG/PCL/collagen & PCL/collagen & Wound healing & 164 \\
\hline PLGA/gelatin & PLGA & Gelatin & Wound healing & 163 \\
\hline Polyglycolic acid (PGA)-PCL & PGA & PCL & Wound healing & 164 \\
\hline
\end{tabular}


TABLE II. (Continued.)

\begin{tabular}{|c|c|c|c|c|}
\hline Polymer system & Core & Sheath & Application & Reference \\
\hline PLGA/TGF- $\beta 1-P L G A$ & PLGA & PLGA/TGF- $\beta 1$ & Sutures & 8 \\
\hline VEGF/BSA-regenerated SF (RGF) & VEGF/BSA & RGF & Sutures & 4 \\
\hline PLA-PLGA & PLGA & PLA & Sutures & 167 \\
\hline $\begin{array}{l}\text { Tetracycline loaded alginate/soy pro- } \\
\text { tein isolate (TCH-Alg/SPI)-PCL }\end{array}$ & TCH-Alg/SPI & PCL & Antimicrobial & 168 \\
\hline PVA/ZnO-PMMA & $\mathrm{PVA} / \mathrm{ZnO}$ & PMMA & Antimicrobial & 169 \\
\hline $\begin{array}{l}\text { Nylon-poly[styrene-co-N-N } \mathrm{N}^{\prime}, \mathrm{N}^{\prime} \text { - } \\
\text { dimethyl-3-aminopropyl) maleimide] }\end{array}$ & Nylon & $\begin{array}{l}\text { Poly[styrene-co-N- } \\
\mathrm{N}^{\prime}, \mathrm{N}^{\prime} \text {-dimethyl-3-ami- } \\
\text { nopropyl) maleimide] }\end{array}$ & Antimicrobial & 170 \\
\hline $\begin{array}{l}\text { Methoxy PEG-b-PLGA/diclofenac } \\
\text { sodium (DS)-methoxy PEG-b-PLGA/ } \\
\text { hydroxycamptothecin (HCPT) }\end{array}$ & $\begin{array}{l}\text { Methoxy PEG-b- } \\
\text { PLGA/diclofenac } \\
\text { sodium (DS) }\end{array}$ & $\begin{array}{l}\text { Methoxy PEG-b- } \\
\text { PLGA/hydroxycampto- } \\
\text { thecin (HCPT) }\end{array}$ & Peritoneal adhesion & 9 \\
\hline $\begin{array}{l}\text { FITC/dextran - PLGA-collagen - } \\
\text { PLGA }\end{array}$ & $\begin{array}{l}\text { FITC/dextran and } \\
\text { PLGA }\end{array}$ & PLGA and collagen & $\begin{array}{l}\text { Drug delivery and bone } \\
\text { tissue engineering }\end{array}$ & 171 \\
\hline PCL-SF & PCL & SF & $\begin{array}{l}\text { Wound healing and } \\
\text { drug delivery }\end{array}$ & 172 \\
\hline PLLA-PLLA-b-PEG/TCH & PLLA & PLLA-b-PEG/TCH & $\begin{array}{l}\text { Wound healing, drug } \\
\text { delivery, and periodon- } \\
\text { tal membranes }\end{array}$ & 173 \\
\hline PCL-fitc BSA PEG & PCL & fitc BSA PEG & $\begin{array}{l}\text { Bioactive molecule } \\
\text { release/tissue } \\
\text { engineering }\end{array}$ & 174 \\
\hline PU-PCL/gelatin & $\mathrm{PU}$ & PCL/gelatin & Tissue engineering & 175 \\
\hline Zein/ketoprofen-PVP/ketoprofen & Zein & PVP & Drug delivery & 176 \\
\hline EC/ketoprofen-PVP/ketoprofen & $\mathrm{EC}$ & PVP & Drug delivery & 177 \\
\hline $\begin{array}{l}\text { Eudragit L100-55 (EL100)/ } \\
\text { ketoprofen-PVP/ ketoprofen }\end{array}$ & EL100 & PVP & Drug delivery & 178 \\
\hline $\begin{array}{l}\mathrm{PVP} / \text { graphene oxide (GO)/vancomy- } \\
\text { cin } \mathrm{HCl} \text { (VAN)-PCL }\end{array}$ & $\mathrm{PVP} / \mathrm{GO} / \mathrm{VAN}$ & PCL & Drug delivery & 179 \\
\hline $\begin{array}{l}\text { Berberine } \mathrm{HCl} / \text { ethylcellulose } \\
\text { (EC)-Glycerol monostearate }\end{array}$ & $\begin{array}{l}\text { Berberine } \mathrm{HCl} / \\
\text { ethylcellulose }\end{array}$ & Glycerol Monostearate & Drug delivery & 180 \\
\hline PCL-PVP/TEHCL & PCL & PVP/TEHCL & Drug delivery & 181 \\
\hline PMMA-PCL/nimesulide & PMMA & PCL/nimesulide & Drug delivery & 182 \\
\hline Metronidazole/PCL-gelatin & Metronidazole/PCL & Gelatin & Drug delivery & 183 \\
\hline EL100-Eudragit S 100 (ES100) & EL100 & ES100 & Drug delivery & 7 \\
\hline EL100-Lecithin (PL)-DS & EL100 & PL-DS & Drug delivery & 184 \\
\hline Poly-(N-isopropylacrylamide)/KET & $\begin{array}{l}\text { Poly-(N-isopropylacry- } \\
\text { lamide)/KET }\end{array}$ & EC & Drug delivery & 185 \\
\hline $\begin{array}{l}\text { Doxorubicin hydrochloride (DOX)/Au } \\
\text { nanocage (AuNC)-PCL }\end{array}$ & DOX/AuNC & PCL & Drug delivery & 186 \\
\hline PVA/BSA-PCL/RhB & PVA/BSA & $\mathrm{PCL} / \mathrm{RhB}$ & Drug delivery & 187 \\
\hline $\begin{array}{l}\text { PVA/gelatin/lysozyme-gelatin/phenyt- } \\
\text { oin sodium }\end{array}$ & PVA/gelatin/lysozyme & $\begin{array}{l}\text { Gelatin/phenytoin } \\
\text { sodium }\end{array}$ & Drug delivery & 188 \\
\hline $\begin{array}{l}\text { Polyacrylic resin II/proteoglycan-CA/ } \\
\text { stachyose }\end{array}$ & $\begin{array}{l}\text { Polyacrylic resin II/ } \\
\text { proteoglycan }\end{array}$ & CA/stachyose & Drug delivery & 189 \\
\hline $\begin{array}{l}\mathrm{PCL} / \text { curcumin-chitosan/PEO/ } \\
\text { lidocaine HCL }\end{array}$ & PCL/curcumin & $\begin{array}{l}\text { Chitosan/PEO/lido- } \\
\text { caine HCL }\end{array}$ & Drug delivery & 190 \\
\hline
\end{tabular}



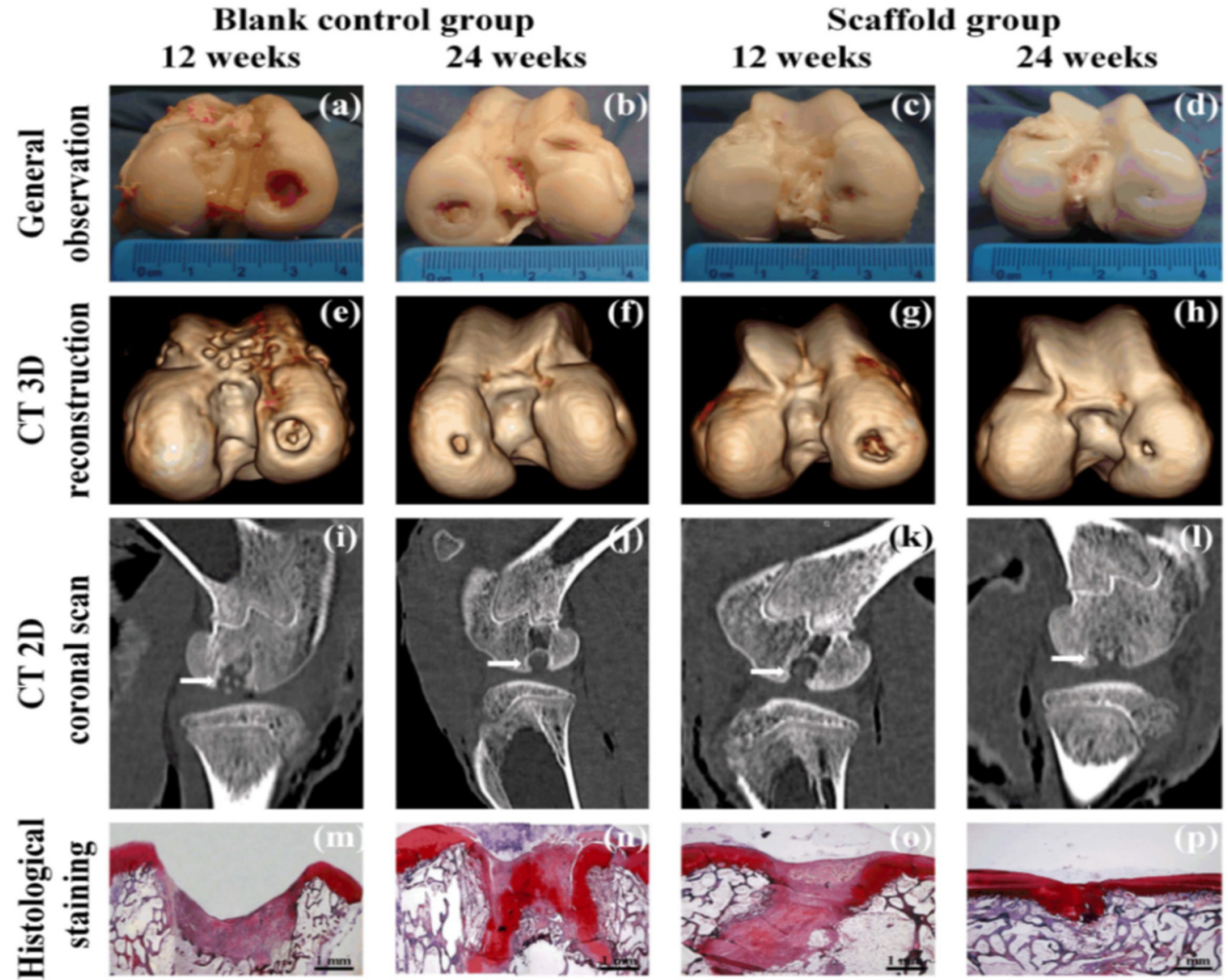

FIG. 28. Goat articular cartilage-defect repair at 12- and 24-weeks post implantation. (a), (e), (i), and (m) Blank control group at 12 weeks and (b), ( $f$ ), (j), and (n) at 24 weeks. (c), (g), (k), and (o) Scaffold group at 12 weeks and (d), (h), (I), and (p) at 24 weeks. Evaluation of goat articular cartilage-defect repair: (a)-(d) general observation, (e)-(h) CT 3D-reconstruction images, (i)-(I) 2D coronal scan images, and (m)-(p) histological staining with Safranin O. Reproduced with permission from Zhang et al., Biofabrication 9 , 025021 (2017). Copyright 2017 IOP Publishing.

vehicle is evaluated by improved bioactive component encapsulation, controlled and sustained release, and the managed interaction with the host environment. In this respect, core-sheath fibers are the "pillars of success" of delivery of drugs, molecules, or any bioactive components and improve the quality of life of millions of patients worldwide. Generally, drug release in core-sheath structures is divided into three types: (i) biphasic drug release, (ii) stimuli-responsive drug release, and (iii) dual/multi-drug release. In biphasic drug release, the drugs are delivered at two different rates or two different time intervals. A single drug is enclosed either in the core or the sheath to cure the disease. In the first phase, a fraction drug is rapidly released to promptly treat the disease, followed by sustained or controlled release to optimize the therapy. In stimuli-responsive drug release, the drugs are released from the core-sheath structure either by changing the temperature, $\mathrm{pH}$, or ionic strength or by shinning photons onto them. In dual drug release, two or more drugs are encapsulated in the core and the sheath structures and released either simultaneously or at multi-stages.

\section{Biphasic drug delivery}

Unlike the invariable zero-order release behavior, a biphasic drug release pattern involves a rapid burst release followed by a prolonged sustained release. The initial burst release phase provides prompt treatment of the disease, while subsequent slow drug release ensures the effective therapeutic period and avoids repeated administration of the drugs which can be time-consuming and costly. For example, in implantation, a high burst release of antimicrobial drug can eliminate the invading bacteria during surgery and the continued slow release can prevent the potential occurrence of the latent infection. The dissolution studies of ketoprofen (KET) incorporated PVP-Zein coresheath fibers exhibited an immediate release of $\sim 42 \%$ of the contained $\mathrm{KET}$, followed by a sustained release of the remaining drugs for $10 \mathrm{~h} .{ }^{176}$ On the other hand, the KET containing PVP sheath with ethyl cellulose as a core showed an immediate release of $\sim 31 \%$ within half an hour, followed by the sustainable release of the $\sim 51 \%$ remaining KET over $24 \mathrm{~h}$. The increase in sheath thickness altered the release profile, where $\sim 41 \%$ was lost by burst release and $49 \%$ by sustained 

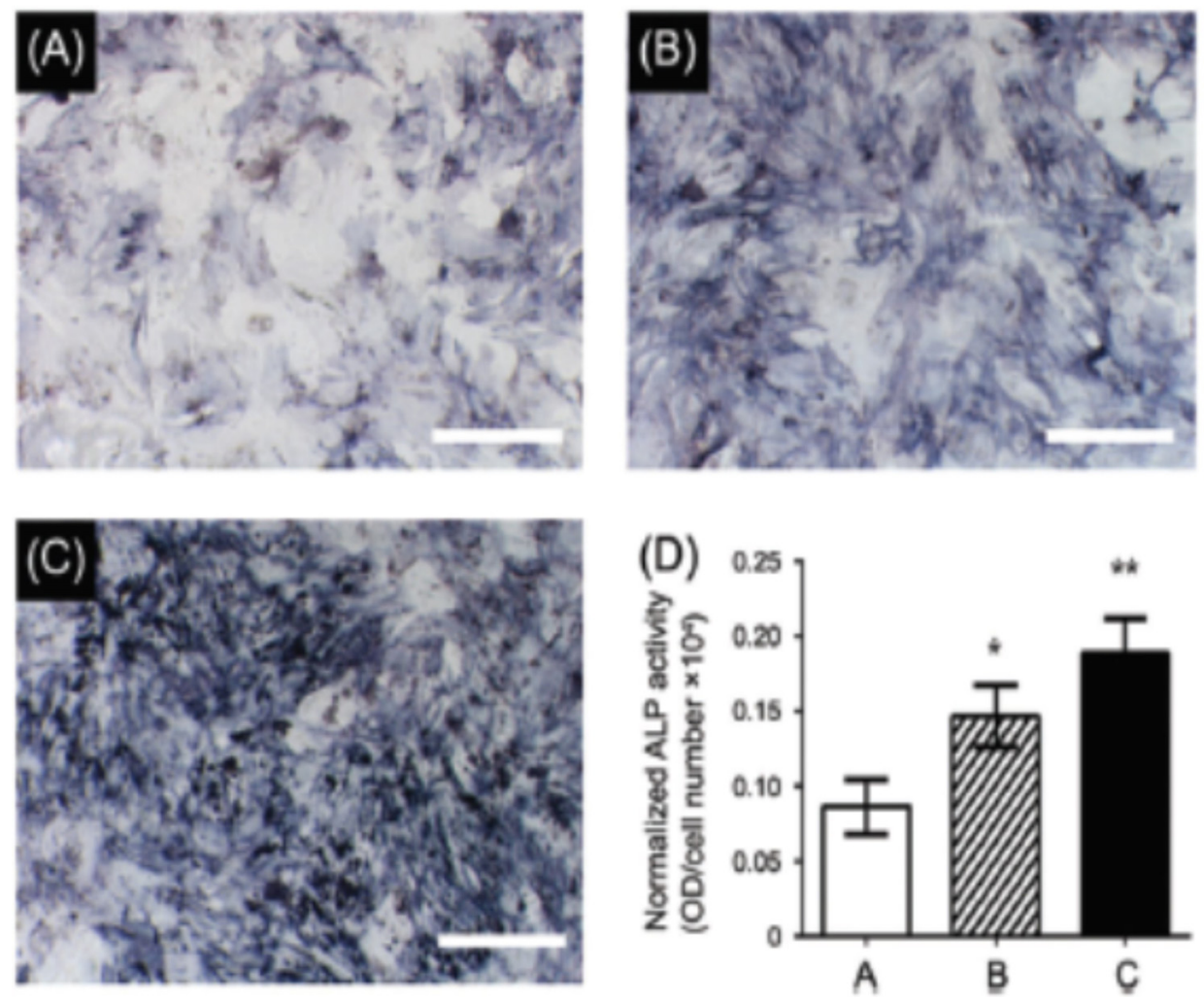

FIG. 29. Osteogenesis of BMSCs on various scaffolds as measured by ALP staining at 7 days. (a) CA-SF, (b) CA-SF/ nHAP, and (c) CA-SF/nHAP/BMP-2. Scale bar $=100 \mu \mathrm{m}$. (d) Normalized ALP activity detected at 7 days. The error bar represents the standard deviation of the mean $(n=3)$. Here, $* p<0.05$ and $* p<0.01$ indicate a statistically significant difference compared to group (a). Reproduced with permission from Tao et al., J. Mater. Chem. B 5, 9219 (2017). Copyright 2017 Royal Society of Chemistry. release (Fig. 31). ${ }^{177}$ Moreover, KET contained in PVP and EL 100 core-sheath fibers showed dual drug release profiles with an immediate release of $\sim 35 \%$ in acidic solutions and a sustained release of $\sim 62 \%$ in pH 6.8 PBS. $^{178}$ Yu et al. ${ }^{179}$ studied the release behavior of the vancomycin hydrochloride (VAN) model drug encapsulated in PVP/ graphene oxide (GO) core and PCL sheath fibrous structures. The interaction of GO sheets with the VAN molecules significantly influenced the biphasic drug release of the core-sheath fibers. ${ }^{179}$ A combination of polymer-lipid has been used to make core-sheath nanofibers, where drug-free glycerol monostearate acted as a sheath material and drug-loaded nanocomposite containing berberine chloride and ethylene cellulose acted as a core material. In vitro dissolution studies proved that this hybrid structure can provide a sustained release profile than monolithic medicated nanocomposites in terms of initial burst release, sustained-release time, and tailing-off time. ${ }^{180}$ Drug patches made of PVP core and PCL sheath microfibers showed relatively high encapsulation efficiency $(\sim 96 \%)$ of drug tetracycline hydrochloride (TEHCL). The cumulative release of TEHCL was shown to depend on the thickness of the patch and exhibited a burst release within $25 \mathrm{~h}$ followed by a stable sustained release for 120 h (Fig. 32). ${ }^{181}$ Anti-inflammatory drug Nimesulide was loaded in PMMA-PCL core-sheath fibers and the release pattern was found to be reliant of the loading area of the drug. The active release was faster and higher when loaded in the sheath compared to the core. ${ }^{182}$ Another anti-inflammatory agent metronidazole (MNA) encapsulated in a PCL core and gelatin sheath cross-linked with genipin displayed superior sustained release compared to blended nanofibers. In addition, these fibers were shown to inhibit the colonization of bacteria, cell adhesion, proliferation without cytotoxicity, and are suggested for use in guided tissue regeneration. ${ }^{183}$

\section{Stimuli-responsive drug release}

$\mathrm{pH}$-sensitive dissolution could be utilized to deliver anticancer drug either for treating cancer or preventing the recurrence of cancer after surgery by taking advantage of different $\mathrm{pH}$ levels present in the targeted organ. This has greater efficacy than systematic drug delivery where the drug is delivered to the entire body, resulting in dilution of drugs in the bloodstream. Multi-pH response delivery of active components attained in two different Eudragit polymers used as the core and sheath materials while changing the $\mathrm{pH}$ from 5 to 7 could pave the way to treat targeted diseases. Yang et al. ${ }^{184}$ prepared a $\mathrm{pH}$ sensitive polymer composite core-sheath fiber with diclofenac sodium (DS), a non-steroidal anti-inflammatory drug, in the core. Under acidic conditions, a meager $2.1 \%$ of DS was released from the fibers compared to a remarkable $79.1 \%$ release in neutral medium. Ex vivo permeation tests also indicated that core-sheath composite nanofibers give a more than twofold uplift in the amount of DS passing through the colonic membrane than pure DS. ${ }^{184}$ Thermoresponsive polymerbased core-sheath fibers are shown to release the drugs by changing the temperature of the dissolution medium. KET drug-loaded thermoresponsive poly-(N-isopropyl acrylamide) core and hydrophobic ethylcellulose (EC) sheath displayed a sustained release of the drug by changing the temperature. ${ }^{185}$ Chemotherapeutic anticancer drug in 

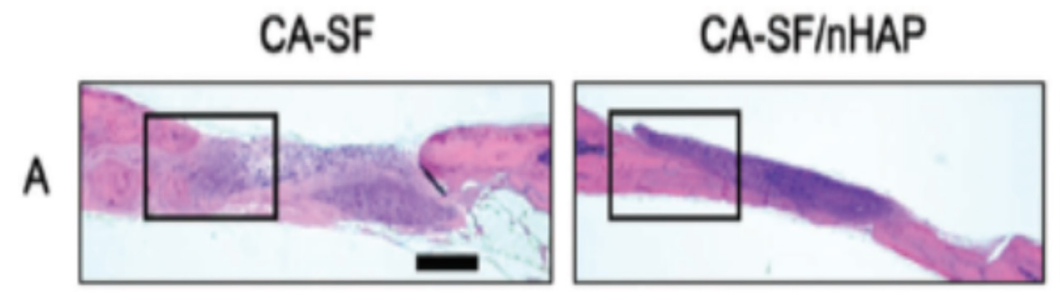

\section{CA-SF/nHAP/BMP-2}
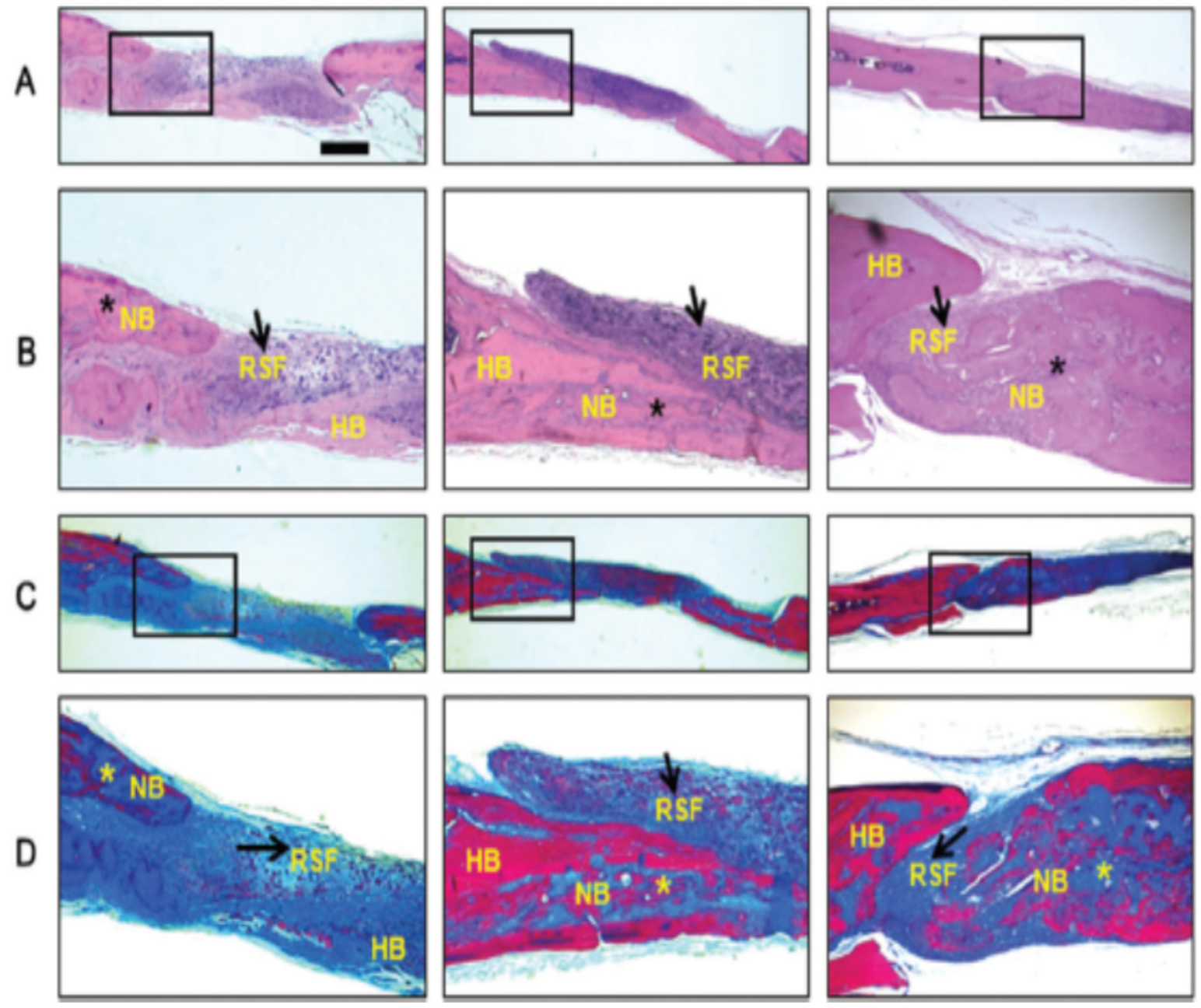

FIG. 30. [(a) and (b)] Hematoxylin and eosin staining and [(c) and (d)] Masson's trichrome staining of various scaffold explants at 12 weeks. The images in (a) and (b) were obtained at low magnification $(25 \times)$; the images in (b) and (d) were obtained at high magnification $(100 x)$ and used to analyze the sectional structure of the critical-size defects. Scale bar $=1 \mathrm{~mm}$. NB and HB represent the new bone and host bone, respectively. An asterisk marks the ossification center. The black arrows and RSF pointing to the pink, homogeneous structures indicate the SF scaffolds remaining after implantation. Reproduced with permission from Tao et al., J. Mater. Chem. B 5, 9219 (2017). Copyright 2017 Royal Society of Chemistry.

the core and the photothermal agent phase-changeable fatty acid in the sheath have been incorporated in core-sheath fibers and exhibited a synergetic effect and higher anticancer therapeutic efficacy. ${ }^{186}$

\section{Dual drug release}

The fabrication of advanced drug delivery systems (DDSs) allows loading the active pharmaceutical ingredients (APIs) in the core or sheath, or both, thus improving the control release of multiple APIs. In this regard, dual model drugs rhodamine B and BSA incorporated PVA-PCL core-sheath fibers exhibited different release profiles and different diffusion pathways over $100 \mathrm{~h}$ (Wang et al.). ${ }^{187}$ Model protein lysozyme and therapeutic molecule phenytoin sodium loaded PVA-gelatin core-sheath structures displayed three-stage release trails, including non-Fickian diffusion at the early stage followed by the Fickian diffusion mechanism (Zandi et al.). ${ }^{188}$ Core-sheath structures consisting of a stachyose loaded CA sheath layer and a proteoglycan in the polyacrylic resin II core layer showed biphasic drug release in simulated intestinal fluid (Zhu et al.). ${ }^{189}$ Moreover, they exhibited good biocompatibility on L929 cells and excellent improvement effects on Bifidobacterium bifidum and combined inhibition effect on $E$. coli (Zhu et al.). ${ }^{189}$ Chitosan/PEO sheath and PCL core fibrous mats containing dual drugs, lidocaine hydrochloride in the shell and curcumin in the core, are used to relieve pain and inflammation, respectively. Moreover, both of the drugs exhibited an acidic 


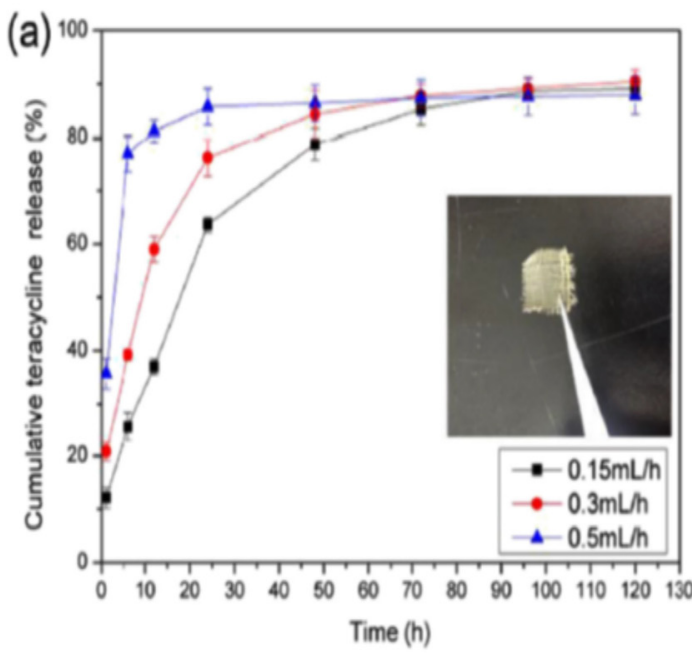

(b)
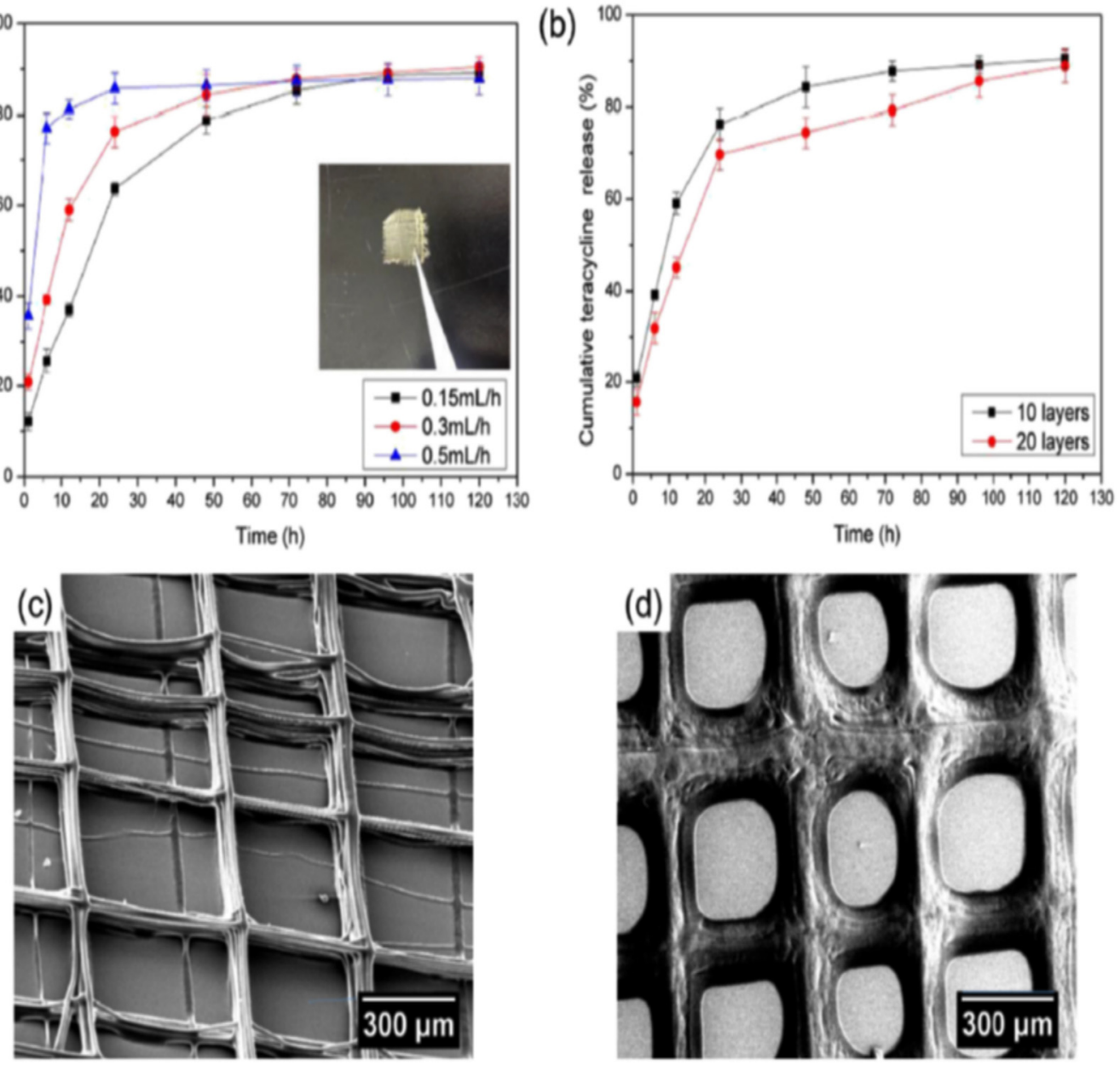

FIG. 31. In vitro dissolution tests: [(a) and (b)] in vitro drug release profiles of KET-loaded EC nanofibers F1, PVP nanofibers F2, and coaxial PVP/EC nanofibers with different sheath thicknesses F3 and F4 over the first $2 \mathrm{~h}$ and the full range. (e) and (f) SEM images and diameter distribution of F3 after the removal of sheath part. Reproduced with permission from Yu et al., Acta Biomater. 9, 5665 (2015). Copyright 2015 Elsevier.

responsive release profile. Furthermore, these mats showed continuous and excellent antimicrobial activity against $E$. coli and $S$. aureus (Guo et al.). ${ }^{190}$

\section{CONCLUDING REMARKS}

Core-sheath fibers feature two different parts with one inner part called "core" and the other outer part called "sheath" partitioned in three-dimensional space to perform two different functions. Such a design offers a multitude of properties and provides an on-demand biomaterial platform for tissue engineering and drug delivery. Fibrous systems comprise various combinations of polymers; natural/ synthetic, aqueous/non-aqueous soluble, and conductive/non-conductive have been exploited in tissue engineering and drug delivery. Indeed, core-sheath fibers and fibrous structures have emerged as a promising approach to manufacture scaffolding materials for tissue engineering and to securely encapsulate therapeutic molecules such as drugs, proteins, and growth factors to deliver to the target sites in a controlled manner. Generally, in a core-sheath fiber system, the core layer imparts mechanical strength and/or encapsulates bioactive molecules and the sheath layer provides the medium that enhances the biological functionality and/or provides a barrier property to the fiber. In addition, exogenous signaling molecules and therapeutic molecules could be loaded in the core and the sheath layer, regardless of their size and configuration. Beyond these, there are still exciting fields in regenerative medicine that can utilize core-sheath configurations to improve the quality of life of patients, for example, fine-tuning the delivery and delivery profile of bioactive molecules, on-demand dictation of stem cells, and ex vivo creation of $3 \mathrm{D}$ tissue mimicking structures. Certainly, these require further development of technology of manufacturing processes and material parameters of core-sheath design. In addition, core-sheath devices should be produced and advanced in much simpler and cheaper ways that ultimately enables practical usage at an affordable price. Therefore, future research should focus on the manufacture of core-sheath devices (large scale) in an economical way to bridge the gap between the demand-supply chain. Moreover, future research and focus 
(a)

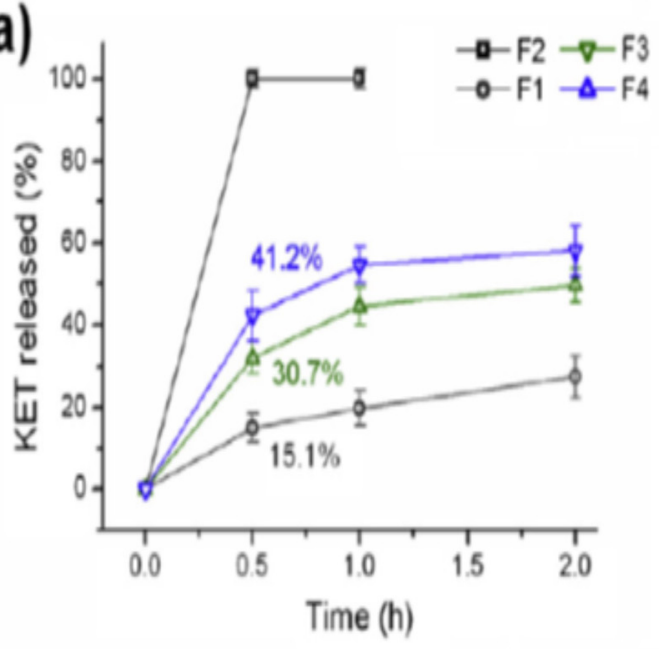

(b)

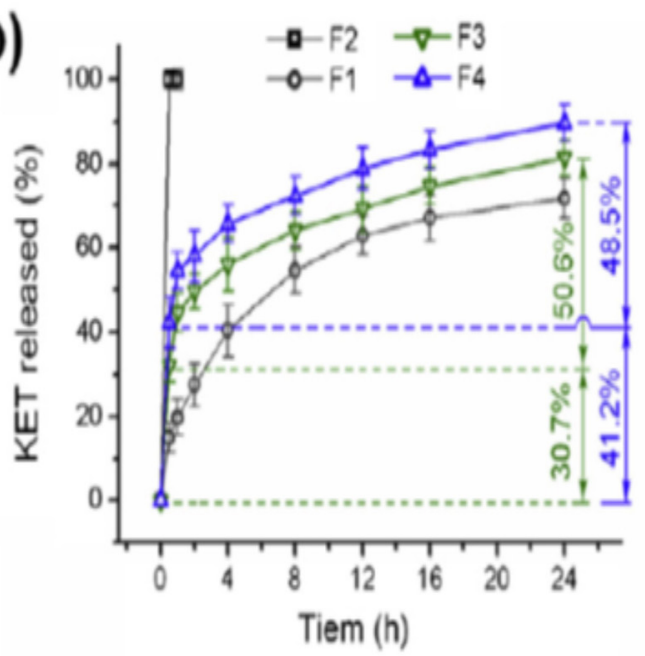

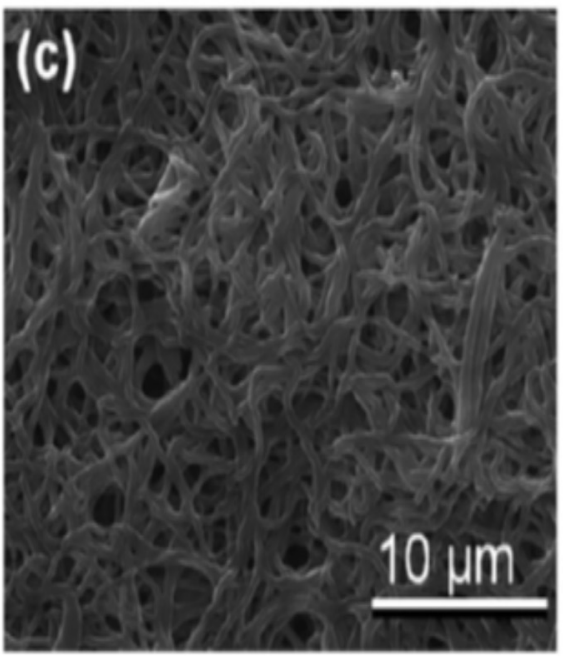

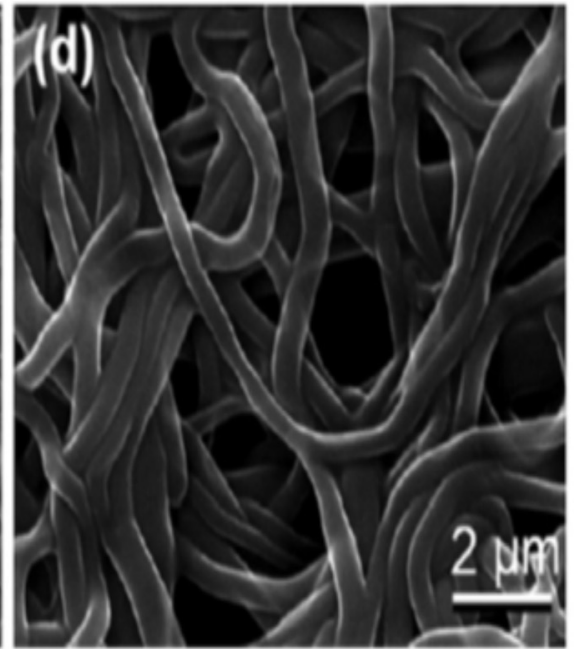

(e)

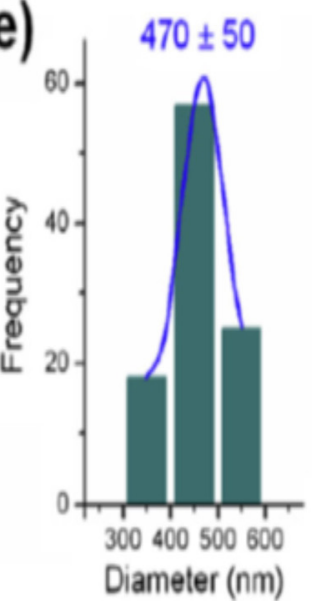

FIG. 32. Effects of various composite patches on release profiles of TEHCL from fibrous matrices. (a) TEHCL released from patches fabricated at different PVP flow rates. (b) TEHCL released from patches with the number of layers. (c) Scanning electron micrographs of drug-loaded patches at selected time intervals over the in vitro release study, (c) $1 \mathrm{~h}$ and (d) $120 \mathrm{~h}$. Reproduced with permission from Yao et al., Mater. Sci. Eng., C 97, 776, 9219 (2019). Copyright 2019 Elsevier.

should be directed toward relevant pre-clinical studies that can essentially realize the potential of core-sheath technologies for practical applications in clinical settings, and that is why we have written this timely review to bring together engineering and medicine and physical and life sciences with respect to this vital area of research.

\section{ACKNOWLEDGMENTS}

The authors are grateful to the UK Engineering and Physical Sciences Research Council (EPSRC) for funding pressurized gyration forming research at University College London to the value of $\sim £ 1.5$ million (Grant Nos. EP/L023059/1, EP/N034228/1, and EP/S016872/1). We also like to thank Mr. Peter Kelly and the staff of the UCL Mechanical Engineering workshop who advised us on the creation of core-sheath fiber making devices.

\section{REFERENCES}

${ }^{1}$ M. Naeimirad, A. Zadhoush, R. Kotek, R. E. Neisiany, S. N. Khorasani, and S. Ramakrishna, J. Appl. Polym. Sci. 135, 46265 (2018).

${ }^{2}$ M. F. Abdulla, T. Nuge, A. Andriyana, B. C. Ang, and F. Muhamad, Polymers 11, 2008 (2019).

${ }^{3}$ G. Y. Liu, Q. Tang, Y. N. Yu, J. Li, J. W. Luo, and M. Z. Li, Polym. Adv. Technol. 25, 1596 (2014).

${ }^{4}$ Z. B. Li, L. J. Song, X. Y. Huang, H. S. Wang, H. L. Shao, M. K. Xie, Y. M. Xu, and Y. P. Zhang, RSC Adv. 5, 16748 (2015).

${ }^{5}$ Y. W. Liu, J. F. Lu, G. S. Xu, J. J. Wei, Z. B. Zhang, and X. H. Li, Mater. Sci. Eng., C 69, 865 (2016).

${ }^{6}$ X. Z. Gu, Y. Matsumura, Y. Tang, S. Roy, R. Hoff, B. Wang, and W. R. Wagner, Biomaterials 133, 132 (2017).

${ }^{7}$ D. Han and A. J. Steckl, ACS Appl. Mater. Interfaces 9, 42653 (2017).

${ }^{8}$ Z. Q. Gu, H. Y. Yin, J. Wang, L. L. Ma, Y. Morsi, and X. M. Mo, Colloids Surf., B 161, 331 (2018).

${ }^{9}$ J. N. Li, W. G. Xu, J. J. Chen, D. Li, K. Zhang, T. J. Liu, J. X. Ding, and X. S. Chen, ACS Biomater. Sci. Eng. 4, 2026 (2018). 
${ }^{10}$ M. Dasdemir, B. Maze, N. Anantharamaiah, and B. Pourdeyhimi, J. Mater. Sci. 47, 5955 (2012).

${ }^{11}$ L. Rayleigh, Philos. Mag. 14, 184 (1882).

${ }^{12}$ J. F. Cooley, U.S. patent 692631 (1902).

${ }^{13}$ W. J. Morton, U.S. patent 705691 (1902).

${ }^{14}$ A. Formhals, U.S. patent 1975504 (1934).

${ }^{15}$ J. D. Watson and F. H. C. Crick, Nature 171, 737 (1953).

${ }^{16} \mathrm{~K}$. Woodings, Regenerated Cellulose Fibers (Woodhead Publishing Ltd and Press LLC, Cambridge, UK, 2001).

${ }^{17}$ K. Lee, M. Do, Y. C. Seo, and H. Lee, Adv. Mater. Interfaces 5, 1800585 (2018).

${ }^{18}$ W. Liu, Y. Gao, X. Y. Liu, Y. P. Qiu, and F. J. Xu, J. Eng. Fibers Fabr. 14, 1 (2019).

${ }^{19}$ S. Sayyar, J. Moskowitz, B. Fox, J. Wiggins, and G. Wallace, J. Appl. Polym. Sci. 136, 47932 (2019).

${ }^{20}$ H. X. Zhang, W. Wu, J. D. Cao, M. Q. Tong, H. Xu, Z. P. Mao, and H. Ma, Composites, Part B 170, 1 (2019).

${ }^{21}$ J. Y. Zhang, M. D. Wang, W. Li, W. Wei, J. Y. Li, M. Jiang, Y. Wang, and Z. W. Zhou, Cellulose 26, 6959 (2019).

${ }^{22}$ S. J. Pomfret, P. N. Adams, N. P. Comfort, and A. P. Monkman, Polymer 41, 2265 (2000).

${ }^{23}$ F. An, P. C. Zhou, C. X. Lu, and Y. D. Liu, Carbon 143, 200 (2019).

${ }^{24}$ M. L. Chen, C. G. Wang, Q. Gao, Y. X. Wang, M. Jing, and W. L. Wang, High Perform. Polym. 31, 662 (2019).

${ }^{25}$ O. D. Velev, S. Smoukov, and M. Marquez, U.S. patent application 20100247908 (2010).

${ }^{26}$ F. Liu, F. T. Saricaoglu, R. J. Avena-Bustillos, D. F. Bridges, G. R. Takeoka, V. C. H. Wu, B. S. Chiou, D. F. Wood, T. H. McHugh, and F. Zhong, Int. J. Mol. Sci. 19, 618 (2018).

${ }^{27}$ Y. J. Song, X. H. Zhang, G. D. Ye, J. J. Xu, and M. J. Jiang, J. Appl. Polym. Sci. 134, 44965 (2017).

${ }^{28}$ S. Bairagi and S. W. Ali, Eur. Polym. J. 116, 554 (2019).

${ }^{29}$ G. Mourgas, E. Giebel, T. Schneck, J. Unold, and M. R. Buchmeiser, J. Appl. Polym. Sci. 136, 47829 (2019).

${ }^{30}$ N. P. Deng, H. S. He, J. Yan, Y. X. Zhao, E. Ben Ticha, Y. Liu, W. M. Kang, and B. W. Cheng, Polymer 165, 174 (2019).

${ }^{31}$ K. L. Jin, A. Banerji, D. Kitto, F. S. Bates, and C. J. Ellison, ACS Appl. Mater. Interfaces 11, 12863 (2019).

${ }^{32}$ Y. F. Zhou, L. Jiang, H. Y. Jia, X. L. Xing, Z. H. Sun, S. J. Chen, J. W. Ma, and S. Jerrams, Fibers Polym. 20, 1200 (2019).

${ }^{33}$ T. M. Andrade, D. C. R. Mello, C. M. V. Elias, J. M. A. Abdala, E. Silva, L. M. R. Vasconcellos, C. R. Tim, F. R. Marciano, and A. O. Lobo, J. Mater. Sci.Mater. Med. 30, 19 (2019).

${ }^{34}$ L. N. Zamproni, M. A. V. M. Grinet, M. T. V. V. Mundim, M. B. C. Reis, L. T. Galindo, F. R. Marciano, A. O. Lobo, and M. Porcionatto, Nanomed. Nanotechnol. Biol. Med. 15, 98 (2019).

${ }^{35}$ C. H. Lu, S. W. Chiang, H. D. Du, J. Li, L. Gan, X. Zhang, X. D. Chu, Y. W. Yao, B. H. Li, and F. Y. Kang, Polymer 115, 52 (2017).

${ }^{36}$ W. M. Chen, Y. Xu, Y. Q. Liu, Z. X. Wang, Y. Q. Li, G. N. Jiang, X. M. Mo, and G. D. Zhou, Mater. Des. 179, 107886 (2019).

${ }^{37}$ L. Cui, Y. H. Song, F. K. Wang, Y. Sheng, and H. F. Zou, Appl. Surf. Sci. 488, 284 (2019).

${ }^{38}$ G. Dognani, P. Hadi, H. Y. Ma, F. C. Cabrera, A. E. Job, D. L. S. Agostini, and B. S. Hsiao, Chem. Eng. J. 372, 341 (2019).

${ }^{39}$ X. Jing, H. Li, H. Y. Mi, Y. J. Liu, and Y. M. Tan, Chem. Eng. J. 372, 785 (2019).

${ }^{40}$ O. Secundino-Sanchez, J. Diaz-Reyes, J. Aguila-Lopez, and J. F. SanchezRamirez, J. Mol. Struct. 1194, 163 (2019).

${ }^{41}$ R. Zhang, Q. Han, Y. Li, Y. F. Cai, X. Y. Zhu, T. Q. Zhang, and Y. Liu, J. Appl. Polym. Sci. 136, 47904 (2019).

${ }^{42}$ C. J. Luo, M. Nangrejo, and M. Edirisinghe, Polymer 51, 1654 (2010).

${ }^{43}$ K. Riazi, J. Kubel, M. Abbasi, K. Bachtin, S. Indris, H. Ehrenberg, R. Kadar, and M. Wilhelm, Polymer 104, 240 (2016).

${ }^{44}$ A. L. Yarin, S. Koombhongse, and D. H. Reneker, J. Appl. Phys. 90, 4836 (2001).

${ }^{45}$ S. Verdoold, L. L. F. Agostinho, C. U. Yurteri, and J. C. M. Marijnissen, J. Aerosol Sci. 67, 87 (2014).

${ }^{46}$ A. L. Yarin, S. Koombhongse, and D. H. Reneker, J. Appl. Phys. 89, 3018 (2001).
${ }^{47}$ H. H. Kim, J. H. Kim, and A. Ogata, J. Aerosol Sci. 42, 249 (2011).

${ }^{48}$ G. Eda, J. Liu, and S. Shivkumar, Mater. Lett. 61, 1451 (2007).

${ }^{49}$ G. Eda, J. Liu, and S. Shivkumar, Eur. Polym. J. 43, 1154 (2007).

${ }^{50}$ C. J. Luo, E. Stride, S. Stoyanov, E. Pelan, and M. Edirisinghe, J. Polym. Res. 18, 2515 (2011).

${ }^{51}$ C. J. Luo, E. Stride, and M. Edirisinghe, Macromolecules 45, 4669 (2012).

${ }^{52}$ S. Haider, Y. Al-Zeghayer, F. A. A. Ali, A. Haider, A. Mahmood, W. A. AlMasry, M. Imran, and M. O. Aijaz, J. Polym. Res. 20, 105 (2013).

${ }^{53}$ Z. Y. Liu, X. Li, Y. Yang, K. Zhang, X. F. Wang, M. F. Zhu, and B. S. Hsiao, Polymer 54, 6045 (2013).

${ }^{54}$ V. Pillay, C. Dott, Y. E. Choonara, C. Tyagi, L. Tomar, P. Kumar, L. C. du Toit, and V. M. K. Ndesendo, J. Nanomater. 2013, 789289.

${ }^{55}$ B. Sun, Y. Z. Long, H. D. Zhang, M. M. Li, J. L. Duvail, X. Y. Jiang, and H. L. Yin, Prog. Polym. Sci. 39, 862 (2014).

${ }^{56}$ F. Topuz and T. Uyar, Mater. Sci. Eng., C 80, 371 (2017).

${ }^{57}$ F. Topuz and T. Uyar, Compos. Commun. 12, 33 (2019).

${ }^{58}$ S. S. Abdelhady, S. H. Zoalfakar, M. A. Agwa, and A. A. Ali, Mater. Res. 6, 095314 (2019).

${ }^{59}$ Z. Y. Li, I. M. Lei, P. Davoodi, L. Huleihel, and Y. Y. S. Huang, ACS Biomater. Sci. Eng. 5, 3676 (2019).

${ }^{60}$ J. M. Deitzel, J. Kleinmeyer, D. Harris, and N. C. B. Tan, Polymer 42, 261 (2001).

${ }^{61}$ J. M. Deitzel, J. D. Kleinmeyer, J. K. Hirvonen, and N. C. B. Tan, Polymer 42, 8163 (2001).

${ }^{62}$ S. Megelski, J. S. Stephens, D. B. Chase, and J. F. Rabolt, Macromolecules 35, 8456 (2002).

${ }^{63}$ G. Eda and S. Shivkumar, J. Mater. Sci. 41, 5704 (2006).

${ }^{64}$ G. Eda and S. Shivkumar, J. Appl. Polym. Sci. 106, 475 (2007).

${ }^{65}$ C. J. Thompson, G. G. Chase, A. L. Yarin, and D. H. Reneker, Polymer 48, 6913 (2007).

${ }^{66}$ T. Liang, S. Mahalingam, and M. Edirisinghe, Mater. Sci. Eng., C 33, 4384 (2013).

${ }^{67}$ T. Abudula, U. Saeed, N. Salah, A. Memic, and H. Al-Turaif, J. Nanosci. Nanotechnol. 18, 8240 (2018).

${ }^{68}$ Y. M. Zhou, H. B. Wang, J. X. He, K. Qi, B. Ding, and S. Z. Cui, Fibers Polym. 19, 2169 (2018).

${ }^{69}$ S. V. Ebadi, A. Fakhrali, and D. Semnani, Bull. Mater. Sci. 42, 115 (2019).

${ }^{70}$ S. Zahmatkesh, S. M. Zebarjad, M. E. Bahrololoom, E. Dabiri, and S. M. Arab, Ceram. Int. 45, 2530 (2019).

${ }^{77}$ D. Deshawar and P. Chokshi, Polymer 131, 34 (2017).

${ }^{72} \mathrm{H}$. Fashandi and M. Karimi, Polymer 53, 5832 (2012).

${ }^{73}$ T. Liang, M. Parhizkar, M. Edirisinghe, and S. Mahalingam, Eur. Polym. J. 61, 72 (2014).

${ }^{74}$ S. Y. Bak, G. J. Yoon, S. W. Lee, and S. W. Kim, Mater. Lett. 181, 136 (2016).

${ }^{75}$ P. Aghasiloo, M. Yousefzadeh, M. Latifi, and R. Jose, J. Alloys Compd. 790, 257 (2019).

${ }^{76}$ F. Topuz, B. Satilmis, and T. Uyar, Polymer 178, 121610 (2019).

${ }^{77}$ S. V. Fridrikh, J. H. Yu, M. P. Brenner, and G. C. Rutledge, Phys. Rev. Lett. 90, 144502 (2003).

${ }^{78}$ R. Stepanyan, A. V. Subbotin, L. Cuperus, P. Boonen, M. Dorschu, F. Oosterlinck, and M. J. H. Bulters, Polymer 97, 428 (2016).

${ }^{79}$ S. L. Lei, Z. Z. Quan, H. N. Zhang, X. H. Qin, R. W. Wang, and J. Y. Yu, Polymer 180, 121762 (2019).

${ }^{80}$ D. W. Schubert, Macromol. Theory Simul. 28, 1900006 (2019).

${ }^{81}$ D. Li and Y. N. Xia, Nano Lett. 4, 933 (2004).

${ }^{82}$ Y. Lu, X. D. Xiao, Y. J. Zhan, C. M. Huan, S. Qi, H. L. Cheng, and G. Xu, ACS Appl. Mater. Interfaces 10, 12759 (2018).

${ }^{83}$ T. Han, A. L. Yarin, and D. H. Reneker, Polymer 49, 1651 (2008).

${ }^{84}$ A. K. Moghe and B. S. Gupta, Polym. Rev. 48, 353 (2008).

${ }^{85}$ A. Greiner, J. H. Wendorff, A. L. Yarin, and E. Zussman, Appl. Microbiol. Biotechnol. 71, 387 (2006).

${ }^{86}$ A. M. Ganan-Calvo, J. M. Lopez-Herrera, M. A. Herrada, A. Ramos, and J. M. Montanero, J. Aerosol Sci. 125, 32 (2018).

${ }^{87}$ C. Larriba and J. F. de la Mora, Phys. Fluids 23, 102003 (2011).

${ }^{88}$ I. G. Loscertales, A. Barrero, I. Guerrero, R. Cortijo, M. Marquez, and A. M. Ganan-Calvo, Science 295, 1695 (2002). 
${ }^{89}$ G. Larsen, R. Velarde-Ortiz, K. Minchow, A. Barrero, and I. G. Loscertales, J. Am. Chem. Soc. 125, 1154 (2003).

${ }^{90}$ Z. C. Sun, E. Zussman, A. L. Yarin, J. H. Wendorff, and A. Greiner, Adv. Mater. 15, 1929 (2003).

${ }^{91}$ I. G. Loscertales, A. Barrero, M. Marquez, R. Spretz, R. Velarde-Ortiz, and G. Larsen, J. Am. Chem. Soc. 126, 5376 (2004).

${ }^{92}$ V. D. Ranjan, P. Zeng, B. Li, and Y. Zhang, Biomater. Sci. 8, 2175 (2020).

${ }^{93}$ Y. K. Dogan, A. Demirural, and T. Baykara, SN Appl. Sci. 1, 415 (2019).

${ }^{94}$ T. Suzuki, J. Cheng, L. Qiao, Y. Xing, M. F. Zhang, H. Nishijima, T. Yano, and W. Pan, RSC Adv. 10, 22113 (2020).

${ }^{95}$ Z. Ahmad, H. B. Zhang, U. Farook, M. Edirisinghe, E. Stride, and P. Colombo, J. R. Soc. Interface 5, 1255 (2008).

${ }^{96}$ S. Labbaf, H. Ghanbar, E. Stride, and M. Edirisinghe, Macromol. Rapid Commun. 35, 618 (2014).

${ }^{97}$ D. Han, R. Serra, N. Gorelick, U. Fatima, C. G. Eberhart, H. Brem, B. Tyler, and A. J. Steckl, Sci. Rep. 9, 17936 (2019).

${ }^{98}$ H. L. Qu, S. Y. Wei, and Z. H. Guo, J. Mater. Chem. 1, 11513 (2013).

${ }^{99}$ D. G. Yu, J. H. Yu, L. Chen, G. R. Williams, and X. Wang, Carbohydr. Polym. 90, 1016 (2012).

${ }^{100}$ J. H. Yu, S. V. Fridrikh, and G. C. Rutledge, Adv. Mater. 16, 1562 (2004).

${ }^{101}$ G. Kwak, G. H. Lee, S. H. Shim, and K. B. Yoon, Macromol. Rapid Commun. 29, 815 (2008).

${ }^{102}$ J. E. Diaz, A. Barrero, M. Marquez, and I. G. Loscertales, Adv. Funct. Mater. 16, 2110 (2006).

${ }^{103}$ D. Li, A. Babel, S. A. Jenekhe, and Y. N. Xia, Adv. Mater. 16, 2062 (2004).

${ }^{104}$ S. Mahalingam and M. Edirisinghe, Macromol. Rapid Commun. 34, 1134 (2013).

${ }^{105}$ F. Brako, R. Thorogate, S. Mahalingam, B. Raimi-Abraham, D. Q. M. Craig, and M. Edirisinghe, ACS Appl. Mater. Interfaces 10, 13381 (2018).

${ }^{106}$ S. Mahalingam, G. G. Ren, and M. Edirisinghe, Carbohydr. Polym. 114, 279 (2014).

${ }^{107}$ S. Mahalingam, X. W. Wu, and M. Edirisinghe, Mater. Des. 134, 259 (2017).

${ }^{108}$ S. Mahalingam, Z. W. Xu, and M. Edirisinghe, Langmuir 31, 9771 (2015).

${ }^{109}$ S. Mahalingam, B. T. Raimi-Abraham, D. Q. M. Craig, and M. Edirisinghe, Langmuir 31, 659 (2015).

${ }^{110} \mathrm{M}$. Orlu-Gul, A. A. Topcu, T. Shams, S. Mahalingam, and M. Edirisinghe, Curr. Opin. Pharmacol. 18, 28 (2014).

${ }^{11}$ A. Amir, S. Mahalingam, X. Wu, H. Porwal, P. Colombo, M. J. Reece, and M. Edirisinghe, Compos. Sci. Technol. 129, 173 (2016).

${ }^{112}$ X. W. Wu, S. Mahalingam, A. Amir, H. Porwal, M. J. Reece, V. Naglieri, P. Colombo, and M. Edirisinghe, ACS Omega 1, 202 (2016).

${ }^{113}$ X. W. Wu, S. Mahalingam, S. K. VanOosten, C. Wisdom, C. Tamerler, and M. Edirisinghe, Macromol. Biosci. 17, 1600270 (2017).

${ }^{114}$ M. Parhizkar, S. Mahalingam, S. Homer-Vanniasinkam, and M. Edirisinghe, Nanomed. Nanotechnol. 13, 5 (2018).

${ }^{115}$ S. Mahalingam, B. T. Raimi-Abraham, D. Q. M. Craig, and M. Edirisinghe, Chem. Eng. J. 280, 344 (2015).

${ }^{116}$ Z. Xu, S. Mahalingam, J. L. Rohn, G. Ren, and M. Edirisinghe, Mater. Sci. Eng., C 56, 195 (2015).

${ }^{117}$ B. T. Raimi-Abraham, S. Mahalingam, P. J. Davies, M. Edirisinghe, and D. Q. M. Craig, Mol. Pharmaceutics 12, 3851 (2015).

${ }^{118}$ S. Mahalingam, G. Pierin, P. Colombo, and M. Edirisinghe, Ceram. Int. 41, 6067 (2015).

${ }^{119}$ S. Q. Zhang, B. T. Karaca, S. K. VanOosten, E. Yuca, S. Mahalingam, M. Edirisinghe, and C. Tamerler, Macromol. Rapid Commun. 36, 1322 (2015).

${ }^{120}$ X. Z. Hong, S. Mahalingam, and M. Edirisinghe, Macromol. Mater. Eng. 302, 1600564 (2017).

${ }^{121}$ X. Z. Hong, A. Harker, and M. Edirisinghe, ACS Omega 3, 5470 (2018).

${ }^{122}$ X. Z. Hong, A. Harker, and M. Edirisinghe, Proc. R. Soc. A-Math. Phys. 475, 20190008 (2018).

${ }^{123}$ Z. W. Xu, S. Mahalingam, P. Basnett, B. Raimi-Abraham, I. Roy, D. Craig, and M. Edirisinghe, Macromol. Mater. Eng. 301, 922 (2016).

${ }^{124}$ H. C. Alenezi, M. E. Cam, and M. Edirisinghe, Appl. Phys. Rev. 6, 041401 (2019).

${ }^{125}$ S. Mahalingam, S. Homer-Vanniasinkam, and M. Edirisinghe, Mater. Des. 178, 107846 (2019)
${ }^{126}$ S. Mahalingam, S. Huo, S. Homer-Vanniasinkam, and M. Edirisinghe, Polymers 12, 1709 (2020).

${ }^{127}$ M. Costantini, C. Colosi, W. Swieszkowski, and A. Barbetta, Biofabrication 11, 012001 (2019)

${ }^{128}$ P. F. Ng, K. I. Lee, S. Meng, J. Zhang, Y. Wang, and B. Fei, ACS Biomater. Sci. Eng. 5, 3119 (2019).

${ }^{129}$ Z. Tang, S. Jia, S. Shi, F. Wang, and B. Li, Sens. Actuators, A 284, 85 (2018).

${ }^{130}$ W. Xu, L. Xia, X.-H. Zhou, P. Xi, P.-W. Cheng, and Y.-X. Liang, Micro Nano Lett. 11, 74 (2016)

${ }^{131}$ A. Magaz, A. D. Roberts, S. Faraji, T. R. L. Nascimento, E. S. Medeiros, W. Zhang, R. D. Greenhalgh, A. Mautner, X. Li, and J. J. Blaker, Biomacromolecules 19, 4542 (2018).

${ }^{132}$ E. D. Boland, J. A. Matthews, K. J. Pawlowski, D. G. Simpson, G. E. Wnek, and G. L. Bowlin, Front. Biosci. 9, 1422 (2004).

${ }^{133}$ W. J. Zhang, Z. Chen, S. J. Ma, Y. G. Wang, F. Zhang, K. Y. Wang, C. G. Yang, X. Y. Pu, J. Z. Ma, Y. L. Wang, F. F. Leng, F. Ran, and Y. B. Kuang, Int. J. Polym. Mater. Biomater. 65, 38 (2016).

${ }^{134} \mathrm{~N}$. Nagiah, R. Johnson, R. Anderson, W. Elliott, and W. Tan, Langmuir 31, 12993 (2015).

${ }^{135}$ X. Yang, J. H. Wei, D. L. Lei, Y. P. Liu, and W. Wu, Biomaterials 88, 34 (2016).

${ }^{136}$ V. M. Merkle, P. L. Tran, M. Hutchinson, K. R. Ammann, K. DeCook, X. Wu, and M. J. Slepian, Acta Biomater. 27, 77 (2015).

${ }^{137}$ R. Johnson, Y. Ding, N. Nagiah, E. Monnet, and W. Tan, Mater. Sci. Eng., C 97, 1 (2019).

${ }^{138}$ W. J. Liu, Z. Zhong, N. Hu, Y. X. Zhou, L. Maggio, A. K. Miri, A. Fragasso, X. Y. Jin, A. Khademhosseini, and Y. S. Zhang, Biofabrication 10, 024102 (2018).

${ }^{139}$ K. Nagata, T. Kurebayashi, K. Imato, and N. Takeda, J. Mater. Chem. 6, 2052 (2018).

${ }^{140}$ Y. J. Son, H. S. Kim, W. Mao, J. B. Park, D. Lee, H. Lee, and H. S. Yoo, Nanoscale 10, 6051 (2018).

${ }^{141}$ A. Khalf, K. Singarapu, and S. V. Madihally, Cellulose 22, 1389 (2015).

${ }^{142}$ P. L. Heseltine, J. Hosken, C. Agboh, D. Farrar, S. Homer-Vanniasinkam, and M. Edirisinghe, Macromol. Mater. Eng. 304, 1800577 (2019).

${ }^{143}$ R. Borah, G. C. Ingavle, S. R. Sandeman, A. Kumar, and S. Mikhalovsky, Biomater. Sci. 6, 2342 (2018).

${ }^{144}$ X. Pan, B. B. Sun, and X. M. Mo, Front. Mater. Sci. 12, 438 (2018).

${ }^{145}$ R. Borah, G. C. Ingavle, S. R. Sandeman, A. Kumar, and S. V. Mikhalovsky, ACS Biomater. Sci. Eng. 4, 3327 (2018).

${ }^{146}$ F. Zamani, M. Amani-Tehran, M. Latifi, M. A. Shokrgozar, and A. Zaminy, J. Biomed. Mater. Res. 102, 506 (2014).

${ }^{147}$ T. Zhang, H. F. Zhang, L. Q. Zhang, S. J. Jia, J. Liu, Z. Xiong, and W. Sun, Biofabrication 9, 025021 (2017).

${ }^{148}$ W. Song, X. W. Yu, D. C. Markel, T. Shi, and W. P. Ren, Biofabrication 5, 035006 (2013).

${ }^{149}$ W. Song, J. Seta, L. Chen, C. Bergum, Z. B. Zhou, P. Kanneganti, R. E. Kast, G. W. Auner, M. Shen, D. C. Markel, W. P. Ren, and X. W. Yu, Biomed. Mater. 12, 045008 (2017).

${ }^{150}$ C. J. Wang, G. L. Meng, L. Q. Zhang, Z. Xiong, and J. Liu, J. Biomed. Biotechnol. 2012, 579141.

${ }^{151}$ P. Vashisth and J. R. Bellare, Nanomed. Nanotechnol. 14, 1325 (2018).

${ }^{152}$ C. Tao, Y. X. Zhang, B. Li, and L. Chen, J. Mater. Chem. B 5, 9219 (2017).

${ }^{153}$ E. M. Chen, L. Yang, C. Y. Ye, W. Zhang, J. S. Ran, D. T. Xue, Z. K. Wang, Z. J. Pan, and Q. L. Hu, Acta Biomater. 73, 377 (2018).

${ }^{154} \mathrm{~K}$. T. Shalumon, C. Sheu, C. H. Chen, S. H. Chen, G. Jose, C. Y. Kuo, and J. P. Chen, Acta Biomater. 72, 121 (2018).

${ }^{155}$ R. Langer and J. P. Vacanti, Science 260, 920 (1993).

${ }^{156}$ M. N. Collins and C. Birkinshaw, Carbohydr. Polym. 92, 1262 (2013).

${ }^{157}$ S. Barrientos, O. Stojadinovic, M. S. Golinko, H. Brem, and M. Tomic-Canic, Wound Repair Regen. 16, 585 (2008).

${ }^{158}$ J. S. Choi, K. W. Leong, and H. S. Yoo, Biomaterials 29, 587 (2008).

${ }^{159}$ Z. B. Wang, Y. N. Qian, L. H. Li, L. H. Pan, L. W. Njunge, L. L. Dong, and L. Yang, J. Biomater. Appl. 30, 686 (2016).

${ }^{160}$ Y. Yang, X. H. Li, L. Cheng, S. H. He, J. Zou, F. Chen, and Z. B. Zhang, Acta Biomater. 7, 2533 (2011).

${ }^{161}$ Y. Yang, T. Xia, F. Chen, W. Wei, C. Y. Liu, S. H. He, and X. H. Li, Mol. Pharmaceutics 9, 48 (2012). 
${ }^{162}$ W. Gao, L. Sun, X. Fu, Z. Lin, W. Xie, W. Zhang, F. Zhao, and X. Chen, J. Mater. Chem. B 6, 277 (2018).

${ }^{163}$ M. Norouzi, I. Shabani, H. H. Ahvaz, and M. Soleimani, J. Biomed. Mater. Res. A 103, 2225 (2015).

${ }^{164}$ B. Y. Li, C. K. Liu, F. L. Zhou, X. Mao, and R. J. Sun, Biotechnol. Lett. 40, 279 (2018).

${ }^{165}$ R. K. Matharu, L. Ciric, and M. Edirisinghe, Nanotechnology 29, 282001 (2018).

${ }^{166}$ R. K. Matharu, H. Porwal, B. Chen, L. Ciric, and M. Edirisinghe, Med. Devices Sens. 3, 10107 (2020).

${ }^{167}$ S. Padmakumar, J. Joseph, M. H. Neppalli, S. E. Mathew, S. V. Nair, S. A. Shankarappa, and D. Menon, ACS Appl. Mater. Interfaces 8, 6925 (2016).

${ }^{168}$ P. Chuysinuan, C. Pengsuk, K. Lirdprapamongkol, S. Techasakul, J. Svasti, and P. Nooeaid, Fibers Polym. 20, 1 (2019).

${ }^{169}$ M. I. Shekh, K. P. Patel, and R. M. Patel, J. Polym. Environ. 26, 4376 (2018).

${ }^{170}$ R. Kemp, B. Klumperman, and N. P. Gule, J. Appl. Polym. Sci. 135, 46303 (2018).

${ }^{171}$ K. Wei, Y. Li, H. Mugishima, A. Teramoto, and K. Abe, Biotechnol. J. 7, 677 (2012).

${ }^{172}$ L. H. Li, H. B. Li, Y. N. Qian, X. Li, G. K. Singh, L. Zhong, W. Q. Liu, Y. G. Lv, K. Y. Cai, and L. Yang, Int. J. Biol. Macromol. 49, 223 (2011).

${ }^{173}$ J. Chen, B. Zhou, Q. Li, O. Y. Jun, J. M. Kong, W. Zhong, and M. M. Q. Xing, Int. J. Nanomed. 6, 2533 (2011).

${ }^{174}$ Y. Z. Zhang, X. Wang, Y. Feng, J. Li, C. T. Lim, and S. Ramakrishna, Biomacromolecules 7, 1049 (2006).

${ }^{175}$ J. M. Gluck, P. Rahgozar, N. P. Ingle, F. Rofail, A. Petrosian, M. G. Cline, M. C. Jordan, K. P. Roos, W. R. MacLellan, R. J. Shemin, and S. HeydarkhanHagvall, J. Biomed. Mater. Res. B 99B, 180 (2011).
${ }^{176}$ Y. N. Jiang, H. Y. Mo, and D. G. Yu, Int. J. Pharm. 438, 232 (2012).

${ }^{177}$ D. G. Yu, X. Wang, X. Y. Li, W. Chian, Y. Li, and Y. Z. Liao, Acta Biomater. 9, 5665 (2013).

${ }^{178}$ D. G. Yu, G. R. Williams, X. Wang, X. K. Liu, H. L. Li, and S. W. A. Bligh, RSC Adv. 3, 4652 (2013).

${ }^{179}$ H. Yu, P. Yang, Y. T. Jia, Y. M. Zhang, Q. Y. Ye, and S. M. Zeng, Colloids Surf., B 146, 63-69 (2016).

${ }^{180}$ T. Hai, X. Wan, D. G. Yu, K. Wang, Y. Y. Yang, and Z. P. Liu, Mater. Des. 162, 70 (2019).

${ }^{181}$ Z. C. Yao, J. C. Wang, Z. Ahmad, J. S. Li, and M. W. Chang, Mater. Sci. Eng., C 97, 776 (2019)

${ }^{182}$ M. C. R. Simoes, S. M. Cragg, E. Barbu, and F. B. De Sousa, J. Mater. Sci. 54, 5712 (2019).

${ }^{183}$ M. He, J. J. Xue, H. Geng, H. Gu, D. F. Chen, R. Shi, and L. Q. Zhang, Appl. Surf. Sci. 335, 121 (2015).

${ }^{184}$ C. Yang, D. G. Yu, D. Pan, X. K. Liu, X. Wang, S. W. A. Bligh, and G. R. Williams, Acta Biomater. 35, 77 (2016).

${ }^{185}$ Y. Lv, Q. Pan, S. W. A. Bligh, H. Li, H. Wu, Q. Sang, and L.-M. Zhu, J. Pharm. Sci. 106, 1258 (2017).

${ }^{186}$ J. H. Park, H. Seo, D. I. Kim, J. H. Choi, J. H. Son, J. Kim, G. D. Moon, and D. C. Hyun, Pharmaceutics 11, 60 (2019).

${ }^{187}$ Y. Wang, Z. Li, P. Shao, S. Hao, W. Wang, Q. Yang, and B. Wang, Mater. Sci. Eng., C 44, 109 (2014).

${ }^{188}$ N. Zandi, R. Lotfi, E. Tamjid, M. A. Shokrgozar, and A. Simchi, Mater. Sci. Eng., C 108, 110432 (2020).

${ }^{189}$ L.-F. Zhu, X. Chen, Z. Ahmad, Y. Peng, and M.-W. Chang, Biofabrication 12, 025026 (2020).

${ }^{190}$ H. Guo, S. Tan, J. Gao, and L. Wang, J. Mater. Chem. B 8, 1759 (2020). 